\title{
Proactive coping post stroke: the Restored4Stroke self-management study
}

Citation for published version (APA):

Tielemans, N. (2015). Proactive coping post stroke: the Restored4Stroke self-management study.

[Doctoral Thesis, Maastricht University]. Maastricht University. https://doi.org/10.26481/dis.20150528nt

Document status and date:

Published: 01/01/2015

DOI:

10.26481/dis.20150528nt

Document Version:

Publisher's PDF, also known as Version of record

\section{Please check the document version of this publication:}

- A submitted manuscript is the version of the article upon submission and before peer-review. There can be important differences between the submitted version and the official published version of record.

People interested in the research are advised to contact the author for the final version of the publication, or visit the DOI to the publisher's website.

- The final author version and the galley proof are versions of the publication after peer review.

- The final published version features the final layout of the paper including the volume, issue and page numbers.

Link to publication

\footnotetext{
General rights rights.

- You may freely distribute the URL identifying the publication in the public portal. please follow below link for the End User Agreement:

www.umlib.nl/taverne-license

Take down policy

If you believe that this document breaches copyright please contact us at:

repository@maastrichtuniversity.nl

providing details and we will investigate your claim.
}

Copyright and moral rights for the publications made accessible in the public portal are retained by the authors and/or other copyright owners and it is a condition of accessing publications that users recognise and abide by the legal requirements associated with these

- Users may download and print one copy of any publication from the public portal for the purpose of private study or research.

- You may not further distribute the material or use it for any profit-making activity or commercial gain

If the publication is distributed under the terms of Article $25 \mathrm{fa}$ of the Dutch Copyright Act, indicated by the "Taverne" license above, 


\section{Proactive coping post stroke: The Restore4Stroke Self-Management study}

Nienke Tielemans 
Cover Hanneke Tielemans - de Rooij

Printed by Proefschriftmaken.nl || Uitgeverij BOXPress

ISBN 978909028947

(C) 2015 NS Tielemans, Utrecht

All rights reserved. No part of this publication may be reproduced or transmitted in any form or by any means, electronic or mechanical, including photocopying, recording, or any other information storage and retrieval system, without written permission from the author. The copyright of the published articles has been transferred to the respective journals. 


\title{
Proactive coping post stroke: The Restore4Stroke Self-Management study
}

\author{
PROEFSCHRIFT
}

ter verkrijging van de graad van doctor aan de Universiteit Maastricht, op gezag van de Rector Magnificus, Prof. dr. L.L.G. Soete, volgens het besluit van het College van Decanen, in het openbaar te verdedigen op donderdag 28 mei 2015 om 16:00 uur

door

Nienke Simone Tielemans 


\section{Promotores}

Prof. dr. C.M. van Heugten

Prof. dr. J.M.A. Visser-Meily (Universitair Medisch Centrum Utrecht)

\section{Copromotor}

Dr. V.P.M. Schepers (Universitair Medisch Centrum Utrecht)

\section{Beoordelingscommissie}

Prof. dr. A.M.C.F. Verbunt (voorzitter)

Prof. dr. J.F.M. Metsemakers

Prof. dr. D.T.D. de Ridder (Universiteit Utrecht)

Prof. dr. M.J. Schuurmans (Universitair Medisch Centrum Utrecht)

Dr. M. de Vugt

Het Restore4Stroke project werd financieel mogelijk gemaakt door het VSBFonds (\#89000004) in samenwerking met ZonMw. Eveneens werd het onderzoek dat aan dit proefschrift ten grondslag ligt mogelijk gemaakt door subsidie van de Nederlandse Hartstichting.

Het verschijnen van dit proefschrift werd mede mogelijk gemaakt door de steun van de Nederlandse Hartstichting. Daarnaast werd de totstandkoming van dit proefschrift mede mogelijk gemaakt door financiële steun van De Hoogstraat Revalidatie en de Stichting De Hoogstraat Onderzoeksfonds te Utrecht. Tot slot, werd financiële steun voor de publicatie van dit proefschrift geboden door ABN AMRO Bank N.V. 
Voor mama 



\section{Table of Contents}

$\begin{array}{lll}\text { Chapter } 1 \quad \text { General introduction } & 9\end{array}$

Chapter 2 Proactive coping post stroke: Psychometric properties of the Utrecht Proactive Coping Competence scale

Chapter 3 Proactive coping, self-efficacy and associations with psychosocial outcomes post stroke

Chapter 4 Study protocol of the Restore4Stroke self-management study: A multicentre randomized controlled trial in stroke patients and their partners

Chaper 5 The Restore4Stroke self-management intevention 'Plan Ahead!': Rationale and description of the treatment protocol based on proactive action planning

Chapter 6 Process evaluation of the Restore4Stroke self-management intervention 'Plan Ahead!' used in a randomized study

Chapter 7 Effectiveness of the Restore4Stroke self-management intervention 'Plan Ahead!': A randomized controlled trial in stroke patients and partners.

Chapter 8 General discussion

References

Summary 159

Samenvatting 167

Valorization 175

Dankwoord 191

Curiculum Vitae 199

List of publications 



\section{CHAPTER 1}

General introduction 
Each year, 45,000 people suffer a first stroke in the Netherlands. ${ }^{1}$ Approximately $60 \%$ of those who survive their stroke return home after discharge from a hospital or rehabilitation centre. ${ }^{2}$ Returning home, however, is no guarantee for an unaffected post-stroke life. Although these patients are largely independent with regard to their activities of daily living and mobility, they are often confronted with lasting physical and nonphysical consequences of stroke. ${ }^{3-5}$ As a consequence, both the patients and their partners often report a negative impact of stroke on their quality of life..$^{5-8}$

\section{Stroke: lasting consequences and impact on daily life}

Stroke patients often report lasting consequences of stroke. ${ }^{3-5}$ These consequences can involve in the physical domain, such as hemiparesis (55\%) or spasticity (19$38 \%)^{9-11}$, but a broad variety of less visible consequences have also been reported. Cognitive impairments occur in 35 to $55 \%$ of stroke patients, for example regarding mental speed and executive functioning. ${ }^{12,13}$ Fatigue is reported by one- to two-thirds of stroke patients. ${ }^{11}$ Examples of emotional and behavioural changes are depressed feelings, which occur in a third, and emotional lability, which occur in a quarter of patients in the first year post stroke. ${ }^{11,13}$

The lasting consequences of stroke impact on a stroke patient's daily life. Reduced life satisfaction has been reported, as well as problems of participation and social relations. ${ }^{14-16}$ The way people deal with the consequences of a stroke is an important determinant of their post-stroke quality of life. ${ }^{17}$ Hence, teaching stroke patients effective strategies to deal with the consequences of stroke is expected to be beneficial.

\section{Partners}

After a stroke, the partners' lives often also change considerably. In addition to their role as life partners, they have to become caregivers and they are confronted with their own emotional and physical strain related to the new situation., ${ }^{71-21}$

Many partners report a negative impact of stroke on their quality of life. ${ }^{5,7}$ Consequences have been reported in terms of caregiver burden, participation restrictions, and decreased life satisfaction. ${ }^{16,20,22-24}$ It is important to teach partners to deal with the long-term consequences and impact of stroke as well. 


\section{Self-Management}

Since patients living at home and their partners are largely responsible for dealing with the consequences of stroke themselves. It is important that they are able to manage their own lives after the stroke. There is a need for interventions aimed at enhancing these self-management abilities of stroke patients and partners

Self-management refers to someone's abilities to deal with the medical, lifestyle, physical, and psychosocial consequences of a condition, and their impact on daily life. ${ }^{25}$ Several self-management interventions have been developed for chronic conditions such as chronic obstructive pulmonary disease (COPD). ${ }^{25}$ However, whereas the major self-management tasks for patients with COPD consists of medical management or preventing exacerbations ${ }^{25}$, stroke patients mainly have to learn strategies to deal with the cognitive, emotional and behavioural consequences of stroke. ${ }^{26}$ Self-management interventions should therefore use a stroke-specific approach.

\section{Stroke-specific self-management interventions}

Most stroke-specific self-management interventions reported in the literature have focused on enhancing self-efficacy levels in stroke patients. ${ }^{27-30}$ Although convincing evidence has been lacking for the effectiveness of these interventions in two larger randomized controlled trials ${ }^{28,30}$, no alternative and possibly better mechanisms to enhance self-management abilities in stroke patients were so far known. In daily life, many patients fail to reach their goals due to unanticipated consequences of stroke, such as cognitive impairments, which hamper goal achievement. ${ }^{31}$ Thus, it might be better to examine whether patients' and partners' strategies to deal with these limiting consequences of stroke can be improved.

The cognitive and emotional strategies people adopt to deal with such hampering consequences of stroke are called coping strategies. ${ }^{32}$ Screening the literature, showed that most coping research in stroke patients has focused on reactive coping processes, as they focused on processes adopted after a stressful situation has occurred. However, research in elderly people and patients with type 2 diabetes has pointed at the potential beneficial effects of proactive coping strategies for people who have to deal with a chronic condition. ${ }^{33,34}$ When people adopt proactive coping strategies they think about potential barriers and requirements for actual goal achievement during their goal-setting process, and 
undertake action to prevent or overcome the barriers or modify their effects. ${ }^{35}$ Stroke patients and their partners might benefit from such proactive coping strategies as well, as adopting such strategies is expected to reduce the restrictions on goal achievement and activities. As far as we know, no stroke-specific selfmanagement interventions are available that aim to teach stroke patients and their partners proactive coping strategies. Therefore, such interventions should be developed and examined on their effectiveness.

\section{The Restore4Stroke Self-Management study}

The present thesis describes the Restore4Stroke Self-Management study, within which we examined the use of proactive coping strategies in stroke patients. Next, we developed and examined the effectiveness of a stroke-specific selfmanagement intervention aimed at teaching stroke patients and their partners proactive coping strategies. The Restore4Stroke Self-Management study was the result of a collaboration between Maastricht University and Brain Centre Rudolf Magnus and Centre of Excellence for Rehabilitation Medicine of the University Medical Centre Utrecht and De Hoogstraat Rehabilitation.

\section{Context of research: Restore4Stroke}

The Restore4Stroke Self-Management study is part of the Dutch national consortium programme called Restore4Stroke, funded by the VSB Fonds (\#89000004) and the Dutch Heart Foundation, and co-ordinated by ZonMw (Dutch Organization for Health Research and Development). The programme is jointly carried out by Maastricht University, Brain Centre Rudolf Magnus and Centre of Excellence for Rehabilitation Medicine of the University Medical Centre Utrecht and Rehabilitation Centre De Hoogstraat, and Radboud University Nijmegen Medical Centre.

The overall aim of the Restore4Stroke programme was to improve the quality of life of stroke patients and their partners. Four studies were conducted within this research programme:

1) The Restore4Stroke Cohort study examined the course of the quality of post-stroke life in patients and partners up to two years post stroke. Special attention is devoted to the influence of personal and environmental factors on quality of life. ${ }^{36}$ 
2) The Restore4Stroke post-stroke depression with or without anxiety (PSDA) trial examined the effectiveness of an augmented cognitive behavioural therapy (CBT) compared to a cognitive training programme in stroke patients with post-stroke depression with or without anxiety. ${ }^{37}$

3) The Restore4Stroke Self-Management study examined the effectiveness of a stroke-specific self-management group-therapy compared to a stroke-specific, group-based education intervention for stroke patients and partners. ${ }^{38}$

4) The €-Restore4Stroke study examined the cost-effectiveness of both the Restore4Stroke augmented CBT and the Restore4Stroke self-Management intervention. In addition it examined the overall economic impact of stroke in the Netherlands. ${ }^{39}$

\section{Aims of this thesis}

The general aim of the Restore4Stroke Self-Management study was to develop a stroke-specific self-management intervention based on proactive coping by stroke patients and their partners, and to test its effectiveness. As a result, this thesis addresses the following research questions:

1) Is the Utrecht Proactive Coping Competence scale a reliable and valid measure to assess proactive coping strategies in stroke patients?

2) What are the associations between proactive coping and self-efficacy and the psychosocial outcomes post stroke?

3) Is a group-based, stroke-specific self-management intervention aimed at teaching proactive coping strategies feasible, and is it more effective in increasing proactive coping and participation in stroke patients and partners than a group-based, stroke-specific education intervention?

\section{Outline of the thesis}

This thesis presents the results of the Restore4Stroke Self-Management study. It consists of the following parts:

- Chapter two presents the psychometric properties of the Utrecht Proactive Coping Competence scale and associations between proactive coping and the health-related quality of life and characteristics of stroke patients. 
- Chapter three explores the associations between proactive coping and selfefficacy and several psychosocial outcomes post stroke.

- Chapter four describes the study protocol of the Restore4Stroke SelfManagement study.

- Chapter five presents the rationale behind and a description of the groupbased self-management intervention 'Plan Ahead!' developed for stroke patients and their partners.

- Chapter six discusses the outcomes of the process evaluation study of the self-management intervention.

- Chapters seven discusses the outcomes of the randomized controlled trial evaluating the effectiveness of the self-management intervention 'Plan Ahead!' compared to an education intervention for stroke patients and their partners.

- Chapter eight presents a general discussion describing the main findings of the studies, methodological strengths and considerations, clinical implications and recommendations for further research. 




\title{
CHAPTER 2 \\ Proactive coping post stroke: Psychometric properties of the Utrecht Proactive Coping Competence scale
}

\author{
Nienke S. Tielemans \\ Johanna M.A. Visser-Meily \\ Vera P.M. Schepers \\ Marcel W.M. Post \\ Caroline M. van Heugten
}

Published in Archives of Physical Medicine and Rehabilitation 2014; 95: 670-5 


\section{Abstract}

Objective: To examine psychometric properties of the Utrecht Proactive Coping Competence scale (UPCC) and explore relations of proactive coping with healthrelated quality of life (HRQOL) in and characteristics of patients with stroke.

Design: Cross-sectional study. Reliability and convergent validity, and associations with HRQOL and characteristics of patients with stroke were examined.

Setting: Inpatient and outpatient settings of hospitals and rehabilitation centres in the Netherlands.

Participants: Patients with stroke $(\mathrm{n}=55$; mean age 58.7 (SD 12.8), mean months since stroke 25.0 (SD 38.5)).

Interventions: Not applicable.

Main Outcome Measures: UPCC, Utrecht Coping List (UCL), and the short Stroke-Specific Quality of Life Scale (SS-QOL-12)

Results: The UPCC showed excellent reliability (Cronbach's $\alpha=0.95$ ) without floor/ ceiling effects, or skewed score distribution. Convergent validity was shown by moderate positive relations with the UCL subscale active problem solving $(\mathrm{r}=0.38)$ and moderate negative relations with the UCL subscales passive reactions $(r=-0.50)$, avoidance $(r=-0.40)$, and expression of emotions $(\mathrm{r}=-0.42)$. Correlations between the UPCC and HRQOL domains were moderate to strong $(r=0.48-0.61)$ and stronger than those between UCL subscales and HRQOL domains. The only characteristic of patients with stroke associated with proactive coping was time after stroke $(r=-0.52)$.

Conclusions: The UPCC appears reliable and valid for patients with stroke. Moreover, we found positive associations between proactive coping and HRQOL. Future research is recommended to confirm our results and to explore ways to enhance proactive coping in patients with stroke. 


\section{Introduction}

The coming years are expected to show a considerable increase in the number of people surviving a stroke, due to decreasing case fatality and the ageing population. ${ }^{40,41}$ Patients with stroke often report reduced health-related quality of life (HRQOL) ${ }^{6,8}$, and many have to adjust their lives to the lasting consequences of stroke. Important determinants in this adjustment process after stroke are coping strategies that is the emotional, cognitive, and behavioural strategies people use to deal with the consequences of stroke., ${ }^{6,32,42-44}$ Traditionally, these strategies are dichotomized as problem-based coping strategies or emotion-based coping strategies. Problem-based coping strategies are strategies adopted to change the situation, while emotion-based coping strategies aim at handling the emotions resulting from the situation. ${ }^{43}$ Few studies have investigated the relation between coping strategies and HRQOL post stroke, though a study reported positive relations between problem-based coping strategies and long-term HRQOL in a sample of patients with acquired brain injury. ${ }^{44}$

Most coping studies have evaluated coping with situations that have already occurred (i.e., reactive coping). ${ }^{35,45}$ Less attention has been paid to proactive coping strategies, that is people's attempts to anticipate the occurrence of potential negative consequences of stroke before undertaking an activity to deal with these consequences as effectively as possible. Proactive coping is expected to result in better adjustment to chronic conditions such as stroke, because it enables patients to prevent and prepare for restrictive consequences of the condition in advance. ${ }^{35}$ Research in elderly people and people with type 2 diabetes has supported this idea, because proactive coping strategies were associated with a better ability to deal with the consequences of a condition and with realistic goal setting and achievement. ${ }^{33,34}$

Many stroke-specific education and self-management interventions aim to teach participants strategies to deal with the consequences of stroke. ${ }^{46,47}$ In our opinion, these interventions should focus on teaching proactive coping strategies. This requires instruments to assess a participant's level of proactive coping strategies in order to determine intervention goals, and effectiveness, but such instruments with good psychometric properties are lacking for patients with 
stroke. Research in other populations suggests that the Utrecht Proactive Coping Competence scale (UPCC) is a promising instrument. . $3,34,48^{-14}$

The aim of this study was therefore to evaluate the psychometric properties of the UPCC patients with stroke. In combination with studying the associations of proactive coping with patients' characteristics and HRQOL, this is expected to provide a first exploration of this concept in patients with stroke.

\section{Methods}

\section{Participants}

People with stroke were recruited from both inpatient and outpatient settings of the University Medical Centre Utrecht, Utrecht; St Antonius Hospital, Nieuwegein; De Hoogstraat Rehabilitation, Utrecht; and Rehabilitation Centre Via Reva, Deventer, all located in The Netherlands, between January and August 2011. People were eligible if they 1) had suffered a first or recurrent stroke (i.e., have had two or more strokes) and 2) were aged 18 years or older. The exclusion criterion was inability to complete the questionnaire because of 1) cognitive impairment or 2) communicative impairment (score $<5$ on the shortened version of the Aphasia Scale of the Dutch Aphasia Foundation). ${ }^{49}$ These criteria were clinically assessed by the attending rehabilitation physician.

\section{Procedure}

People with stroke were informed about the study by their rehabilitation physician at their regular visit to the inpatient or outpatient service of the participating hospitals and rehabilitation centres. If interested, they received an information letter together with the study questionnaire. They were asked to complete the questionnaire at home and return it to the researchers by mail in an enclosed envelope if they consented to participate in the study. They gave permission for using the data on their stroke characteristics to be provided by their rehabilitation physician. The study protocol was approved by the local medical research ethics committees of the participating hospitals and rehabilitation centres. 


\section{Measures}

The rehabilitation physician provided data about stroke characteristics in terms of stroke-affected hemisphere, time since stroke, type of stroke, stroke history and independence in activities of daily living (Barthel Index, 0-20). ${ }^{50}$ The study questionnaire consisted of the UPCC ${ }^{34,48}$, the Utrecht Coping List (UCL) ${ }^{51}$, the short Stroke-Specific Quality of Life Scale (SS-QOL-12) s2 $^{2}$ and questions on demographic characteristics (i.e., age, sex, educational level, marital status, employment status).

The UPCC measures self-rated proactive coping competencies. A total of 21 items are assessed on a 4-point scale, with anchors ranging from 'not competent at all' to 'very competent'. Examples of questions are as follows: 'To what extent do you have the capacity to make realistic plans" and "To what extent do you have the capacity to persist". Total scores are calculated by averaging the individual item scores. Higher scores on the UPCC indicate higher levels of perceived proactive coping competencies. ${ }^{48}$ The updated English and Dutch versions of the UPCC are available on http://selfregulationlab.nl/questionnaires/. In earlier studies, this instrument was also called the Proactive Competence Scale. ${ }^{34}$ The UPCC has shown good internal consistency (Cronbach's $\alpha=0.83-0.95$ ), testretest reliability $(\mathrm{r}=0.45-0.82)$, and sensitivity to changes after education interventions in healthy young people (aged 18 - 35 years), people in late adulthood (aged 50 - 75 years) and people diagnosed with type 2 diabetes. ${ }^{48}$

The UCL is a self-report measure of 7 coping styles: passive reactions ( 7 items), active problem solving ( 7 items), palliative reactions (8 items), seeking social support (6 items), avoidance ( 8 items), expression of emotions (3 items) and reassuring thoughts (5 items). ${ }^{51}$ Items are assessed on a 4-point scale, with anchors ranging from 'seldom' to 'very often'. Total scores for each subscale are calculated by adding up the individual item scores belonging to the particular subscale. Higher scores on the scales indicate a greater tendency to adopt that particular coping style. The UCL is frequently applied in Dutch clinical practice and has been used in several earlier studies among people with stroke or other types of brain injury. ${ }^{44,53}$ Studies among several Dutch samples found that the UCL showed moderate to good internal consistency (Cronbach's $\alpha=0.43-0.89$ ) and test-retest reliability $(\mathrm{r}=0.37-0.85) .{ }^{51}$ 
The SS-QOL-12 measures self-rated HRQOL. Six items represent physical HRQOL and six items psychosocial HRQOL. Items are assessed on either a 5-point scale with anchors from 'not able at al' to 'no trouble at all' or a 5-point scale with anchors ranging from 'strongly agree' to 'strongly disagree'. Domain scores and total scores are calculated by averaging the individual item scores. Higher scores indicate a better HRQOL. The SS-QOL-12 showed good internal consistency (Cronbach's $\alpha=0.77-0.89$ ) and predicted $88 \%$ to $95 \%$ of the variance of the original Stroke Specific Quality of Life scale in studies among people with stroke. ${ }^{52}$

\section{Statistical analyses}

Data were analysed with IBM SPSS Statistics 18. Statistics about the score distribution comprised were reported for the UPCC, and subscales of the UCL and the SS-QOL-12, in terms of its mean, standard deviation, median, range, number of missing values, skewness, and floor and ceiling effects. Skewness values lower than -1.0 or higher than 1.0 were regarded as strong, and those between 0.5 and 1.0 and -0.5 and -1.0 as moderate. ${ }^{54}$ Floor and ceiling effects were interpreted as present if at least $15 \%$ of the participants obtained the highest or lowest score. Internal consistency of the UPCC was assessed in terms of Cronbach's $\alpha$ (> $0.9=$ excellent; $0.9-0.8=$ good; $0.8-0.7=$ acceptable; $0.7-0.6=$ questionable; $0.6-0.5=$ poor, and $<0.5=$ unacceptable $).{ }^{55}$

Convergent validity was examined by calculating Spearman correlation coefficients between the UPCC scores and the UCL subscales, the SS-QOL-12, and participant characteristics. Correlations were interpreted as strong if higher than 0.6 , moderate between 0.3 and 0.6 and weak if smaller than $0.3 .{ }^{56}$ Specifically, a positive correlation was expected between the UPCC and the active problemsolving subscale of the UCL. Negative correlations were expected between the UPCC and the emotion-based coping subscales for avoidance, expression of emotions, reassuring thoughts, palliative reactions, seeking social support, and passive reactions of the UCL. Positive correlations were expected between proactive coping strategies and HRQOL post stroke, and we hypothesized that the correlations between the UPCC and SS-QOL-12 would be stronger than those between the UCL subscales and the SS-QOL-12. 


\section{Results}

\section{Participants' characteristics}

A total of 57 people with stroke returned the questionnaires, 55 of whom completed the UPCC, the UCL and the SS-QOL-12. The characteristics of the participants are presented in table 2.1. Participants had a mean age of 58.7 years (SD 12.8), and the mean time since stroke was 25 months (SD 38.5). Most participants (n $=47$ ) were independent in basic activities of daily living reflected by a Barthel Index score of $20 .^{57}$ The mean Barthel Index score was 19.7 (SD 1.2).

Table 2.1 Participants' characteristics $(n=55)$

Values

Demographic characteristics

Sex: male $28(50.9)$

Age (years) $58.7 \pm 12.8$

Educational level: at least secondary school $50(90.9)$

Marital status: living with partner $40(72.7)$

Employment status: employed $29(52.7)$

Stroke Characteristics

Time after stroke (months) $25.0 \pm 38.5$

Type of stroke: infarction $45(81.8)$

Affected hemisphere: left $26(47.3)$

Stroke history: recurrent $11(20.0)$

Barthel Index score (0-20) $19.7 \pm 1.2$

Note: Values are $\mathrm{n}(\%)$ or mean $\pm \mathrm{SD}$

\section{Score distribution and reliability}

Table 2.2 presents the score distributions of the UPCC and of the subscales of the UCL and the SS-QOL-12. 


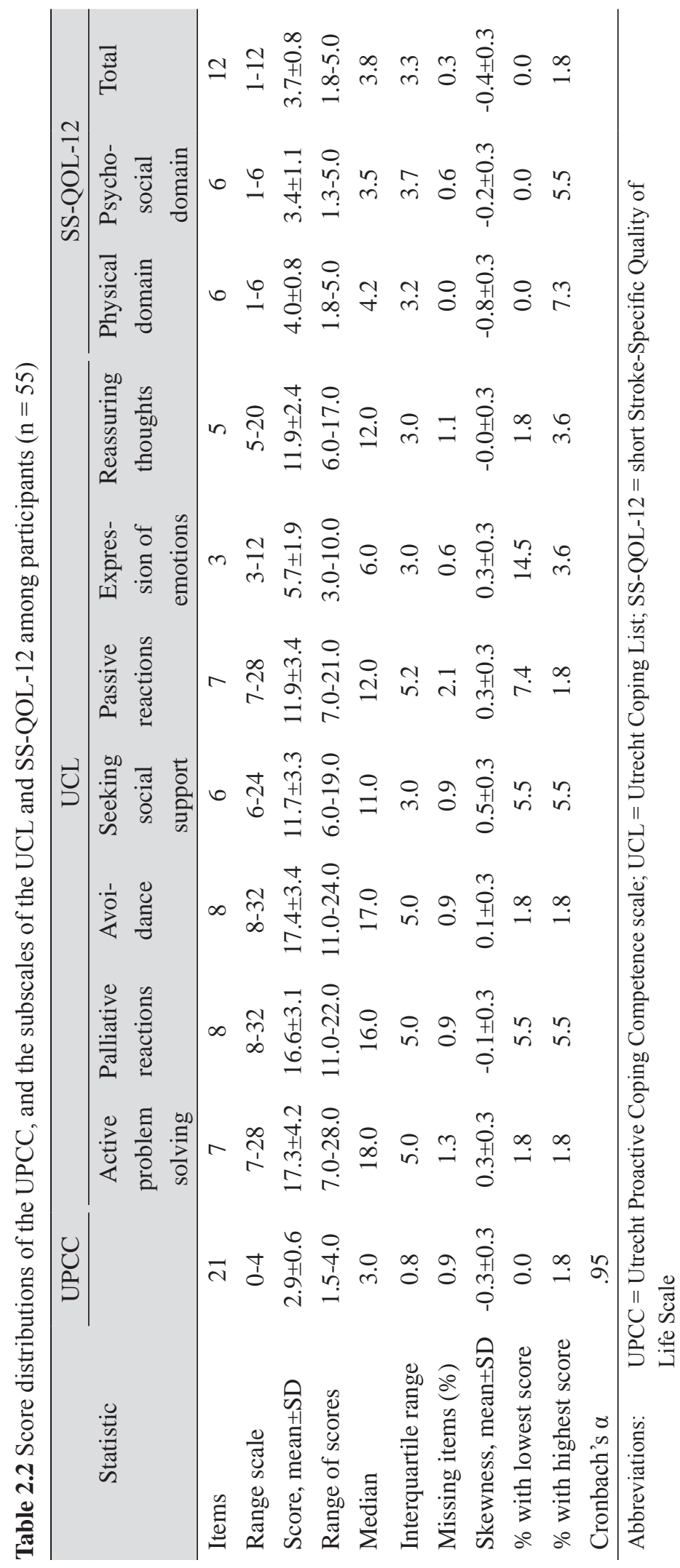


Overall, for the UPCC, $0.9 \%$ of the items were missing, no floor or ceiling effects were detected, and the skewness values were acceptable. The internal consistency of the UPCC score was excellent (Cronbach's $\alpha=0.95$ ).

On average, $1.1 \%$ of the items were missing for the subscales of the UCL and no floor or ceiling effects were detected. The skewness was acceptable for all subscales, although the subscale seeking social support was at the border of what is considered as acceptable (i.e., -0.5).

On average, $0.3 \%$ of the items were missing for the subscales of the SSQOL-12, and no floor or ceiling effects were detected at all. Only the subscale measuring the physical domain of HRQOL was moderately skewed (i.e., -0.8).

Table 2.3 Associations between the UPCC and the subscales of the UCL and participants' characteristics

\begin{tabular}{lc}
\hline & UPCC \\
\hline UCL & $.38^{*}$ \\
Active problem solving & .11 \\
Palliative reactions & $-.40^{*}$ \\
Avoidance & .16 \\
Seeking social support & $-.50^{*}$ \\
Passive reactions & $-.42^{*}$ \\
Expression of emotions & .02 \\
Reassuring thoughts & \\
Demographic characteristics & -.21 \\
Sex & -.06 \\
Age & .11 \\
Educational level & -.22 \\
Living with partner & -.11 \\
Employment status & \\
Stroke characteristics & $-.52 *$ \\
Time after stroke & .02 \\
Type of stroke & -.02 \\
Stroke-affected hemisphere & -.01 \\
Stroke history & .18 \\
Functional status (Barthel index score) &
\end{tabular}

Note: $\quad *=\mathrm{p}<.01$

Abbreviations: $\quad$ UPCC $=$ Utrecht Proactive Coping Competence scale; $\mathrm{UCL}=$ Utrecht Coping List 


\section{Convergent validity of the UPCC}

Table 2.3 presents correlations of the UPCC with the UCL subscales and participants' characteristics.

There was a moderate positive correlation between the UPCC and the UCL active problem-solving subscale $(r=0.38 ; \mathrm{p}<0.01)$. Moderate negative correlations were found between the UPCC and the UCL subscales for passive reactions $(\mathrm{r}=-0.50 ; \mathrm{p}<0.01)$, avoidance $(\mathrm{r}=-0.40 ; \mathrm{p}<0.05)$ and expression of emotions $(\mathrm{r}=-0.42 ; \mathrm{p}<.05)$. No significant correlations were found between the UPCC and the UCL subscales for seeking social support, palliative reactions, and reassuring thoughts.

None of the demographic characteristics showed a significant relation with the UPCC scores. Concerning the stroke characteristics, only time after stroke was significantly associated with scores on the UPCC. When time after stroke increased, UPCC scores decreased $(r=-0.52 ; \mathrm{p}<.01)$.

\section{Proactive coping and HRQOL}

Table 2.4 presents the correlations between the SS-QOL-12, the UPCC, and the UCL.

Table 2.4 Associations between the SS-QOL-12 and the UPCC and the scale of the UCL

\begin{tabular}{lccc}
\hline & \multicolumn{3}{c}{ SS-QOL-12 } \\
\cline { 2 - 4 } & $\begin{array}{c}\text { Physical } \\
\text { domain }\end{array}$ & $\begin{array}{c}\text { Psychosocial } \\
\text { domain }\end{array}$ & Total \\
\hline UPCC & $.48^{\dagger}$ & $.58^{\dagger}$ & $.61^{\dagger}$ \\
UCL & $.33^{\dagger}$ & .20 & $.28^{*}$ \\
Active problem solving & -.03 & -.12 & -.10 \\
Palliative reactions & $-.29^{*}$ & $-.45^{\dagger}$ & $-.43^{\dagger}$ \\
Avoidance & .15 & .13 & .15 \\
Seeking social support & $-.43^{\dagger}$ & $-.49^{\dagger}$ & $-.51^{\dagger}$ \\
Passive reactions & $-.27^{*}$ & $-.45^{\dagger}$ & $-.42^{\dagger}$ \\
Expressions of emotions & $-.23^{*}$ & $-.25^{*}$ & $-.26^{*}$ \\
Reassuring thoughts & &
\end{tabular}

Note: $\quad * \mathrm{p}<.05 ;{ }^{\dagger} \mathrm{p}<.01$

Abbreviations: $\quad$ UPCC $=$ Utrecht Proactive Coping Competence scale; UCL $=$ Utrecht Coping List; SS-QOL-12 = short Stroke-Specific Quality of Life scale 
A strong positive correlation was found between the UPCC score and the total SS-QOL-12 score. Moderate positive correlations were found between the UPCC and the physical and psychosocial domains of the SS-QOL-12. The associations between coping strategies measured with the UCL and the HRQOL were weaker, ranging from $|r|=0.10$ to 0.51 with the total HRQOL domain, from $|r|=0.03$ to 0.43 with the physical domain and from $|r|=0.12$ to 0.49 with the psychosocial domain.

The associations between coping strategies measured with the UCL and HRQOL were weaker than those between the UPCC and HRQOL, ranging from $|r|=0.23$ to 0.43 within the physical domain; $|r|=0.25$ to 0.49 within the psychosocial domain and $|\mathrm{r}|=0.26$ to 0.51 within the total domain.

\section{Discussion}

This study demonstrated good psychometric properties of the UPCC in people with stroke in terms of score distribution, reliability, and convergent validity. Having such a measure enables us to further explore the construct of proactive coping in patients with stroke. The moderate to strong correlations between the UPCC and the SS-QOL-12 suggest the relevance of proactive coping strategies for HRQOL post stroke.

The results of this study were similar to those of earlier UPCC studies in other populations. ${ }^{48}$ The internal consistency of the UPCC was outstanding compared with the alpha values of most other coping measures in patients with stroke. ${ }^{58}$ This high internal consistency can be partly explained by the relatively large number of items all measuring the same coping construct, while most other coping questionnaires measure several coping constructs with a smaller number of questions per scale. ${ }^{58}$

The expected negative relations between the UPCC and UCL subscales for palliative reactions, seeking social support, and reassuring thoughts failed to appear. However, this is in line with the growing number of researchers proposing that the broad spectrum of coping is not adequately captured by the traditional dichotomy as problem-based or emotion-based coping strategies. As a reaction, several new classifications of coping have been proposed, in terms of new subdivisions of coping and classifications at higher order levels ${ }^{6,51,58,59}$; the concept of proactive coping is one of these new forms. 
No association was found between the level of independence in basic activities of daily living and proactive coping strategies. However, this could be the result of the high level of functioning of the surveyed patients with stroke in this study.

The second part of our study supported the proposed positive associations between active problem-based coping strategies and long-term HRQOL. ${ }^{44}$ Although the cross-sectional design of the study means that caution should be exercised in interpreting this result, the associations of HRQOL with proactive coping were stronger than with other coping strategies measured with the UCL. Therefore, our results clearly provide further support for the importance of proactive coping post stroke.

In view of the positive association between proactive coping and HRQOL, it is striking that we found a moderate negative association between proactive coping strategies and time after stroke. However, the cross-sectional nature of our data limits us in making inferences about the nature of the association reflects an actual reduction in the levels of proactive coping strategies over time or whether other explanations are possible.

This study distinguishes itself from earlier coping studies in stroke patients in several ways. First, it is the first study to explore proactive coping strategies in patients with stroke. Second, convergent validity of the UPCC was assessed by exploring associations with measures of other coping strategies, instead of determining associations with related variables (such as anxiety or well-being). ${ }^{58}$

\section{Study Limitations}

A few critical notes are also in order. First, further research is needed to assess other psychometric properties of the UPCC, such as test-retest reliability and responsiveness, in patients with stroke. Second, although our sample size was sufficient for a clinimetric study ${ }^{55}$, it was relatively small, which limits the accuracy of our conclusions about the effect of clinical and demographical variables. Therefore, more research is recommended to confirm our results. Finally, it is uncertain whether the outcomes of our study can be generalized to more severely affected groups of patients with stroke than higher functioning patients. 


\section{Conclusions}

The UPCC proved to be a reliable and valid measure for use in patients with stroke and thus suitable to assess proactive coping strategies in this diagnostic group. We recommend this coping construct because our findings suggest positive relations of proactive coping with HRQOL. 



\title{
CHAPTER 3 \\ Proactive coping, self-efficacy and associations with psychosocial outcomes post stroke
}

\author{
Nienke S. Tielemans \\ Vera P.M. Schepers \\ Johanna M.A. Visser-Meily \\ Marcel W.M. Post \\ Caroline M. van Heugten
}

Accepted for publication in Archives of Physical Medicine and Rehabilitation as:

Tielemans NS, Schepers VPM, Visser-Meily JMA, Post MWM, Van Heugeten $\mathrm{CM}$. Associations of proactive coping and self-efficacy with psychosocial outcomes in individuals after stroke. 


\section{Abstract}

Objective: To examine the associations of proactive coping with self-efficacy and psychosocial outcomes in stroke patients.

Design: Cross-sectional study. Regression analyses were performed.

Setting: Outpatient settings of hospitals and rehabilitation centres in the Netherlands.

Participants: Stroke patients $(\mathrm{n}=112$; mean age 57.1 (SD 8.9) years; mean months since stroke 18.9 (SD 28.5)).

Interventions: Not applicable

Main Outcome Measures: Proactive coping was measured with the Utrecht Proactive Coping Competence scale (UPCC) and self-efficacy with the General Self Efficacy Scale (GSES). Psychosocial outcome was measured as participation with the restriction and satisfaction subscales of the Utrecht Scale for Evaluation of Rehabilitation-Participation (USER-Participation), emotional problems with the Hospital Anxiety and Depression Scale (HADS total), life satisfaction with two questions (2LS), and health-related quality of life with the Short StrokeSpecific Quality of Life scale (SS-QOL-12).

Results: Higher UPCC scores were associated with lower HADS total scores $(\beta=-.55 ; \mathrm{p}<.001)$, and with higher USER-Participation satisfaction $(\beta=.31$; $\mathrm{p}=.001), 2 \mathrm{LS}(\beta=.34 ; \mathrm{p}<.001)$, and SS-QOL-12 scores $(\beta=.44 ; \mathrm{p}<.001)$. Higher GSES scores were associated with higher UPCC scores $(\beta=.65$; $\mathrm{p}<.001)$, which in turn were associated with lower HADS scores $(\beta=-.51$; $\mathrm{p}<.001)$, andhigher $2 \mathrm{LS}(\beta=.34 ; \mathrm{p}<.001)$ and SS-QOL-12 $\operatorname{scores}(\beta=.47 ; \mathrm{p}<.001)$. Higher GSES scores were also directly associated with lower HADS total scores $(\beta=-.27 ; p=.010)$ and higher SS-QOL-12 scores $(\beta=.32 ; p=.002)$. GSES scores did not influence the association between UPCC scores and all psychosocial outcomes (all $\mathrm{p}>.05$ ).

Conclusions: Proactive coping and self-efficacy have different associations with each of the psychosocial outcomes. Proactive coping could be a target for psychosocial interventions facilitating emotional acceptance. 


\section{Introduction}

Stroke is a major health problem, with a worldwide incidence of 257.96 per 100,000 persons in $2010 .{ }^{60}$ Increasing numbers of patients in the Western world survive a stroke ${ }^{61}$, and most of them return home after hospital admission. ${ }^{62,63}$ Many of these patients have to adjust to long-term physical and psychosocial consequences. ${ }^{3,5}$ Coping and self-efficacy have been proposed as important determinants of the adaptation process post stroke. ${ }^{64}$

Folkman, Lazarus, Gruen and DeLongis defined coping as "the person's cognitive and behavioural efforts to manage (reduce, minimize, master, or tolerate) the internal and external demands of the person-environment transaction that is appraised as taxing or exceeding the person's resources". ${ }^{65}$ (p.572) Coping strategies are important determinants of the adaptation process post stroke. ${ }^{64}$ Prior research on coping mainly focused on reactive coping strategies, i.e., coping strategies adopted as a reaction to a situation. ${ }^{35}$ Recent research investigated the more future-oriented coping strategy of proactive coping, i.e., coping strategies adopted to prevent or modify a potential problem situation before it actually arises. ${ }^{33-35,66}$ In stroke patients proactive coping was not only positively related to health-related quality of life (HRQOL), but also this association was stronger than associations between other (reactive) coping strategies and HRQOL. ${ }^{66}$ Increasing the use of proactive coping strategies seems to be an important aim of interventions for stroke patients.

Self-efficacy is defined as the confidence someone has in his own competence to successful accomplish actions or reach goals. ${ }^{67}$ Various types of associations have been described between coping and self-efficacy, and the way they influence psychosocial outcomes in people with chronic conditions. For example, research in patients with diabetes suggested that self-efficacy influences the association between coping and behavioural outcomes, i.e., self-efficacy acts as a moderator (figure 3.1) ${ }^{68}$ By contrast, an adjustment model for spinal cord injury patients, and an adaptation model for acquired brain injury patients both suggest that the influence of self-efficacy on psychosocial outcomes is indirect through coping, i.e., the influence of self-efficacy is mediated by proactive coping (figure 3.2). ${ }^{64,69}$ Next to this, the adaptation model for acquired brain injury patients assumes a direct impact of self-efficacy on psychosocial outcomes as well (see the dashed 
arrow in figure 3.2) ${ }^{64}$ As far as we know, associations between proactive coping and self-efficacy, and psychosocial outcomes have not yet been investigated in stroke patients. Investigating these associations is important when developing interventions aimed at enhancing proactive coping strategies in stroke patients.

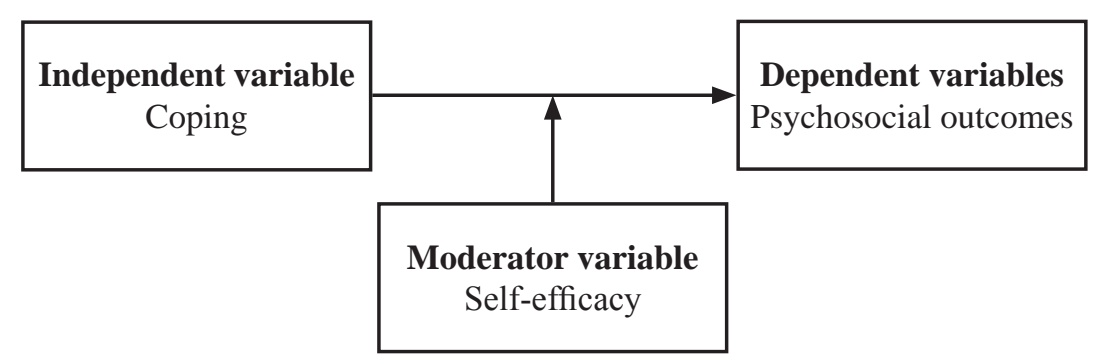

Figure 3.1 Schematic representation of self-efficacy as moderator between coping responses and psychosocial outcomes.

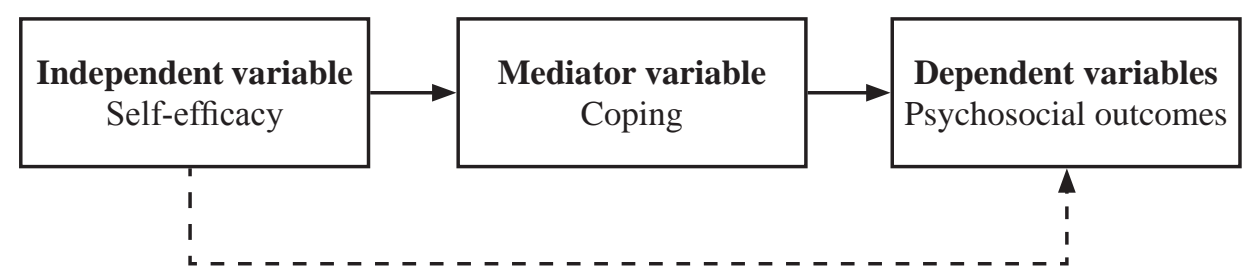

Figure 3.2 Schematic representation of alternative models explaining the influence of self-efficacy on coping and psychosocial outcomes/ adaptation.

The aim of this study was therefore to examine the nature of the associations between proactive coping and self-efficacy, and psychosocial outcomes post stroke. As this study is part of the Dutch Restore4Stroke research program, we focused on psychosocial outcomes of this program. ${ }^{36}$ Specifically, we measured restrictions in participation on the one hand, and satisfaction with participation, emotional functioning, life satisfaction, and HRQOL on the other hand, which we considered as domains reflecting emotional acceptance. 


\section{Method}

\section{Design}

This cross-sectional study examined the baseline data of the Restore4Stroke SelfManagement study: a randomized controlled trial examining the effectiveness of a self-management intervention aimed at teaching stroke patients and partners proactive coping strategies, in comparison to an education program. The complete design of the study is published elsewhere. ${ }^{38}$ The study was approved by the Medical Ethics Committee of the University Medical Centre Utrecht and the ethics committees of the participating institutes. All patients provided written informed consent.

\section{Participants}

The present study considered only the stroke patients of the Restore4Stroke selfmanagement study for analysis (i.e., not the partners). Inclusion criteria for stroke patients were 1) having had a first or recurrent symptomatic stroke (ischemic or intracerebral hemorrhagic) at least 6 weeks before recruitment, 2) living at home, 3) being at least 18 years old, and 4) having participation problems as indicated by the rehabilitation physician on at least two items of the restriction subscale of the Utrecht Scale for Evaluation of Rehabilitation-Participation (USER-Participation). ${ }^{70}$ Exclusion criteria were 1) inadequate mental ability to understand or profit from the Restore4Stroke self-management intervention, 2) behavioural problems interfering with adequate group functioning, 3) inadequate Dutch language skills (score $<5$ on the Shortened version of the Aphasia Scale of the Dutch Aphasia Foundation) ${ }^{49}$, 4) having a major depression and/or 5) participating in a psychological treatment aimed at proactive coping at the time of recruitment. These exclusion criteria were clinically judged by a rehabilitation physician or nurse practitioner. ${ }^{38}$ This study only included patients who had completed all self-assessment questionnaires of this study.

\section{Procedures}

Between February 2012 and May 2013 rehabilitation physicians and nurse practitioners selected eligible stroke patients for the Restore4Stroke SelfManagement study based on case finding in eight Dutch rehabilitation centres 
and hospitals. Eligible stroke patients were informed about the study during their regular outpatient consultation, and received an information letter about the study if interested. After five days the researcher asked interested patients if they wanted to participate in the study. When they consented they were put on a waiting list. After eight patients in the same centre had been recruited, the researcher made an appointment for the baseline measurement at the patients home or on site. At the start of the baseline measurement stroke patients signed informed consent.

\section{Measures}

\section{Predictors}

Proactive coping strategies were measured with the Utrecht Proactive Coping Competence scale (UPCC). This self-assessment scale consists of 21 items rated on a 4-point scale ranging from 'not competent at all' to 'very competent'. The total score is computed by averaging all item scores (range 1-4). Higher scores represent higher levels of proactive coping strategies. The UPCC has shown good psychometric properties in stroke patients. ${ }^{66}$

Self-efficacy was measured with the Dutch version of the General Self Efficacy Scale (GSES). This self-assessment scale consists of 10 items assessed on a 4-point scale ranging from 'not at all true' to 'exactly true'. Total score is computed by adding up all item scores (range 10-40). Higher scores represent higher levels of self-efficacy. The GSES has shown good psychometric properties in the Dutch population. ${ }^{71}$

\section{Outcome measures}

Psychosocial outcomes assessed in this study were restrictions in participation on the one hand, and emotional acceptance on the other hand which was measured in terms of satisfaction with participation, emotional functioning, life satisfaction, and HRQOL.

Participation was measured with both the restriction and the satisfaction subscales of the Utrecht Scale for Evaluation of Rehabilitation-Participation. The USER-Participation restriction subscale consists of 11 items assessed on a 3-point scale ranging from 'not possible at all' to 'effortless'. The USERParticipation satisfaction subscale consists of 11 items measured on a 5-point 
scale ranging from 'not satisfied at all' to 'very satisfied'. On both subscales, participants can indicate if an item is not relevant to their situation, using 'not applicable' option. Total scores are calculated for both subscales separately by adding all item scores and converting the resulting sum score into scores on a 0 - 100 scale. Higher scores represent higher levels of participation, that is, lower levels of participation restriction or higher satisfaction with participation. Both subscales showed good psychometric properties in former and current outpatient rehabilitation patients..$^{70,72}$

Emotional functioning was measured with the total scale of the Dutch version of the Hospital Anxiety and Depression Scale (HADS total). This self-assessment scale consists of seven items measuring depressive symptoms and seven items measuring anxiety symptoms. The total score is computed by adding all item scores (range 0-42), with higher scores representing higher levels of emotional problems. The HADS total has shown good psychometric properties in stroke patients and several other Dutch populations. ${ }^{73,74}$

Life satisfaction was measured with two life satisfaction questions (2LS). One question assessed life satisfaction at the moment of questioning itself, on a 6-point scale ranging from 'very unsatisfactory' to 'very satisfactory'. The other question assessed the current life satisfaction compared to life satisfaction before the stroke, on a 7-point scale ranging from 'much worse' to 'much better'. The total 2LS score (range 2-13) was calculated by adding the scores of these two questions, with higher scores representing higher levels of life satisfaction. Higher scores represent higher levels of life satisfaction. Psychometric properties have been shown to be sufficient in spinal cord injury patients. ${ }^{75}$

HRQOL was measured with the Dutch version of the Short Stroke-Specific Quality of Life scale. This self-assessment scale consists of 12 items, measured on a 5-point scale ranging from 'not able at all' to 'no trouble at all'. A total score was calculated by adding the item scores (range 12-60), with higher scores representing a higher HRQOL. The SS-QOL-12 has shown good psychometric populations in stroke patients. ${ }^{52}$ 


\section{Confounders}

Demographic characteristics taken into account as potential confounders during the regression analyses were age, gender, and marital status (living together with partner or not). Stroke characteristics taken into account as potential confounders were the time since stroke in months, and stroke history (having suffered a first stroke or suffered more than one stroke). Additional potential confounders taken into account were dependence in activities of daily living (no/ yes) and cognitive impairment (no/ yes). Activities of daily living were measured with the Barthel Index 0-20 (BI), with dependent in activities of daily living if $\mathrm{BI}<18$ and independent if $\mathrm{BI} \geq 18 .{ }^{50} \mathrm{Cognitive}$ functioning was measured with the Montreal Cognitive Assessment (MoCA), with impaired cognitive functioning if $\mathrm{MoCA}<26$ and unimpaired if MoCA $\geq 26 .{ }^{12,76}$

\section{Statistical analysis}

Associations between UPCC and GSES, with the dependent variables USERParticipation restrictions, USER-Participation satisfaction, HADS total, 2LS, and SS-QOL-12 were described. Correlations smaller than 0.3 indicated a weak association, those between 0.3 and 0.6 a moderate association, and correlations higher than 0.6 indicated a strong association. ${ }^{56}$

Regression analyses were performed to examine the direct associations between UPCC (independent variable) and each of the psychosocial outcomes of this study (dependent variables, i.e., USER-Participation restrictions, USERParticipation satisfaction, HADS total, 2LS or SS-QOL-12).

In addition, regression analyses were performed to determine if the effects of self-efficacy on the psychosocial outcomes were mediated through proactive coping. That is, if the influence of self-efficacy on the psychosocial outcomes was (at least partly) transmitted through proactive coping. This was done by following the four-step approach proposed by Baron \& Kenny (1986). That is, first a regression analysis was performed to investigate if GSES had a direct association with each of the psychosocial outcome measures. Then the regression analysis was performed to investigate if GSES had a direct effect on UPCC. Finally, it was examined with a multiple regression analysis whether or not GSES had an additional predictive value over UPCC for each of the psychosocial outcome measures. ${ }^{77}$ 
Finally, multiple regression analyses were performed to examine if the associations between UPCC and each of the psychosocial outcome measures were moderated by GSES. That is, it was investigated if GSES influences the association between proactive coping and the psychosocial outcome measures. If so, this can be shown statistically with a significant interaction effect between UPCC and GSES. As such, in the multiple regression analyses performed with the UPCC and GSES as independent variables, the interaction term GSES $x$ UPCC was added to the model.

Demographic and stroke characteristics were considered as confounders in each of the analyses if adding them to the model caused a change of more than $10 \%$ in the B-values of the main effect or interaction term. In case of multiple confounders, confounders were added to the model step by step, with the strongest confounder added to the model first. This process stopped when the B-vales did not change by more than $10 \%$ after adding new potential confounders had been added to the model. ${ }^{78}$

Data was analysed with IBM SPSS Statistics 21.0 , with $\mathrm{p}<.05$ considered as statistically significant. The continuous variables and confounders were centred to their mean, to facilitate the interpretation of the outcomes of the regression analyses.

\section{Results}

\section{Participants}

A total of 113 stroke patients performed the baseline measurement, of whom 112 completed the required questionnaires. Table 3.1 presents the characteristics of the participants. Participants had an average age of 57.1 (SD 8.9) years, and a mean number of months since stroke of 18.9 (SD 28.5). Most patients were independent in activities of daily living $(n=92)$. More than half of the participants were cognitively impaired $(n=66)$, and approximately half of them were communicatively impaired $(n=53)$. 
Table 3.1 Participants' characteristics $(n=112)$

Values

Demographic characteristics

Sex: male

Age (years)

$57.1 \pm 8.9$

Educational level: high ${ }^{* \dagger}$

Marital status: living with partner

$81(72.3)$

Employment status: employed after stroke

\section{Stroke Characteristics}

Time after stroke (months)

$18.9 \pm 28.5$

Stroke history: > 1 stroke

Dependence in activities of daily living: patients with $\mathrm{BI}<18^{\S}$

$20(17.9)$

Cognitive Impairment: patients with $\mathrm{MoCA}<26^{\S}$

Communicatively impaired: patients with SAN $<7$

Measures

$\operatorname{UPCC}(1-4)^{\|}$

$2.9 \pm .5$

GSES (1-40)\|

$28.2 \pm 6.4$

USER-Participation restrictions (0-100) II

$72.1 \pm 16.0$

USER-Participation satisfaction (0-100) \|

$60.8 \pm 17.1$

HADS total (0-42)\|

$13.1 \pm 6.9$

2LS (1-13)\|

$6.7 \pm 2.6$

SS-QOL-12 (1-5)\|

$3.6 \pm .8$

Note:

Values are $\mathrm{n}(\%)$ or mean $\pm \mathrm{SD}$

* Higher professional education or university degree;

${ }^{\dagger} \mathrm{n}=109 ;{ }^{\star} \mathrm{n}=108 ;{ }^{\S} \mathrm{n}=111$;

" higher scores indicate higher levels of the measured construct;

"I higher scores indicate lower levels of the measured construct

Abbreviations: $\quad \mathrm{BI}=$ Barthel Index $;$ MoCA = Montreal Cognitive Assessment; $\mathrm{SAN}=$ Shortened version of the Aphasia Scale of the Dutch Aphasia Foundation; UPCC $=$ Utrecht Proactive Coping Competence scale; GSES = General Self Efficacy Scale; USER-Participation restrictions = restriction subscale of the Utrecht Scale for Evaluation of Rehabilitation-Participation; USERParticipation satisfaction $=$ satisfaction subscale of the Utrecht Scale for Evaluation of Rehabilitation-Participation; HADS total = total scale of the Hospital Anxiety and Depression Scale; 2LS = two life satisfaction questions; SS-QOL-12 total = total scale of the Short Stroke-Specific Quality of Life scale 
Table 3.2 Associations between proactive copnig, self-efficacy, and psychosocial outcomes

\begin{tabular}{|c|c|c|c|c|c|}
\hline & $\begin{array}{l}\text { USER- } \\
\text { Participation } \\
\text { restrictions }\end{array}$ & $\begin{array}{c}\text { USER- } \\
\text { Participation } \\
\text { satisfaction }\end{array}$ & $\begin{array}{c}\text { HADS } \\
\text { total }\end{array}$ & $2 \mathrm{LS}$ & $\begin{array}{l}\text { SS-QOL-12 } \\
\text { Total }\end{array}$ \\
\hline UPCC & .05 & $.34^{\dagger}$ & $-.54^{\dagger}$ & $.36^{\dagger}$ & $.38^{\dagger}$ \\
\hline GSES & .10 & $.23 *$ & $-.53^{\dagger}$ & $.35^{\dagger}$ & $.41^{\dagger}$ \\
\hline Note: & \multicolumn{5}{|c|}{$\begin{array}{l}\mathrm{r}_{\text {UPCC, GSES }}=.67 ; \mathrm{p}<.001 \\
*=\mathrm{p}<.05 ;{ }^{\dagger}=\mathrm{p}<.01\end{array}$} \\
\hline Abbreviations: & \multicolumn{5}{|c|}{$\begin{array}{l}\text { UPCC = Utrecht Proactive Coping Competence scale; GSES = General Self } \\
\text { Efficacy Scale; USER-Participation restrictions = restriction subscale of } \\
\text { the Utrecht Scale for Evaluation of Rehabilitation-Participation; USER- } \\
\text { Participation satisfaction = satisfaction subscale of the Utrecht Scale for } \\
\text { Evaluation of Rehabilitation-Participation; HADS total = total scale of the } \\
\text { Hospital Anxiety and Depression Scale; 2LS = two life satisfaction } \\
\text { questions; SS-QOL-12 total = total scale of the Short Stroke-Specific } \\
\text { Quality of Life scale }\end{array}$} \\
\hline
\end{tabular}

\section{Associations between proactive coping, self-efficacy and the psychosocial outcomes}

Table 3.2 shows the correlations between the UPCC and, GSES, and psychosocial outcomes: USER-Participation restrictions, USER-Participation satisfaction, HADS total, 2LS, and SS-QOL-12 scores.

No association was found between the UPCC and USER-Participation restriction scores $(\mathrm{p}>.05)$. Moderate, positive associations were found for the UPCC scores with the USER-Participation satisfaction scores $(r=.34 ; \mathrm{p}<.001)$, $2 \mathrm{LS}(\mathrm{r}=.36 ; \mathrm{p}<.001)$, and SS-QOL-12 $(\mathrm{r}=.38 ; \mathrm{p}<.001)$ indicating higher scores on the UPCC were associated with higher scores on the USER- Participation satisfaction, 2LS, and SS-QOL-12. A moderate, negative association was found between UPCC and HADS total scores $(r=-.54 ; \mathrm{p}<.001)$ indicating higher scores on the UPCC were associated with lower scores on the HADS total.

A strong, positive association was found between the GSES and UPCC $(\mathrm{r}=.67 ; \mathrm{p}<.001)$, indicating higher scores on the GSES were associated with higher scores on the UPCC. No association was found between the GSES and USER-Participation restrictions scores $(\mathrm{p}>.05)$. A weak, positive association 
was found between the GSES and USER-Participation satisfaction scores $(\mathrm{r}=.23 ; \mathrm{p}=.013)$, indicating higher scores on the GSES were associated with higher scores on the USER-Participation satisfaction. Moderate positive associations were found between the GSES and 2LS $(r=.35 ; \mathrm{p}<.001)$, and the SS-QOL-12 $(\mathrm{r}=.41 ; \mathrm{p}<.001)$ scores, indicating higher scores on the GSES were associated with higher scores on the 2LS and SS-QOL-12. A moderate, negative association was found between the GSES and HADS total scores $(\mathrm{r}=-.53 ; \mathrm{p}<.001)$, indicating higher scores on the GSES were associated with lower scores on the HADS total.

Table 3.3 shows that higher scores on the UPCC were associated with lower scores on the HADS total $(\beta=-.55 ; p<.001)$ and higher scores on the USERParticipation satisfaction $(\beta=.31 ; p=.001), 2 \mathrm{LS}(\beta=.34 ; \mathrm{p}<.001)$, and SSQOL-12 $(\beta=.44 ; \mathrm{p}<.001)$. Scores on the UPCC were not associated with scores on the USER-Participation restrictions and USER-Participation satisfaction (both $\mathrm{p}>.05)$.

Table 3.4 shows that, higher scores on the GSES were associated with lower scores on the HADS total $(\beta=-.51 ; \mathrm{p}<.001)$ and higher scores on the $2 \mathrm{LS}(\beta=.34 ; \mathrm{p}<.001)$, and SS-QOL-12 $(\beta=.47 ; \mathrm{p}<.001)$. Higher scores on the GSES were associated with higher scores on the UPCC $(\beta=.65 ; \mathrm{p}<.001)$.

Table 3.5 shows that, next to its indirect effect through proactive coping, self-efficacy showed a direct association only with emotional problems and HRQOL. That is, higher scores on the GSES were associated with lower scores on the HADS total $(\beta=-.27 ; \mathrm{p}=.010)$ and higher scores on the SS-QOL-12 ( $\beta$ $=.32 ; \mathrm{p}=.002)$. 


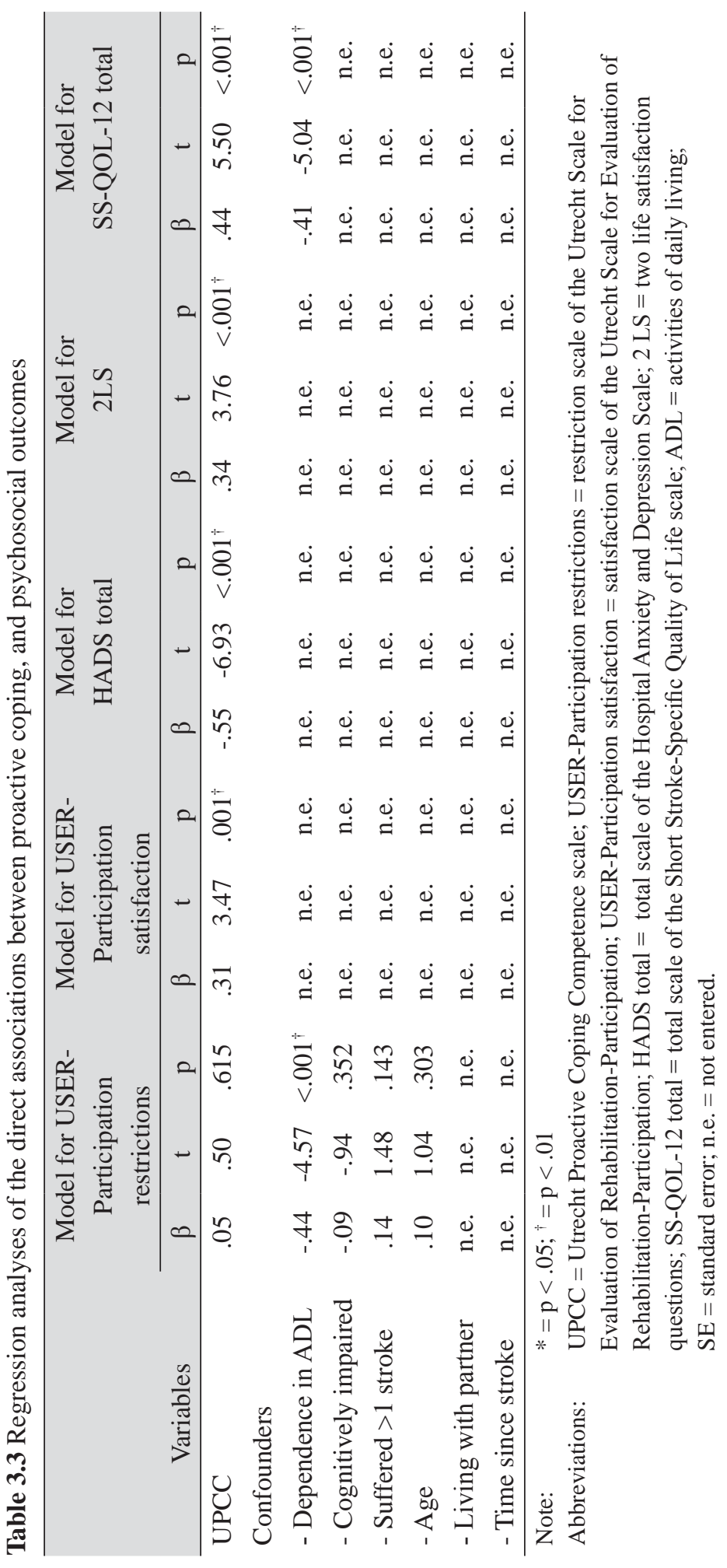




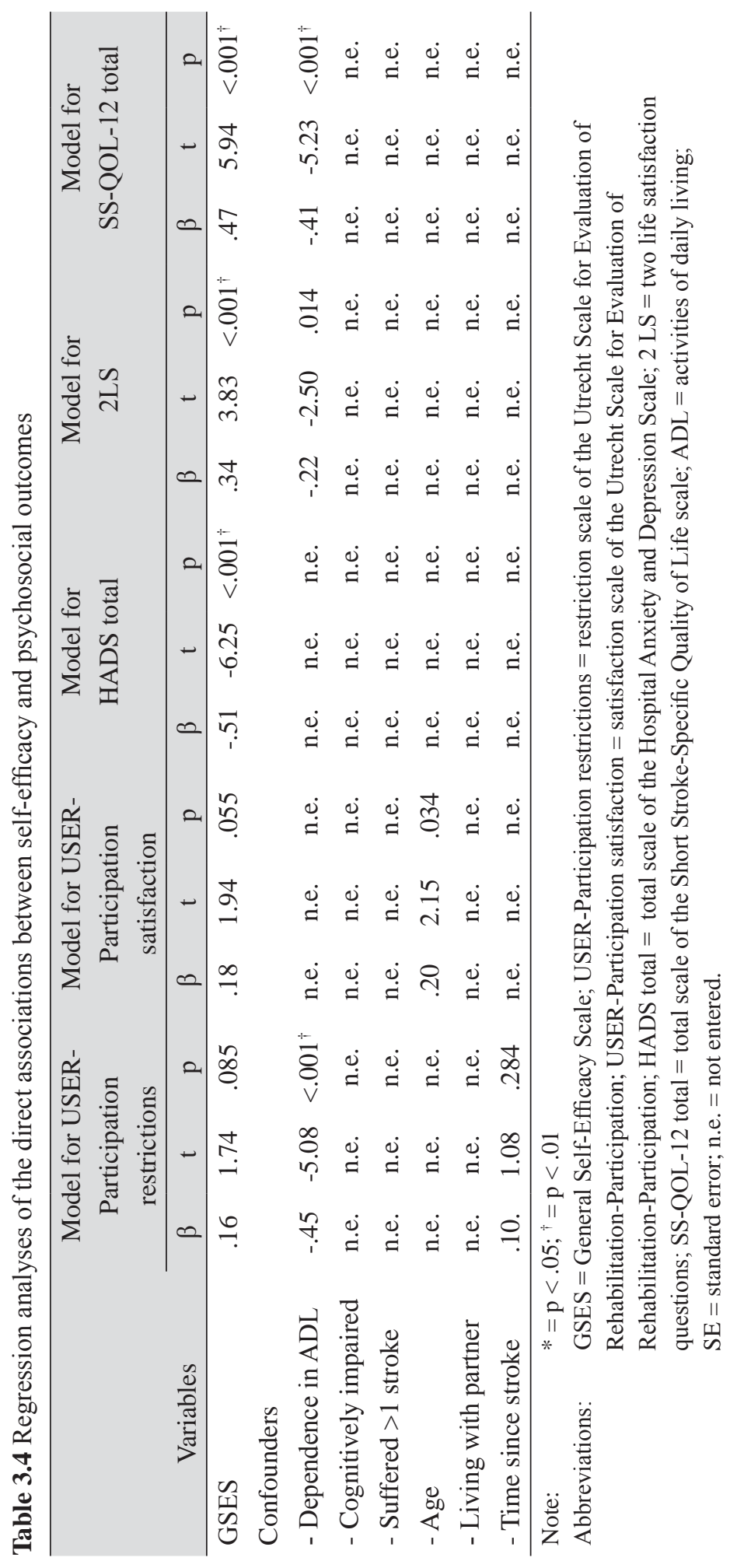




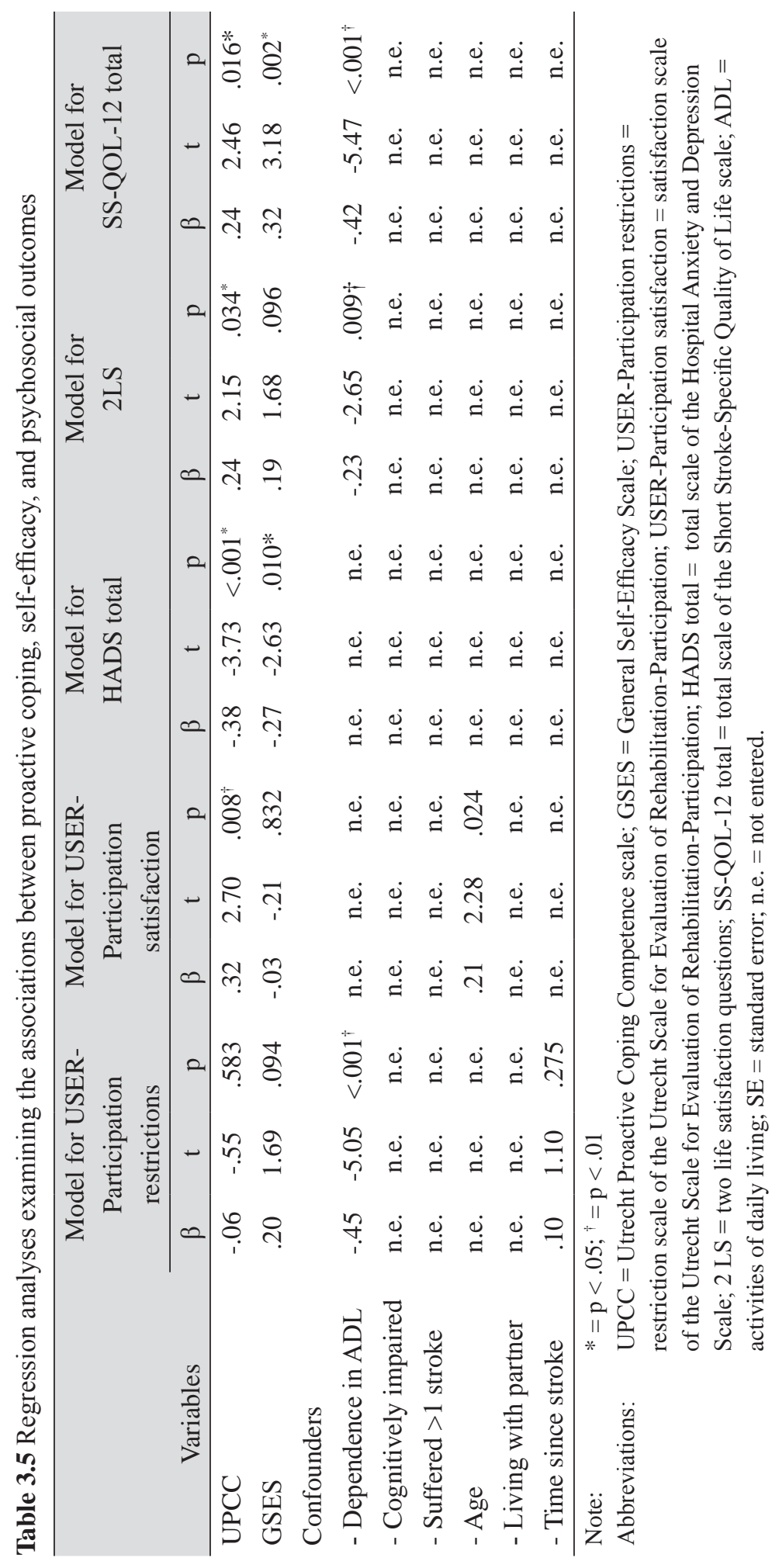


No significant UPCC x GSES interaction effects were found in any of the models ( $p>.05)$. In other words, the associations between the UPCC and each of the psychosocial outcome measures were not moderated by GSES. Therefore, the results of these analyses are not presented in a separate table.

\section{Discussion}

This study found that proactive coping and self-efficacy were differently associated with various psychosocial outcomes post stroke. Proactive coping was associated with psychosocial outcomes measuring emotional acceptance, but not with participation restrictions. Self-efficacy was positively associated with proactive coping, which in turn was positively associated with emotional functioning, life satisfaction and HRQOL. Self-efficacy was also directly associated with emotional functioning and HRQOL. Finally, self-efficacy did not influence the association between proactive coping and the psychosocial outcome measures, so no moderation effects of self-efficacy on these associations were found.

The absence of an association between proactive coping and participation was also found in patients with chronic obstructive pulmonary disease. ${ }^{79}$ However, this result does not fit with the traditional dichotomy of coping strategies in either problem-based (i.e., coping strategies aimed at changing a situation) or emotionbased coping strategies (i.e., coping strategies aimed at regulating the emotions elicited by a situation at hand). ${ }^{65}$ That is, based on this traditional dichotomization proactive coping should be considered as a problem-based coping strategy, and therefore should be associated with participation and not with emotional acceptance. Further research is needed to clarify this unexpected result.

Our finding that self-efficacy was not associated with restrictions in and satisfaction with participation deviated from findings in spinal cord injury patients. ${ }^{80}$ Compared to spinal cord injury patients, it could be that other factors than self-efficacy, determine participation in stroke patients. For example, spinal cord injury often results in clearly visible physical impairments such as reduced arm and leg functioning. ${ }^{81}$ In contrast, stroke patients living at home are often 
confronted with behavioural, cognitive and emotional consequences, which are largely invisible from the outside..$^{82-85}$ As a consequence the capacities of stroke patients are easily overestimated by relatives and people in the community, resulting in unrealistic expectations of stroke patients' participation levels. ${ }^{31,86}$ Therefore, social pressure might stronger determine participation of stroke patients than self-efficacy.

The present study was the first to investigate the associations between proactive coping and a broad variety of psychosocial outcomes post stroke. It was based on several theoretical frameworks for coping and self-efficacy.

\section{Study limitations}

Several limitations should also be noted. First of all, due to the cross-sectional nature of the data we were not able to make inferences about the causal nature of the associations. Next, the generalizability of the results might be limited as the sample included a selected group of patients with a relatively mild stroke who had participation problems and were willing to participate in the group intervention.

\section{Conclusions}

Our study showed that the associations between proactive coping and selfefficacy differ depending on which psychosocial outcome is being studied. Further investigation is needed for a better understanding of how psychosocial outcomes can be influenced post stroke. Our results suggest that proactive coping could be a target for psychosocial interventions facilitating emotional acceptance. 



\title{
CHAPTER 4 Study protocol of the Restore4Stroke self-management study: A multicentre randomized controlled trial in stroke patients and their partners
}

\author{
Nienke S. Tielemans \\ Johanna M.A. Visser-Meily \\ Vera P.M. Schepers \\ Marcel W.M. Post \\ Derick T. Wade \\ Caroline M. van Heugten
}

Published in International Journal of Stroke 2014; 9: 818-23. 


\section{Abstract}

Rationale: Many stroke patients and their partners report long-term negative consequences of stroke on their health-related quality of life. Adequate selfmanagement abilities may help manage the consequences of the stroke, but it is unknown what specific intervention might be effective to enhance selfmanagement abilities of stroke patients and their partners.

Aim: The study aims to investigate the effectiveness of a 10-week group selfmanagement intervention addressing proactive coping strategies compared with a group education intervention in stroke patients and their partners.

Design: The study is a multicentre randomized controlled trial. A total of 106 stroke patients with, if applicable, their partners are randomly assigned to the self-management intervention or the education intervention within each of the 10 participating hospitals and rehabilitation centres. The main inclusion criteria are a symptomatic stroke at least six-weeks ago, living at home, and reporting at least two participation restrictions on the Utrecht Scale for Evaluation of Rehabilitation-Participation's restriction scale. Measurements are performed at baseline, immediately after intervention, three-months and nine-months post intervention.

Study outcomes: Primary outcome measures are stroke patients' and partners' proactive coping competencies (Proactive Competence Inventory) and participation (Utrecht Scale for Evaluation of Rehabilitation-Participation's restriction scale).

Discussion: If effective, the results of this study will enable stroke patients and their partners to deal better with the lasting consequences of stroke. In the context of the growing number of people returning home after stroke, a large number of people may profit from this intervention. 


\section{Introduction}

Stroke has long-term consequences on the health-related quality of life (HRQOL) of both the patients and their partners. ${ }^{7,88}$ In the long term, stroke patients living at home become largely responsible for managing their own health, including practical difficulties in daily living function, any medical management of the disease, lifestyle changes, and all the other consequences of stroke. ${ }^{25}$ Thus, the person requires self-management skills to deal with these tasks effectively. ${ }^{88}$

In other chronic diseases, interventions aimed at enhancing self-management skills show positive effects on coping, goal achievement and self-efficacy, HRQOL, and utilization of healthcare services. ${ }^{88-91}$ These interventions, however, may need modification to be useful for stroke patients and their partners, because stroke patients face condition-specific challenges ${ }^{25,91}$, such as reducing the impact of cognitive and emotional impairments. A specific self-management intervention for stroke patients and their partners might therefore be helpful.

There is some evidence for stroke-specific self-management interventions, at least in the short term. ${ }^{27-30,92}$ Many of these interventions aim to enhance cognitions underlying intentions of behaviour (e.g. self-efficacy and control cognitions). Another approach is to improve patients' goal-related planning and action strategies. Many stroke patients fail to achieve their goals, as they are restrained by unanticipated consequences of stroke. ${ }^{31}$ Therefore, it may be effective to teach them 'proactive coping strategies', that is to have them learn to anticipate the consequences of their stroke and develop corresponding solutions in advance. ${ }^{35}$ Aspinwall and Taylor (1997) modelled proactive coping as consisting of five interrelated stages: 1) resource accumulation, 2) recognition of potential stressors, 3) initial appraisal, 4) preliminary coping efforts, and 5) elicit and use feedback. ${ }^{35}$

In the current Restore4Stroke Self-Management study, we investigate whether a self-management intervention based on the proactive coping model results in an increase in the use of proactive coping strategies and participation compared with an education intervention. Additionally, we examine levels of self-efficacy and HRQOL and partner's burden. The present paper describes the study protocol of the Restore4Stroke Self-Management study. This study is part of the Dutch national consortium Restore4Stroke. ${ }^{36,37,39}$ 


\section{Methods}

\section{Design}

In this multicentre randomized controlled trial, stroke patients with, if applicable, their partners, are randomly assigned to either the self-management intervention or an education intervention. Patients are recruited by rehabilitation physicians and nurse practitioners in 10 Dutch hospitals and rehabilitation centres where the self-management and control interventions are offered in addition to standard rehabilitation care. These co-operating centres both recruit a minimum of eight participants, and provide the intervention. Tests are administered at baseline (T0), immediately post intervention (T1), and at three-months (T2) and nine-months (T3) follow-up (figure 4.1). Participants and the researcher sign an informed consent form prior to the $\mathrm{T} 0$ measurement.

\section{Participants - inclusion and exclusion criteria}

Eligible stroke patients are adults aged 18 or over, and living at home who have had a first or a recurrent symptomatic stroke (ischemic or intracerebral haemorrhagic lesion confirmed by a neurologist and recorded in the medical file) at least six-weeks earlier, and have problems on at least two items of the restriction scale of the Utrecht Scale for Evaluation of Rehabilitation-Participation, USERParticipation. ${ }^{93}$ Clinically judged exclusion criteria comprise insufficient mental ability to understand and profit from the intervention, insufficient command of the Dutch language (score $<5$ on the Shortened version of the Aphasia Scale of the Dutch Foundation, SAN) ${ }^{49}$, inability to function in a group because of behavioural problems, major depression, and already taking part of a structured, psychological counselling aimed at proactive coping post stroke at the moment of recruitment. Stroke patients can join the study whether or not they have a partner taking part in the study.

Eligible partners have to be at least 18 years of age and have to live together with the stroke survivor taking part in the study. Clinically judged exclusion criteria for partners are inability to function in a group because of behavioural problems and insufficient command of the Dutch language to participate in the intervention or complete the questionnaires. Partners cannot take part without their stroke patient. 


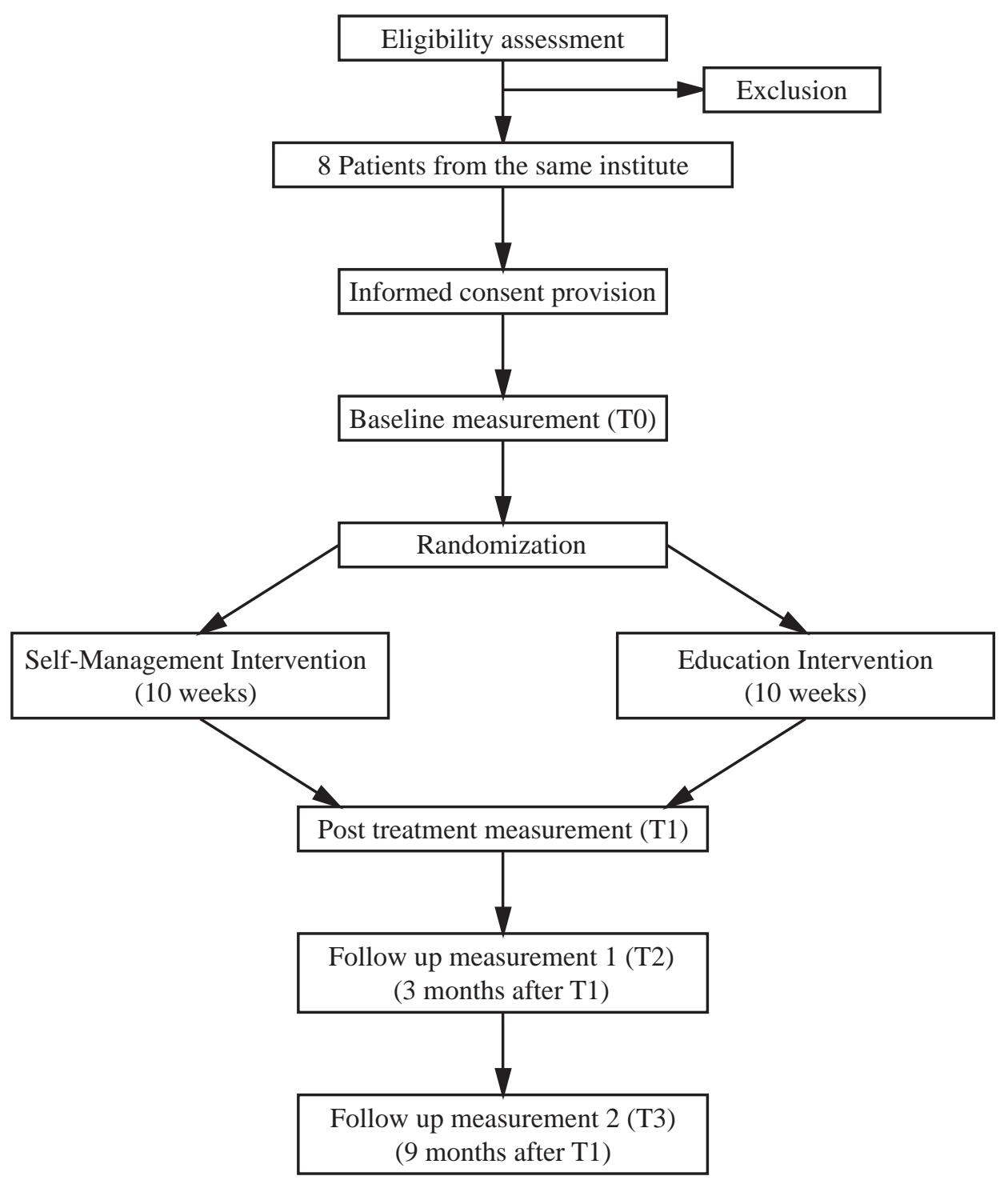

Figure 4.1 Schematic representation of the procedure of the study

\section{Randomization}

In blocks of eight, stroke patients are randomized to the two interventions (1:1 ratio), stratified by centre. Patients choose one out of eight blank envelopes with their assigned treatment group indicated inside. Partners follow the patient in the appointed intervention. 


\section{Interventions}

Characteristics of both interventions are summarized in table 4.1.

\section{Self-management intervention}

This 10 -week intervention consists of six two-hour sessions in the first six-weeks and a two-hour booster session in the tenth week. During the first two sessions, participants are introduced to each other and to the self-management intervention, and stroke-related consequences and experiences are discussed. In the third session, the concept of proactive coping is introduced, with the corresponding action plan, which serves as a tool to teach participants how to adopt proactive coping strategies when setting personal goals. Action plans are based on patients' and partners' own goals and consist of the following five steps: 1) getting an idea of what they want to change in their lives; 2) putting a goal into words; 3) mapping restrictions and requirements to achieve the goal, and thinking of possible solutions; 4) formulating the concrete action for the following week; and 5) evaluation of the concrete action..$^{90}$ The next three sessions involve discussing information, beliefs, emotions, and experiences regarding the themes: 1) coping with negative feelings; 2) social support and relations; and 3) participation in society. Resulting insights are integrated with the formulated action plans. At the end of every session, participants are asked to execute the formulated action plan or are asked to further elaborate the action plan if not yet finished. During the booster session, a summary of the provided information is offered and selfmanagement intervention related improvements are discussed.

The self-management intervention is provided as an outpatient rehabilitation service in the participating hospitals and rehabilitation centres. Further details are provided in table 4.1 .

\section{Control intervention}

The education intervention aims to improve stroke-related knowledge of participants only. This 10 -week intervention consists of three one-hour sessions during the first six weeks and a one-hour booster session during the last week. After getting introduced to each other and the education intervention, information is provided about: 1) the brain and a stroke (first session), 2) consequences of stroke (second session), and 3) prevention of a recurrent stroke (third session). 
During the booster session a summary of the discussed information and additional information booklets are provided. The education intervention is also provided as an outpatient rehabilitation service in the participating hospitals and rehabilitation centres. Further information is provided in table 4.1.

Table 4.1 Characteristics of both the self-management intervention and education intervention

\begin{tabular}{|c|c|c|}
\hline & Self-management intervention & Education intervention \\
\hline $\begin{array}{l}\text { Duration of } \\
\text { intervention }\end{array}$ & $\begin{array}{l}10 \text { weeks with } 7 \text { two-hour group } \\
\text { sessions }\end{array}$ & $\begin{array}{l}10 \text { weeks with } 4 \text { one-hour group } \\
\text { sessions }\end{array}$ \\
\hline \multirow[t]{7}{*}{ Content } & - proactive action planning & \\
\hline & - peer support & - peer support \\
\hline & $\begin{array}{l}\text { - information provision about the } \\
\text { themes }\end{array}$ & $\begin{array}{l}\text { - information provision about the } \\
\text { themes }\end{array}$ \\
\hline & $\begin{array}{l}\text { 1) general consequences of stroke } \\
\text { including the invisible } \\
\text { consequences of stroke }\end{array}$ & $\begin{array}{l}\text { 1) general consequences of stroke } \\
\text { stroke including the invisible } \\
\text { consequences of stroke }\end{array}$ \\
\hline & 2) handling negative emotions & 2) the brain and a stroke \\
\hline & 3) social relations and support & 3) prevention of a recurrent stroke \\
\hline & 4) participation in society & \\
\hline \multirow[t]{6}{*}{ Therapists } & two healthcare professionals with & one healthcare professional with \\
\hline & - at least a Higher Professional & - at least a Higher Professional \\
\hline & Education degree & Education degree \\
\hline & - experience in group counselling & - experience in group counselling \\
\hline & $\begin{array}{l}\text { - experience in working with } \\
\text { brain injury patients }\end{array}$ & \\
\hline & $\begin{array}{l}\text { - receiving an one-day-training } \\
\text { about the self-management } \\
\text { intervention }\end{array}$ & $\begin{array}{l}\text { - receiving an 1,5-hour training } \\
\text { about the self-management } \\
\text { intervention }\end{array}$ \\
\hline Participants & $\begin{array}{l}\text { 4- } 8 \text { participants ( } 4 \text { patients and } \\
\text { their partners) }\end{array}$ & $\begin{array}{l}\text { 4- } 8 \text { participants ( } 4 \text { patients and } \\
\text { their partners) }\end{array}$ \\
\hline \multirow[t]{2}{*}{$\begin{array}{l}\text { Intervention } \\
\text { materials }\end{array}$} & $\begin{array}{l}\text { - guides and presentations for } \\
\text { professionals }\end{array}$ & $\begin{array}{l}\text { - guides and presentations for } \\
\text { professionals }\end{array}$ \\
\hline & - workbooks for participants & - workbooks for participants \\
\hline Location & Outpatient facilities & Outpatient facilities \\
\hline $\begin{array}{l}\text { Timing of } \\
\text { provision }\end{array}$ & At least 6 weeks after stroke & At least 6 weeks after stroke \\
\hline
\end{tabular}




\section{Measurements}

An overview of all measures and the time of assessment is presented in table 4.2.

\section{Baseline descriptors}

The patients are characterised on general clinical, functional, and the cognitive parameters. The Barthel Index is used to assess stroke severity in terms of basic activities of daily living ${ }^{50}$, the Shortened version of the Aphasia Scale of the Dutch Aphasia Foundation to assess communicative abilities ${ }^{49}$, the Montreal Cognitive Assessment to assess general cognitive functioning ${ }^{76}$, the Key Search Task and Zoo Map Test of the Dutch Behavioural Assessment of the Dysexecutive Syndrome to assess executive functioning ${ }^{94}$, and the Checklist for Cognitive and Emotional Consequences following stroke to assess subjective cognitive complaints. ${ }^{95}$ All participants are asked about some demographical characteristics (i.e., age, sex, ethnicity, education level, marital status, employment), and rehabilitation physicians provide data about stroke characteristics in terms of type of stroke, stroke-affected hemisphere and artery, date of stroke, and stroke history. Also it is registered if the partner of the patient takes part of the intervention.

\section{Primary outcomes}

Two primary outcome variables were chosen: the proactive coping competencies measured with the Proactive Competence Inventory (PCI) and participation restrictions measured by the USER-Participation restrictions subscale.

Proactive coping competencies are assessed with the 21-item PCI, a selfreport measure with a 4-point response scale ranging from 'not competent at all' to 'competent'. ${ }^{33,48}$ The PCI has shown good psychometric properties in healthy people and people diagnosed with type 2 diabetes. ${ }^{48}$ Both the updated English and Dutch versions of the Proactive Coping Inventory are available at http:// selfregulationlab.nl/questionnaires/.

Restrictions in participation are assessed with the 11-item USERParticipation Restrictions subscale. This scale has shown sufficient psychometric properties in rehabilitation outpatients including stroke patients..$^{70,72,93}$ The final English-language version of the Utrecht Scale for Evaluation of Rehabilitationparticipation is available at http://www.dehoogstraat.nl/images/products/297/ USER\%20Participatie\%20English.pdf. 
Table 4.2 All baseline and outcome measures

\begin{tabular}{|c|c|c|c|c|c|}
\hline \multirow[b]{2}{*}{ Domain } & \multirow[b]{2}{*}{ Instruments } & \multicolumn{4}{|c|}{ Measurment } \\
\hline & & T0 & $\mathrm{T} 1$ & $\mathrm{~T} 2$ & T3 \\
\hline \multicolumn{6}{|l|}{ Baseline descriptors } \\
\hline Demographic factors & $\begin{array}{l}\text { Specific questions about age, sex, ethnicity, } \\
\text { education level, marital status and employment }\end{array}$ & $\begin{array}{l}\mathrm{X} \\
\mathrm{O}\end{array}$ & & & \\
\hline Stroke characteristics & $\begin{array}{l}\text { Specific questions about type, hemisphere, artery, } \\
\text { date of stroke and stroke history }\end{array}$ & $\mathrm{x}$ & & & \\
\hline Partner participation & $\begin{array}{l}\text { Specific question about participating with or } \\
\text { without partner in intervention }\end{array}$ & $\mathrm{x}$ & & & \\
\hline \multirow[t]{4}{*}{ Cognitive functioning } & Montreal Cognitive Assessment ${ }^{76}$ & $\mathrm{x}$ & & & \\
\hline & $\begin{array}{l}\text { Dutch Behavioural Assessment of the Dysexecu- } \\
\text { tive Syndrome Key Search \&Zoo Map tests }\end{array}$ & $\mathrm{x}$ & & & \\
\hline & $\begin{array}{l}\text { Checklist for Cognitive and Emotional } \\
\text { Consequences following stroke }\end{array}$ & $\mathrm{x}$ & & & \\
\hline & $\begin{array}{l}\text { Shortened version of the Aphasia Scale of the } \\
\text { Dutch Foundation }^{49}\end{array}$ & $\mathrm{x}$ & & & \\
\hline Activities of daily living & Barthel Index ${ }^{50}$ & $\mathrm{x}$ & & & \\
\hline \multicolumn{6}{|l|}{ Primary outcomes } \\
\hline \multirow[t]{2}{*}{ Proactive Coping } & Proactive Competence Inventory ${ }^{33,48}$ & $\mathrm{x}$ & $\mathrm{x}$ & $\mathrm{x}$ & $\mathrm{x}$ \\
\hline & & $\mathrm{O}$ & $\mathrm{O}$ & $\mathrm{O}$ & $\mathrm{O}$ \\
\hline Restrictions in & Restriction subscale of the Utrecht Scale for & $\mathrm{x}$ & $\mathrm{x}$ & $\mathrm{x}$ & $\mathrm{x}$ \\
\hline participation & Evaluation of Rehabilitation-Participation ${ }^{93}$ & o & o & o & o \\
\hline \multicolumn{6}{|l|}{ Secondary outcomes } \\
\hline Burden & Expanded Caregiver Strain Index ${ }^{96}$ & $\mathrm{o}$ & o & & o \\
\hline \multirow[t]{2}{*}{ Self-efficacy } & General Self-Efficacy scale ${ }^{71}$ & $\mathrm{x}$ & $\mathrm{x}$ & $\mathrm{x}$ & $\mathrm{x}$ \\
\hline & & o & $\mathrm{o}$ & o & o \\
\hline \multicolumn{6}{|l|}{ HRQoL } \\
\hline \multicolumn{6}{|l|}{ General } \\
\hline Disease specific & Stroke Specific Quality of Life scale- $12^{52}$ & $\mathrm{x}$ & $\mathrm{x}$ & & $\mathrm{x}$ \\
\hline \multirow[t]{2}{*}{ Generic } & Six-Dimensional Euro-QoL ${ }^{97}$ & $\mathrm{x}$ & $\mathrm{x}$ & $\mathrm{x}$ & $\mathrm{x}$ \\
\hline & & $\mathrm{o}$ & $\mathrm{o}$ & o & o \\
\hline \multicolumn{6}{|l|}{ Domain specific } \\
\hline \multirow[t]{2}{*}{ Societal participation } & Frequency and satisfation subscales of the Utrecht & $\mathrm{x}$ & $\mathrm{x}$ & & $\mathrm{x}$ \\
\hline & Scale for Rehabilitation-Particiption ${ }^{93}$ & o & o & & o \\
\hline Emotional & Hospital Anxiety and Depression scale ${ }^{74}$ & $\mathrm{x}$ & $\mathrm{x}$ & & $\mathrm{x}$ \\
\hline functioning & & o & o & & o \\
\hline Subjective well-being & Three life satisfaction questions ${ }^{98}$ & $\mathrm{x}$ & $\mathrm{x}$ & & $\mathrm{x}$ \\
\hline
\end{tabular}

Abbreviations: $\quad \mathrm{x}=$ outcome measure stroke patient; $\mathrm{o}=$ outcome measure partner; $\mathrm{T} 0=$ baseline measurement; $\mathrm{T} 1$ = post treatment measurement; $\mathrm{T} 2$ = first follow-up measurement; $\mathrm{T} 3=$ second follow-up measurement 


\section{Secondary outcomes}

Partner's burden is assessed with the 18 items of the expanded Caregiver Strain Index, which accounts for both positive and negative caregiver experiences. ${ }^{96}$ General self-efficacy is assessed with the 10 items of Dutch version of the General Self-Efficacy Scale. ${ }^{71}$ Disease-specific HRQOL is assessed with the 12-item short version of the Stroke-Specific Quality of Life Scale, covering a physical and a psychosocial domain. ${ }^{52}$ Generic HRQOL is assessed with the six-item Six Dimensional Euro-QoL. ${ }^{97}$ In addition, the frequency and satisfaction with participation are assessed with the other two scales of the USER-Participation, with 11 and 10 items, respectively. ${ }^{93}$ Emotional functioning is assessed with the 14-item Hospital Anxiety and Depression Scale, covering symptoms of anxiety and depression. ${ }^{74}$ Subjective well-being is assessed with three questions covering actual and pre-stroke life satisfaction, and the difference between them..$^{98}$

\section{Data monitoring board}

No data monitoring board took part in this study.

\section{Sample size}

Sample size calculations are based on both the PCI and restriction subscale of the USER-Participation. For the PCI, a standardized difference of 0.6 was expected, based on previous self-management intervention studies. ${ }^{48}$ For the Restrictions subscale of the USER-Participation, a standardized difference of 0.5 was expected. ${ }^{72}$ Based on an alpha .05 and a power of $80 \%$, a minimum of $2 \times 45$ stroke patients is required for sufficient statistical power. ${ }^{99}$ Assuming a dropout rate of $15 \%, 106$ stroke patients are recruited.

\section{Blinding}

Participants are told two interventions are compared without mentioning the specific hypotheses of our study. Baseline measures are conducted before randomization by the researcher and research assistants. Subsequent measures are completed by participants themselves at home. Only when needed, a research assistant who is blinded to group allocation assists participants in filling out the post-treatment questionnaires. 


\section{Statistical analyses}

By means of independent t-tests, Mann-Whitney U-tests, and chi-square tests, similarity of the two groups at baseline is checked.

Effectiveness is evaluated using 'intention to treat' and secondarily using 'on treatment' analyses. Differences in effect are determined using repeated measures analysis of variance with measurement (T0, T1, T2 and T3) as withinsubject factor, group (self-management intervention, education intervention) as between-subject factor, and the outcome measures as dependent variables. Baseline characteristics which significantly differ between the two groups are included in the analyses as covariates. Both short and long-term effects of the self-management intervention, and the possible transitions between these effects, are of interest. Analyses will be performed using SPSS version PASW Statistics 18.0 (IBM Corporation, Armonk, NY, USE); alpha will be set at 0.05 .

\section{Summary and conclusion}

In this paper we described the research protocol of the Restore4Stroke selfmanagement study, which examines the clinical effectiveness of a group selfmanagement intervention teaching proactive self-management strategies compared with a group education intervention in stroke patients and partners.

Innovative aspects of the Restore4Stroke research program are clearly present in this study, such as its focus on proactive coping as a psychological variable influencing HRQOL of stroke patients ${ }^{100}$, including the generic, disease-specific and domain-specific perspectives on HRQOL ${ }^{101}$, and considering participation as a primary outcome of a self-management intervention. Furthermore, a familycentred approach is strongly presented in this study, putting equal focus on patients and partners during the intervention. Moreover, the cost-effectiveness of the intervention is evaluated as well, which is expected to facilitate its implementation if effective. ${ }^{39}$

The strengths of this study are its randomized design with blinding both participants and research assistants, relatively large sample size, and extended follow-up period compared to available studies, and that it is conducted in many institutes, thereby reducing the risk of the result being very dependent upon one person or group. It has an explicit theoretical basis for the intervention 
and includes a stroke-specific education intervention as control condition instead of referring participants to a care as usual or general self-management programs. ${ }^{28,30,92}$ A potential weakness of this study is that the patients are likely to not be representative of all survivors. Furthermore, using an education group control intervention has the risk of insufficient contrast between the experimental and control conditions. The advantage, however, is that this comparison allows to attribute possible between-group differences in outcomes specifically to the selfmanagement component of the trial.

In summary, we have described a study evaluating a novel self-management intervention for stroke patients living at home and their partners. If effective, this study will enable stroke patients and their partners to deal with the lasting consequences of stroke. In the context of the growing number of people returning home after stroke, a large number of people may benefit from this intervention. 




\title{
CHAPTER 5 \\ The Restore4Stroke self-management intervention 'Plan Ahead!': Rationale and description of the treatment protocol based on proactive action planning
}

\author{
Nienke S. Tielemans \\ Vera P.M. Schepers \\ Johanna M.A. Visser-Meily \\ Jos van Erp \\ Mariette Eijkenaar \\ Caroline M. van Heugten
}

Published in Clinical Rehabilitation 2014; 28: 530-40. 


\section{Abstract}

Objective: To describe the rationale behind and description of a group-based self-management intervention developed for stroke patients and their partners.

Rationale: Based on the assumption that proactive coping strategies are beneficial for the re-uptake of daily life by stroke patients and partners, we developed a new stroke-specific, group-based self-management intervention based on proactive action planning. A first concept of the treatment protocol was developed based on the proactive coping theory, the Health Action Process Approach model, existing interventions and expert consultations. Further adjustments were based on two pilot studies, including addition of solution-based therapeutic techniques.

Description of the intervention: 'Plan ahead! is a 10-week group-based selfmanagement intervention, consisting of six two-hour sessions in the first six weeks and a two-hour booster session in the tenth week. It is offered in an outpatient setting by two rehabilitation professionals with experience in group counselling and working with stroke patients. It is provided to groups of four stroke patients living at home (stroke $\geq$ two months ago) and their partners. The main features are: 1) proactive action planning as the main constituent, 2) strokespecific elements, and 3) considering partners as full participants.

Discussion: This stroke-specific intervention is expected to increase the use of proactive action planning and thus improve the participation of stroke patients and their partners. It is innovative in its aim to change behaviour patterns of participants directly, teaching participants a general action planning strategy and considering partners as full participants with their own goals and opportunities. 


\section{Introduction}

Stroke puts heavy demands on patients' self-management abilities, their abilities to manage the medical, physical, emotional and social consequences of stroke and its considerable impact on their daily lives. ${ }^{25}$

Stroke is a chronic (long-term) condition. In other chronic diseases, interventions aimed at enhancing self-management capacities show positive effects on coping, goal achievement, self-efficacy, health-related quality of life and utilization of healthcare services ${ }^{89-91,102}$ Several of these interventions are based on the assumption that self-management tasks are similar in different chronic diseases, and that performance of these tasks can be enhanced with a generic programme. ${ }^{25,103}$

However, in case of stroke we believe it is better to adopt a disease-specific approach with tailored levels of self-management tasks. Although it is required to some extent to control or change life-style and cardiovascular risk factors, and to manage the medical condition, the greater part of the self-management tasks result from the need for adjustment to the sudden, lasting consequences. ${ }^{104}$ In addition to the possible physical consequences, stroke patients and their partners are confronted with a wide range of nonphysical consequences regarding cognitive, emotional, behavioural and social functioning. These consequences can result not only from the emotional processes related to being confronted with a chronic condition, but can also be the direct result of the brain damage itself. Because of the persistent nature of these consequences, adjusting to them is important. ${ }^{31}$ Influential determinants for successful adjustment post stroke are the coping strategies someone adopts. ${ }^{6,44}$ Therefore, self-management interventions aimed at specific coping strategies are expected to be beneficial after stroke.

At the moment, most effective stroke-specific self-management interventions aim to change cognitive processes underlying goals, such as increasing selfefficacy and adequate goal setting. ${ }^{27-30,92}$ In daily life, however, patients fail to pursuit their goals, as they are restrained by unanticipated consequences of stroke. ${ }^{31}$ Several interventions have been proposed to deal with such problems in stroke patients, such as motivational interviewing or problem solving therapy. ${ }^{105-108}$ However, these interventions have a reactive nature, as they focus on already existing/identified problems. Proactive coping post stroke involves 
anticipating potential difficulties and alternative solutions before undertaking an activity, in order to prevent or to prepare oneself for these consequences in advance..$^{35}$ Thus, teaching stroke patients proactive coping strategies is expected to enable them to accomplish more goals and activities successfully, resulting in improved participation. In patients newly diagnosed with type 2 diabetes and elderly people, such interventions have already been shown to be effective. . $33,34^{3}$ We therefore developed a group-based self-management intervention called 'Plan ahead!', which to our knowledge is the first stroke-specific self-management intervention teaching proactive coping strategies to stroke patients and partners in order to improve their participation.

This paper describes the theoretical basis and content of the treatment protocol for 'Plan ahead!' . The design of the study evaluating the effectiveness of this intervention is published elsewhere. ${ }^{38}$

\section{Theoretical background}

Our intervention aims to teach participants strategies to plan their intended goals proactively. In daily life, many stroke patients may fail to achieve their goals. ${ }^{31}$ According to the Health Action Process Approach model, goal achievement is the result of a two-phase process. ${ }^{109}$ First, intentions for achieving a particular goal are developed based on levels of risk perception, outcome expectancies and self-efficacy. Subsequently, actual actions are planned, initiated, maintained and adjusted both to reach the goal and to deal with potential barriers. In stroke patients, problems frequently occur during this second phase: patients fail to pursuit their goals, as they are restrained by consequences of stroke. ${ }^{31}$

Proactive coping strategies are expected to enable stroke patients to prevent or prepare themselves for these consequences before undertaking an activity. ${ }^{35}$ According to Aspinwall and Taylor (1997), proactive coping consists of five interrelated stages: 1) resource collection, 2) noticing potential stressors, 3) initial estimation of the stressor, 4) adoption of the first coping strategies, and 5) evaluation and use of feedback. ${ }^{35}$ We hypothesized that when stroke patients learn to set their goals proactively, they are less constrained by the consequences of stroke as they have already anticipated the potential occurrence of these barriers/ requirements and thought about solutions for them. Therefore, it is expected that 
the impact of stroke on stroke patients' daily lives is reduced when proactive coping strategies are applied.

After a stroke, partners are confronted with their own physical and emotional problems, in addition to their role as family member and caregiver. ${ }^{21}$ Interventions aimed at coping strategies are expected to be beneficial to them as well, which is why we regard partners of stroke patients as full participants in the intervention instead of being in the more usual role as caregiver to the patient. ${ }^{110}$

\section{The intervention 'Plan ahead!'}

\section{Development of the intervention}

In figure 5.1 a flowchart depicts the development process of the intervention. The basis for our intervention 'Plan ahead!' is the proactive coping theory, and an existing self-management intervention specifically developed for patients newly diagnosed with type 2 diabetes. ${ }^{33,111,112}$ From this latter programme we adopted the proactive action planning tool and adjusted it for stroke patients.

The initial version of our intervention was developed and reviewed by consultations with several experts (both clinicians and self-management experts), and previous experiences with two other interventions. ${ }^{113-115}$ The development process was finished by testing the intervention in two pilot studies. The intervention group of our latter pilot study also included one patient with an acquired brain injury condition other than stroke. The practical reason behind this was that the intervention had to fit into the fixed schedule of continuous intervention provision of the piloting institute to mixed groups of acquired brain injury patients. This required a quicker recruitment of participants than possible with stroke patients only. After each pilot study, we adjusted the treatment protocol based on our own observations and the feedback reported by participants and rehabilitation medicine professionals. 


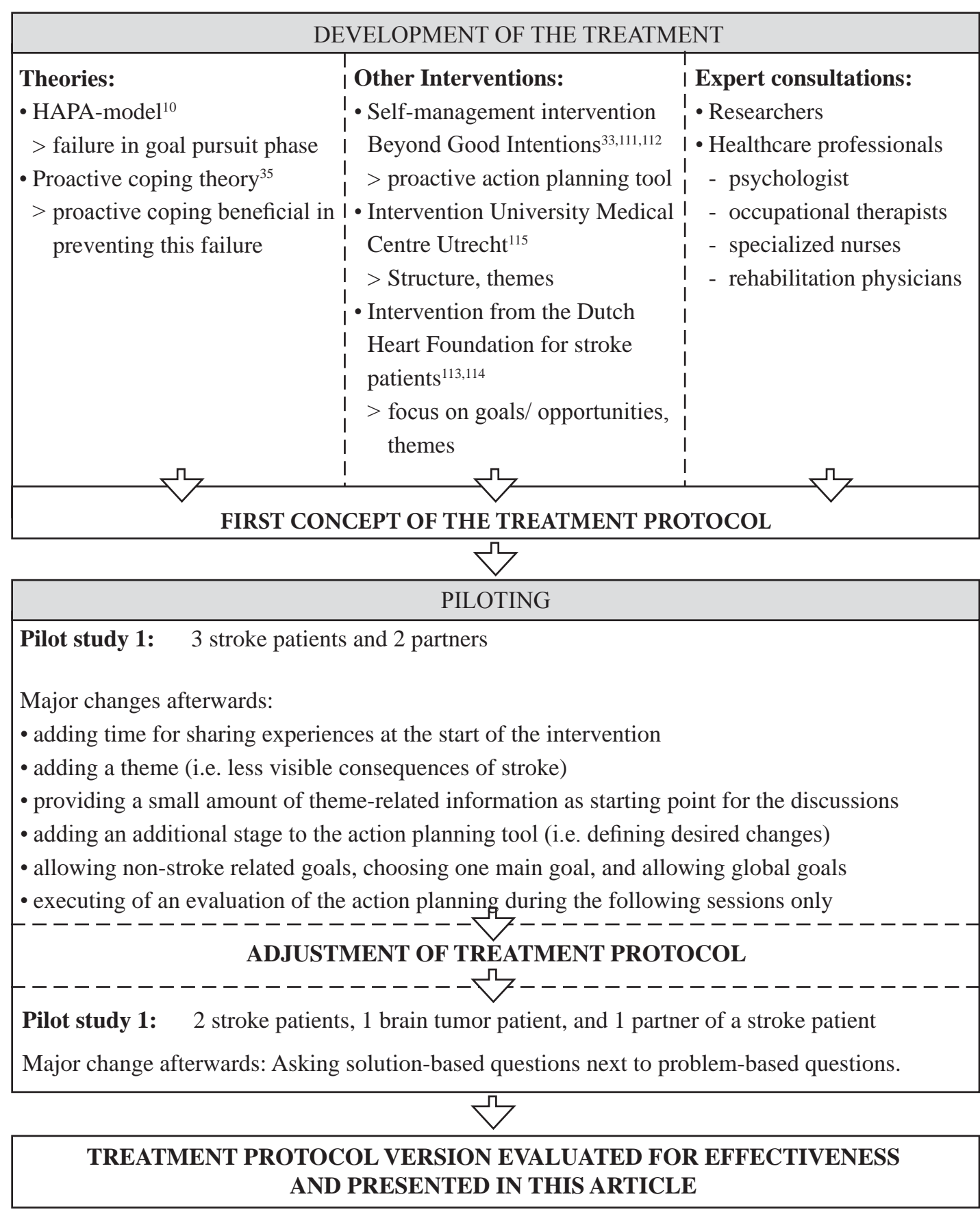

Figure 5.1 Flow-chart of the development process of the intervention 


\section{Participants}

The intervention was developed for stroke patients living at home who experience restrictions in their daily lives. A minimum period of two months is recommended between the stroke and the start of the intervention, as recovery has taken place for a large extent after two months. ${ }^{116}$ Since many of the consequences of stroke are long-term, no maximum period after the stroke is indicated. ${ }^{4,31,84,117,118}$ Partners of participating stroke patients are invited to take part in the intervention as well. Patients and partners should not be offered the intervention if they 1) have insufficient mental and/or communicative ability to understand and learn from the intervention, and/or 2) are unable or unwilling to function in a group because of behavioural problems. These criteria can be clinically judged, for example, by a rehabilitation physician.

\section{Therapists}

The intervention is offered by two rehabilitation professionals such as occupational therapists, psychologists, social workers or specialized nurses. At least one-year working experience with stroke patients is recommended, as we assume this enables the professionals to provide appropriate support, discuss relevant themes and make realistic estimations of achievable goals of participants. Moreover, some experience in group counselling is recommended, to ensure that the professional knows how to lead group processes and handle interactions between group members.

\section{Stroke-specific elements of the intervention}

Several stroke-specific elements are applied in our intervention. The most important one is the stroke-specific version of the proactive action plan tool, which is presented in table 5.1. Two examples of participants working with this tool are given in Box 5.1 and Box 5.2. It is important to note that action planning by means of this plan is a dynamic process. Participants can return to previous stages at any moment to refine or change the decisions made earlier on. 


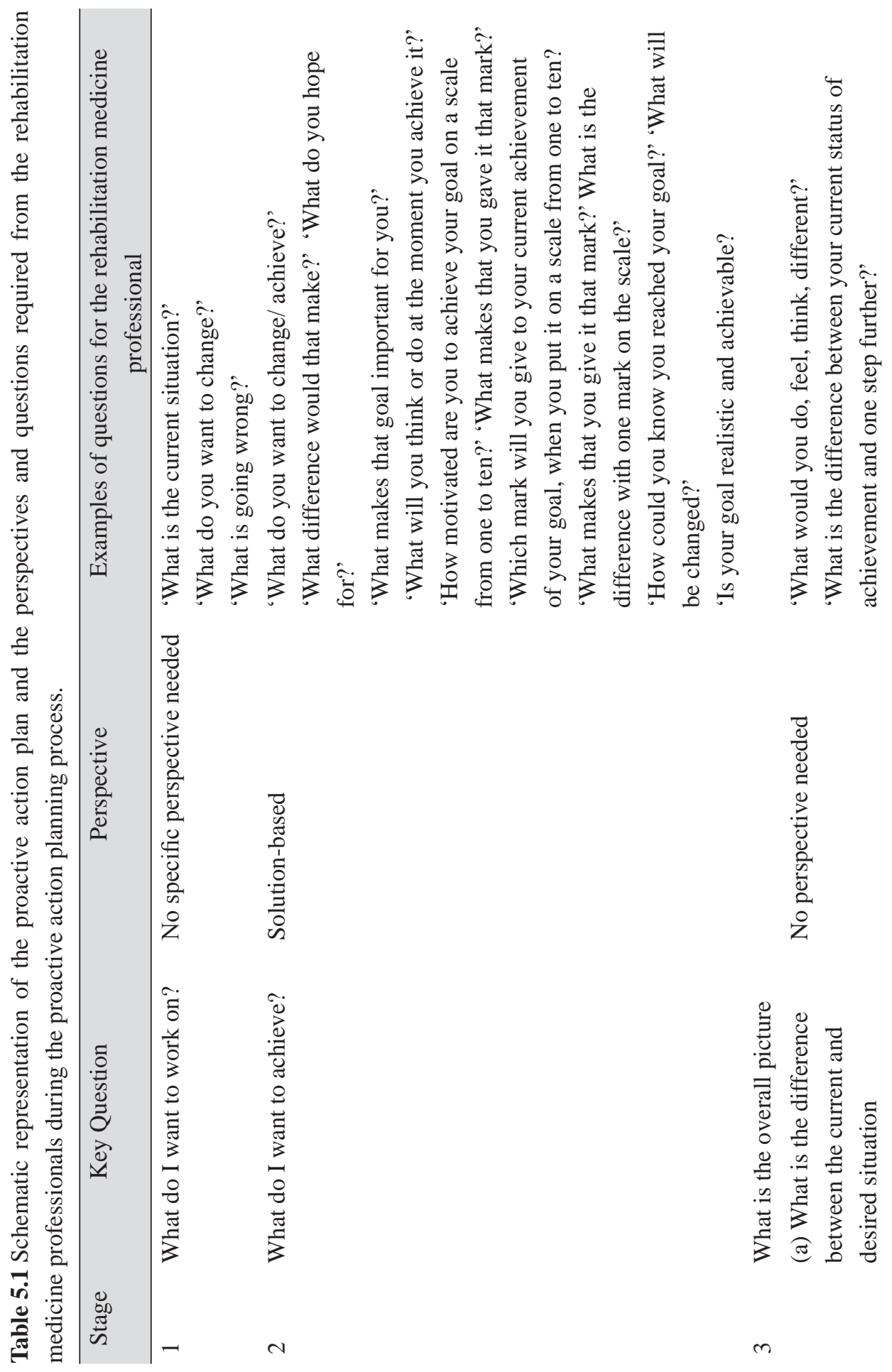




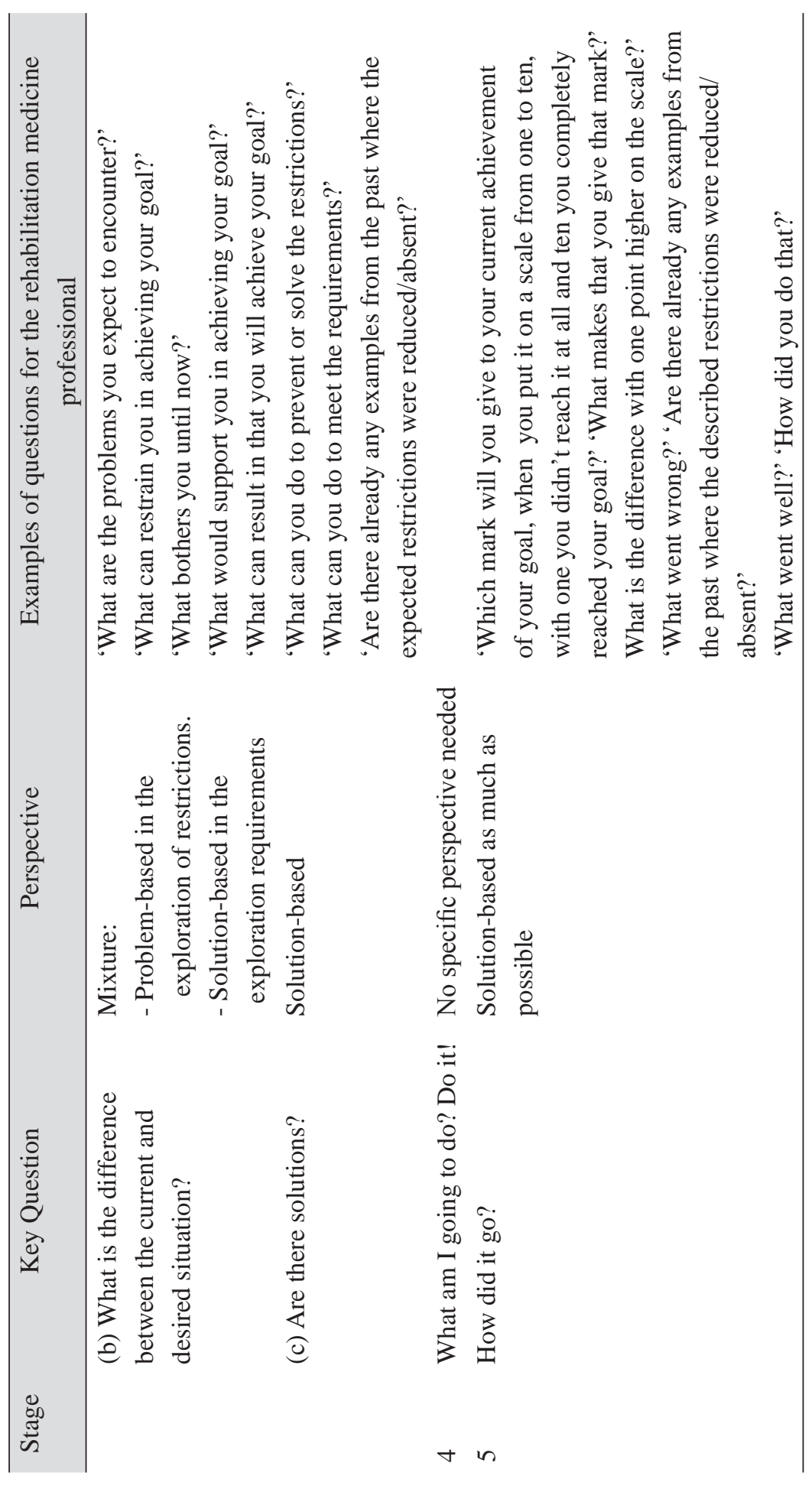




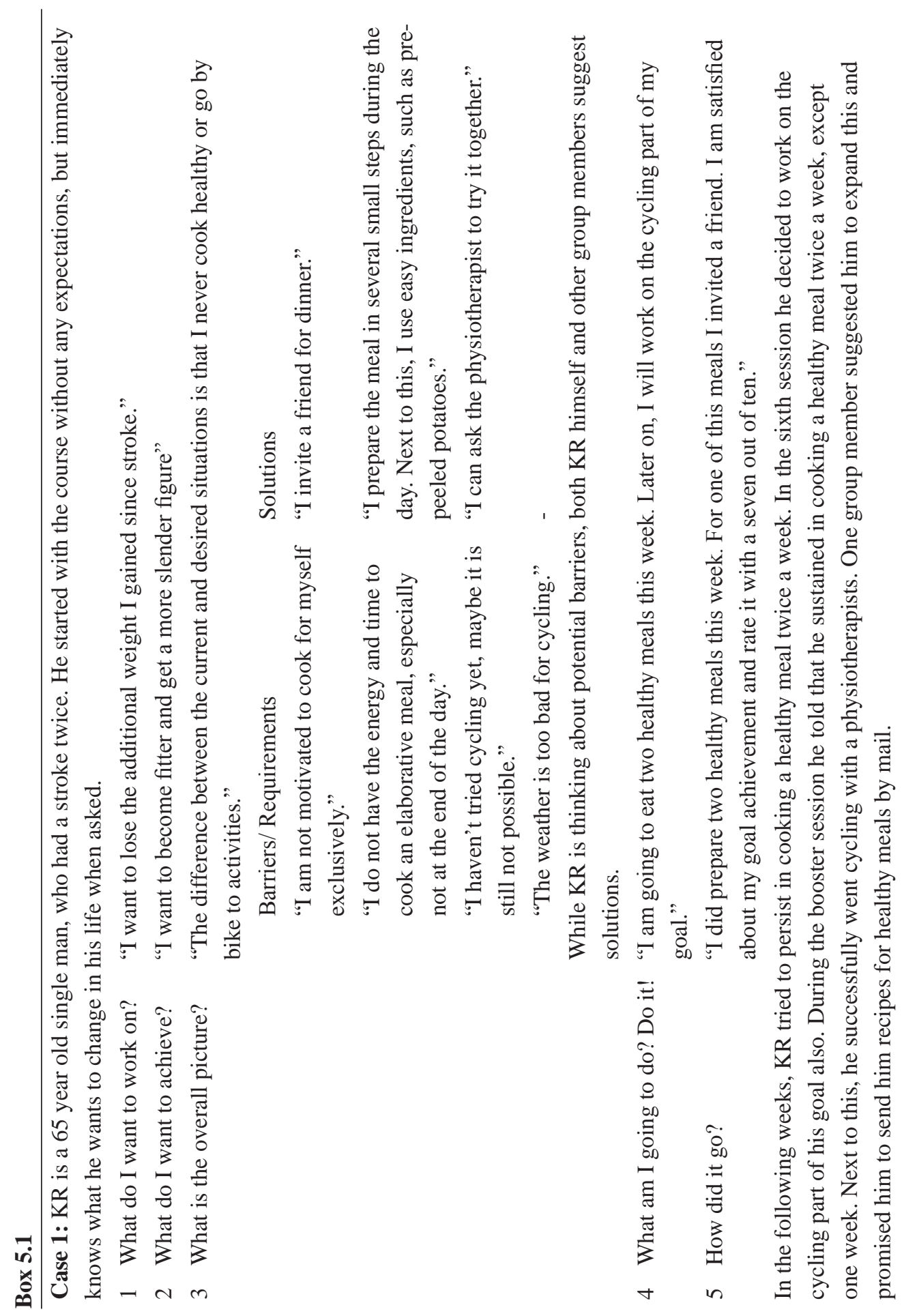




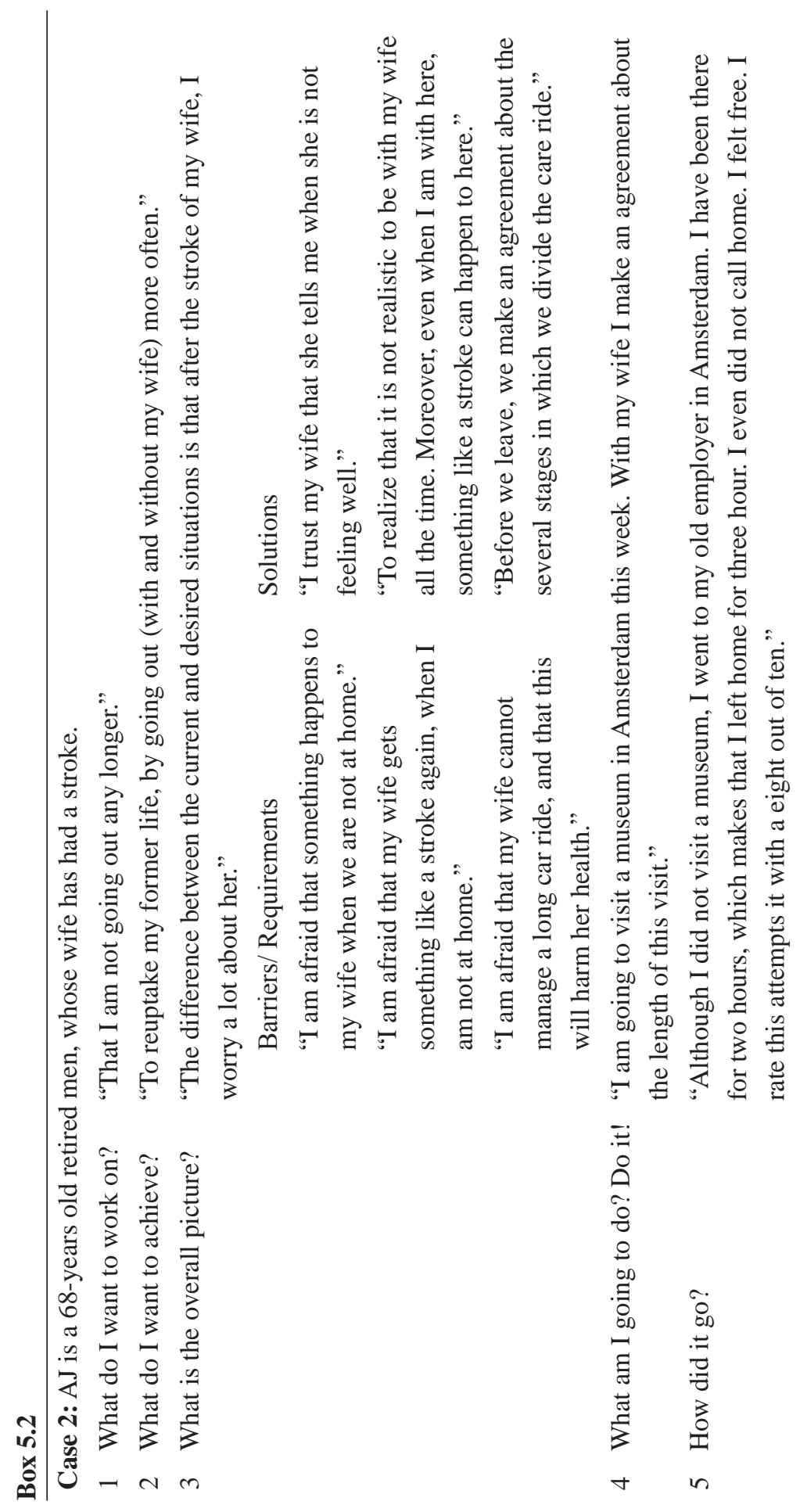


During the pilot studies, it appeared that participants were used to thinking about problems, barriers and situations in which they fail, but found it hard to think about goals, opportunities and solutions spontaneously. Rehabilitation medicine professionals were able to facilitate proactive action planning by not only asking questions from problem-based perspective, but also from a solution-based perspective. ${ }^{119}$ Problem-based questions are expected to stimulate discussions about problems and barriers. Examples of problem-based questions are 'What is restraining you?' and 'Can you describe a recent situation in which the problem occurred?'. Solution-based questions facilitate thinking about goals, opportunities and solutions. Examples of solution-based questions are 'What do you want to achieve?' and 'Can you describe a recent situation in which the problem did not occur, although you were expecting it?'. Table 5.1 schematically presents the perspective rehabilitation medicine professionals should adopt during each stage of proactive-action planning.

Another stroke-specific element is the time provided to discuss strokerelevant information. During our first pilot study, it appeared to be essential to provide participants some time to discuss their stroke-related experiences, before focusing on future changes related to proactive action-planning. A small amount of stroke-relevant information functioned as a good starting point for these discussions. Moreover, we expect this information provision facilitates awareness of the condition ${ }^{120}$ as well as proactive action planning. ${ }^{121,122}$ Next to this, we limit the group sizes and split up the group when participants work on their proactive action plan, to enable more individual assistance from a healthcare professional.

\section{Description of the intervention}

The 10-week, group-based intervention consists of six two-hour sessions in the first six weeks and a two-hour booster session in the tenth week. All sessions are group sessions. Groups consist of four stroke patients, with potentially their partners. It is provided as an outpatient healthcare service at hospitals and rehabilitation centres in the Netherlands. The main elements of our intervention are presented in table 5.2.

The first session starts with providing information about the intervention, after which participants are given some time to get to know each other. Subsequently, participants are asked about their expectations of the intervention. Participants 
are then asked to write down the most notable changes they have experienced since their stroke or the stroke of their partner and to categorize them as affecting physical functioning, cognition, social relations and/or activities. Finally, participants are invited to discuss the changes they have experienced.

Table 5.2 Characteristics of the intervention

\begin{tabular}{|c|c|c|c|}
\hline \multicolumn{2}{|l|}{ Participants } & \multicolumn{2}{|c|}{$\begin{array}{l}\text { Stroke patients (stroke } \geq 2 \text { months ago) with participation } \\
\text { problems, living at home, and their partners }\end{array}$} \\
\hline \multicolumn{2}{|l|}{ Therapists } & \multicolumn{2}{|c|}{$\begin{array}{l}\text { Rehabilitation medicine professionals with at least one- } \\
\text { year working experience with patients with brain injury. } \\
\text { Moreover, some experience in group counselling is } \\
\text { recommended. }\end{array}$} \\
\hline \multirow[t]{11}{*}{ Intervention } & Duration & \multicolumn{2}{|c|}{$\begin{array}{l}\text { Ten weeks, with } 6 \text { two-hour group sessions and a booster } \\
\text { session }\end{array}$} \\
\hline & Group size & \multicolumn{2}{|c|}{ 4-8 participants ( 4 stroke patients and partners) } \\
\hline & Setting & \multicolumn{2}{|c|}{$\begin{array}{l}\text { Outpatient healthcare service of hospitals and } \\
\text { rehabilitation centres }\end{array}$} \\
\hline & Content & Session & Topic \\
\hline & & & $\begin{array}{l}\text { Time to get to know each other } \\
\text { Information about the consequences of stroke, } \\
\text { with special attention for the less visible } \\
\text { consequences. }\end{array}$ \\
\hline & & & $\begin{array}{l}\text { Sharing common problems with fellow } \\
\text { sufferers }\end{array}$ \\
\hline & & \multirow[t]{2}{*}{3} & Formulating goals \\
\hline & & & $\begin{array}{l}\text { Getting acquainted with proactive action } \\
\text { planning }\end{array}$ \\
\hline & & $4-6$ & $\begin{array}{l}\text { Provision of theme-related information to } \\
\text { improve understanding of potential barriers/ } \\
\text { requirements and solutions } \\
\text { Integration of theme-related information with } \\
\text { proactive action planning }\end{array}$ \\
\hline & & Booster & $\begin{array}{l}\text { Recapitulating intervention content } \\
\text { Sharing intervention-related experiences }\end{array}$ \\
\hline & Materials & \multicolumn{2}{|c|}{ Manuals and presentations for professionals } \\
\hline
\end{tabular}


During the second session, information is provided about less visible consequences of stroke (i.e. cognitive impairments, causes and symptoms of cognitive problems, recovery, and advices to deal with these consequences). Participants are asked to supplement the information by their own experiences, to clarify the information further and facilitate recognition. At the end of this session, participants are asked to think about a (realistic) change they would desire.

During the third session, the proactive action plan tool is introduced, and illustrated by means of an example. Participants are asked to specify their desired change on the basis of the proactive action plan tool. Non-stroke related goals are allowed, in view of the importance of autonomous motivation. ${ }^{123}$ The participants are asked to carry out the first step towards reaching their goal in the following week. If participants do not manage to complete their proactive action plan during the session, they are asked to complete their proactive action plan on their own at home.

Sessions four, five and six start with an evaluation of the participants' progress towards their goals. After this evaluation, the sessions continue with standardized information provision and sharing common problems related to the themes of: 1) (negative) emotional consequences (session four), 2) social support and relations (session five), and 3) participation in society (session six). ${ }^{20,124}$ The sessions are continued by encouraging participants to identify theme-related barriers and conditions that might be relevant to their proactive action plan. The group is then split up into two subgroups in which participants can work out their individual proactive action plans with more individual assistance from a professional. As group dynamics vary between groups, therapists themselves had to decide how they split up the groups. Participants are allowed to work on the same goal through all sessions, as participants experienced changing their goal every week as frustrating during the pilot study. If ready, participants are asked to implement the formulated concrete actions for the following week in their daily lives.

A booster session takes place in the 10th week. This session starts with an evaluation of the progress made in achieving the goal and continues with a recapitulation of the proactive action plan. This is followed by a discussion of the expectations of the intervention at the first session, overall progress made by participants and course-related experiences, and future implementation of what they have learned. 


\section{Materials}

Participants receive a workbook containing all the information provided during the intervention. If necessary, participants can contact the therapist providing the intervention for advice during the week. For rehabilitation medicine professionals a manual and PowerPoint presentation are available. These materials are available on request from the authors.

\section{Discussion}

In comparison to other stroke-specific self-management interventions, the 'Plan ahead!' self-management intervention for stroke patients and partners aims to change behaviour patterns directly, instead of changing underlying cognitive processes. ${ }^{27-30,92}$ Next to this, it distinguishes itself in its theoretical basis of the proactive coping theory. ${ }^{47}$ Furthermore, our intervention differs from most other stroke-specific self-management interventions in the status of full participation given to partners. ${ }^{47}$ Our intervention sets itself apart from more general rehabilitation practice in teaching a general proactive action planning strategy, rather than achieving a particular goal. ${ }^{125}$ Moreover, instead of focusing on problems, the basis of our intervention is shaped by the participants' own goals and opportunities. ${ }^{105-108}$

A strength of the intervention is that during its development, elements were already taken into account that are required for the generalization of the proactive action planning strategies to daily life, such as homework assignments and patient-centred goal setting, inventory barriers and facilitators in different life domains and with examples of other participants, and adding a booster session to our intervention. ${ }^{126,127}$

A limitation is that we were not able to specify the criteria for appropriate timing of our intervention in further detail. Patients differ in their psychosocial adjustment trajectories, as result of differences in awareness of the condition and its consequences, as well as in their ability to accept the condition. Therefore, differences might result in patients' needs for interventions and their timing. ${ }^{104,128}$ Further research is needed to investigate when provision of an intervention such as ours is appropriate. 
The intervention was developed by integrating a theoretical framework with interventions that have proved effective ${ }^{33,35,109,111-115}$ as well as our own observations, experiences and feedback from rehabilitation medicine professionals, stroke patients and their partners. The next step will be to examine the clinical effectiveness and cost-effectiveness of this intervention. The Restore4Stroke self-management project is currently investigating the clinical effectiveness of this self-management intervention in a multicentre randomized controlled trial with a one-year follow-up period ${ }^{38}$, in which the intervention is compared with an education intervention which is also given as group therapy to patients and partners. The cost-effectiveness of the study is being investigated in the $€$-Restore4Stroke study. ${ }^{39}$

\section{Clinical messages}

- Stroke imposes great demands on patients' and partners' abilities to manage lasting consequences. Self-management interventions aimed at coping strategies are expected to be beneficial.

- A new self-management intervention is described aimed at teaching stroke patients and partners proactive action planning.

- Partners are invited as full participants. 




\section{CHAPTER 6 \\ Process evaluation of the Restore4Stroke self-management intervention 'Plan Ahead! used in a randomised study'}

Nienke S. Tielemans

Vera P.M. Schepers Johanna M.A. Visser-Meily Jolanda C.M. van Haastregt Wendy J.M. van Veen

Haike E. van Stralen Caroline M. van Heugten

Submitted 


\section{Abstract}

Objective: To determine whether a self-management intervention was implemented as intended, reached the target audience and has satisfied the participants and therapists with it.

Method: Mixed method design, combining qualitative and quantitative data, collected using session evaluation forms, questionnaires for therapists and participants (patients and partners), and focus groups.

Results: In this evaluation 53 patients, 26 partners and 19 therapists took part. At least three quarters of the intervention sessions were followed by 33 patients and 24 partners. On a scale from 1 to 10, patients, partners, and therapists rated the intervention with mean scores of 7.5 (SD1.6), 7.8 (SD.7),

and 7.4 (SD.7), peer support being the most frequently appreciated element for participants and therapists. The proactive action planning tool was inadequately applied in 20 of the 96 sessions.

Conclusion: Although the target audience was reached and both participants and therapists were satisfied with the intervention, the proactive action planning tool that distinguishes the current intervention from existing stroke-specific selfmanagement interventions was only partly implemented according to protocol. 


\section{Introduction}

After a stroke, patients' and their partners' lives change considerably. Stroke patients discharged home often report cognitive, emotional and/ or behavioural consequences. ${ }^{5}$ Stroke patients and partners must cope with the lasting consequences of stroke in daily life. Therefore, it is important that long-term care for stroke patients and partners focuses on enhancing their ability to effectively deal with these stroke consequences themselves. Thus, strokespecific interventions aimed at enhancing these self-management abilities seem to be a promising approach. ${ }^{104,129}$

Self-management refers to someone's abilities to manage the consequences of a condition, and its impact on daily life. ${ }^{25}$ Several stroke-specific self-management interventions have been developed, focusing on effective goal-setting. ${ }^{27-30}$ However, patients often fail to reach intended goals because of unexpected obstacles, such as fatigue, lack of time, or lack of support from others. ${ }^{31}$ Selfmanagement interventions aimed at teaching stroke patients proactive coping strategies might be more successful. That is, when patients learn to think about potential barriers and ways to overcome these barriers while setting goals, they might be better prepared to pursue their goals, and less easily overwhelmed when obstacles occur. ${ }^{35,130}$

In the context of the Restore4Stroke Self-Management study, we developed a stroke-specific self-management intervention called 'Plan Ahead!', aimed at teaching stroke patients and their partners proactive coping strategies. ${ }^{130}$ The effectiveness of this intervention has been evaluated in a randomized controlled trial. ${ }^{38}$ As many processes influence the outcomes of such trials, it is important to conduct a process evaluation to reveal factors influencing outcomes, providing a correct interpretation and explanation of the intervention effects. ${ }^{131-133}$ Moreover, such insights provide opportunities to facilitate intervention implementation. ${ }^{134}$

In this article, we present the outcomes of our process evaluation, which was performed alongside the Restore4Stroke Self-Management trial. In this evaluation we investigated the degree to which the intervention was implemented as intended, as well as involvement and satisfaction of the target audience (i.e. patients, partners and therapists). The study was based on the following elements of the process evaluation framework proposed by Saunders, Evans and 
Joshi (2005): 1) reach (i.e., the proportion of target audience that participates in the intervention), 2) dose delivered (i.e., the extent to which the intervention components were delivered to participants), 3) dose received in terms of exposure (i.e., extent to which participants actively engage in the intervention), 4) dose received in terms of satisfaction (i.e., participants' and therapists' satisfaction with the intervention), and 5) recruitment (i.e., procedures to approach participants and ensure participants' continued partaking in the intervention). ${ }^{135}$

\section{Method}

\section{Intervention}

The stroke-specific self-management intervention called 'Plan ahead!' aims to increase patients' and their partners' participation by teaching them proactive action planning. This 10-week group intervention involves six two-hour sessions during the first six weeks and a two-hour booster session in the tenth week. The intervention is offered as an outpatient healthcare service by hospitals and rehabilitation centres. Each group consists of four stroke patients and, if available, their partners. The intervention is delivered by two rehabilitation professionals with at least one year of experience with stroke patients. Participants receive a workbook describing the intervention content, while a manual and PowerPoint presentation are available for therapists.

During the first two sessions participants are given time to get to know each other, and share their stroke-related experiences. In addition, therapists provide some information about stroke and its consequences. In the third session, participants are asked to set goals and the proactive action planning tool is introduced. According to this tool, proactive action planning can be divided into five steps: 1) 'What do I want to work on?', 2) 'What do I want to achieve?', 3) 'What is the difference between the current and desired situation, in terms of barriers and requirements? Are there any solutions available for these barriers or requirements?', 4) 'What am I going to do? Do it!', and 5) 'How did it go?'. The first hour of sessions 4, 5 and 6 involves providing information around the themes of 'handling negative emotions', 'social relations and support', and 'participation in society'. During the second hour of these sessions, the group is split up into two subgroups, each led by one therapist. The therapists decide how the group 
is split up, with patients and partners not automatically being assigned to the same group. Participants are asked to work on their proactive action plans, and to think of theme-related barriers specific to their goals. Participants can work on the same goal during all sessions, or can set new goals during each session. At the end of sessions 4,5 and 6, participants are asked to implement the actions of their proactive action plan during the following week. These actions are evaluated at the beginning of the next session. The booster session is used to evaluate goals, recapitulate intervention content, and share experiences.

Therapists are asked to support participants as much as possible from a solution-based therapeutic perspective, as this is expected to stimulate participants to think in terms of goals, opportunities and solutions instead of problems and barriers. ${ }^{119}$ Therapists receive a one-day group training course before they deliver the intervention, in which they learn about 1) the intervention content, mainly focusing on proactive action planning, 2) solution-based therapeutic techniques, and 3) integrating these techniques with proactive action planning. The intervention is described in more detail in our treatment protocol. ${ }^{130}$

\section{Participants}

For the process evaluation study data was collected from patients, partners and therapists $(n=19)$ who were involved in the self-management intervention 'Plan Ahead!' of the Restore4Stroke Self-Management study. ${ }^{38}$ Inclusion for the Restore4Stroke Self-Management study took place between February 2012 and May 2013. Rehabilitation physicians and nurse practitioners selected eligible stroke patients through case finding in three hospitals and five rehabilitation centres across the Netherlands. ${ }^{38}$

Stroke patients were included if they had suffered a first or recurrent symptomatic stroke ( $\geq 6$ weeks ago), were living independently, and had at least two restrictions on the Restrictions subscale of the Utrecht Scale for Evaluation of Rehabilitation-Participation. ${ }^{70}$ Patients were excluded when the recruiting rehabilitation physician or nurse practitioner clinically assessed them as having 1) insufficient mental abilities to understand and benefit from the intervention, 2) insufficient knowledge of the Dutch language, 3) inability to function in a group due to behavioural problems, 4) major depression, or 5) already taking part at the time of recruitment in structured, psychological counselling aimed at proactive coping post stroke. ${ }^{38}$ 
Partners living together with a stroke patient participating in the selfmanagement intervention of the Restore4Stroke Self-management study were invited to take part in the study as well. Exclusion criteria for partners were inability to function in a group because of behavioural problems, and insufficient command of the Dutch language, based on clinical judgement. ${ }^{38}$

Therapists in the study were rehabilitation professionals, with at least one year of experience of working with patients with brain injury and experience with group counselling. ${ }^{38}$

\section{Data collection}

We gathered information about reach, dose delivered, dose received in terms of exposure, dose received in terms of satisfaction, and recruitment. ${ }^{135}$ Table 6.1 presents an overview of measures used to collect this information.

Data of participants were gathered using an evaluation form which they received after completing the intervention, as part of the post-intervention measurement of the Restore4Stroke Self-Management study. This form was used to assess participants' satisfaction with the intervention using structured questions (i.e., a scale question, Likert scales and a multiple selection question).

Therapist data were gathered using a recording form, an evaluation form, and a two-hour focus group interview. Therapists were asked to complete the recording form at the end of each session. These forms were used to assess the session course and content, using open and structured questions (i.e., yes-no or Likert scales). Next, therapists were asked to complete a digital evaluation form after the self-management intervention was provided in all hospitals and rehabilitation centres at least once. This evaluation form assessed therapists' satisfaction with the intervention and group training using structured questions (i.e., a scale question, Likert scales, yes-no questions, and a multiple choice question). All participating therapists were also invited to take part in a two-hour focus group held at a central location after they had completed the evaluation form. If two or more therapists of the same centre were willing to participate but all were hampered by practical reasons, the researcher visited them at their own centre for a local focus group with only the therapists of that centre. Such centrespecific focus groups were only used if the intervention had been delivered to at least 16 patients at the participating centre. Focus groups were led by a research 
assistant, and recorded on video and audiotape for transcription. Therapists were asked to discuss their satisfaction with the intervention, and their opinion about recruitment procedures, and about maintaining participant engagement.

Patients' background characteristics were recorded using a self-assessment questionnaire before the start of the intervention, assessing age, sex, education level, employment status, marital status and several stroke characteristics (i.e., months since stroke, stroke history, and independence in activities of daily living assessed with the Barthel Index 0-20 $0^{50}$ ). Partners' background characteristics were also recorded using a self-assessment questionnaire before the start of the intervention, assessing age, sex, education level, and employment status. Therapists' background characteristics were recorded using the digital evaluation form, assessing sex, age, work setting, profession, years of experience working with acquired brain injury patients, and number of times they had delivered the intervention.

\section{Data analysis}

Quantitative data from the evaluation and recording forms were analysed in terms of descriptive statistics using IBM SPSS Statistics 21. Answers to structured, categorical questions (i.e., multiple choice questions, yes-no questions, and Likert-scales) from the evaluation and recording forms were described in terms of percentages. Qualitative data from open questions on the evaluation and recording forms were categorized based on their content and reported if an answer had been given by at least half of the patients, partners or therapists.

The taped focus groups were transcribed verbatim by researcher NT, after which transcription accuracy was checked by researcher WV. Data was then analysed using open, axial and selective coding. Each of these steps was first performed independently by WV and NT, after which they compared their results. ${ }^{136}$ 


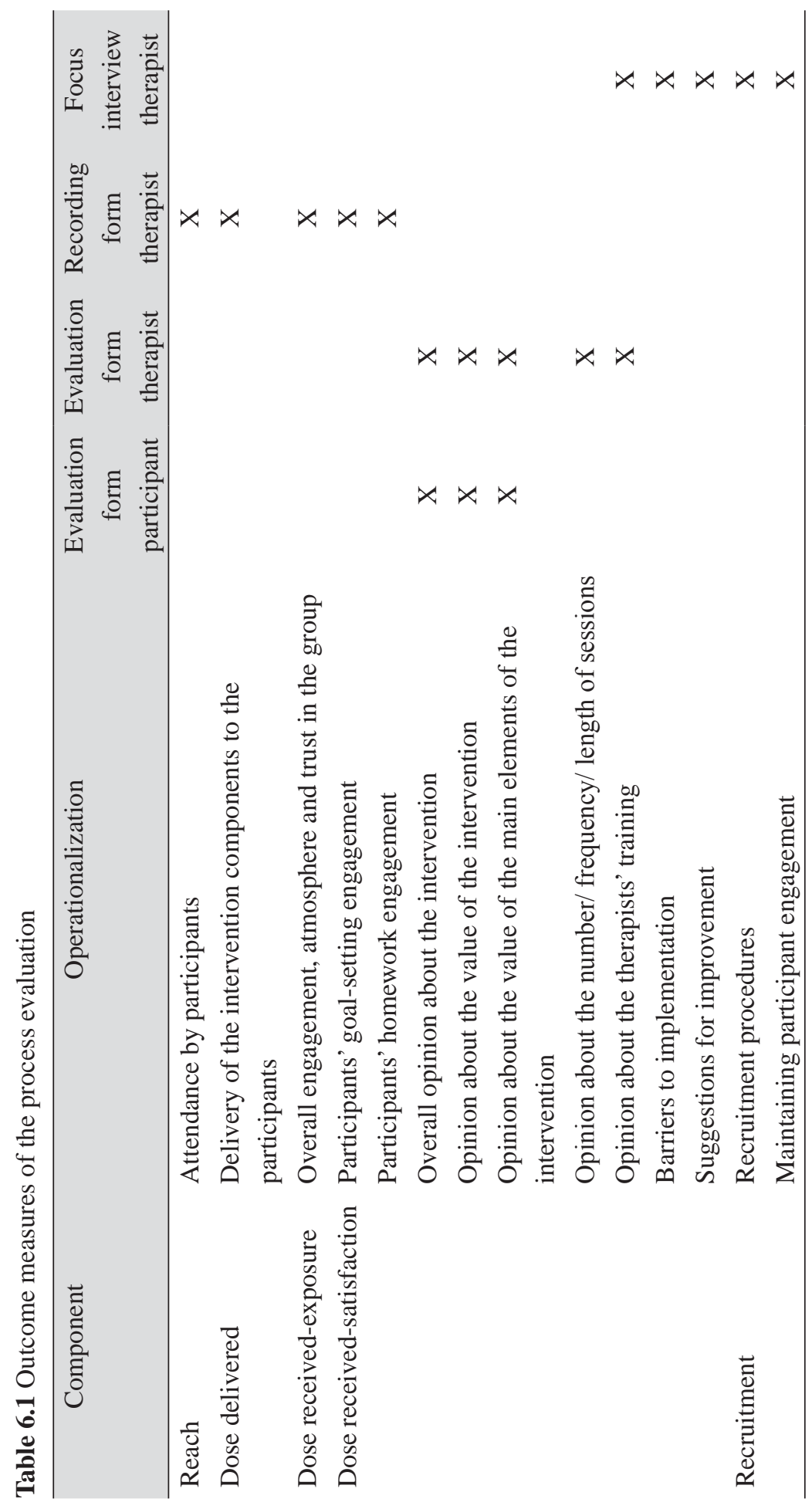




\section{Results}

\section{Response and background characteristics}

In total, 58 patients and 29 partners were assigned to the self-management intervention in three hospitals and five rehabilitation centres. Figure 6.1 presents the number of patients and partners assigned to the self-management intervention at each institute. All institutes participated in this process evaluation. Centrespecific focus groups were held at De Trappenberg Almere and Orbis Medical Centre.

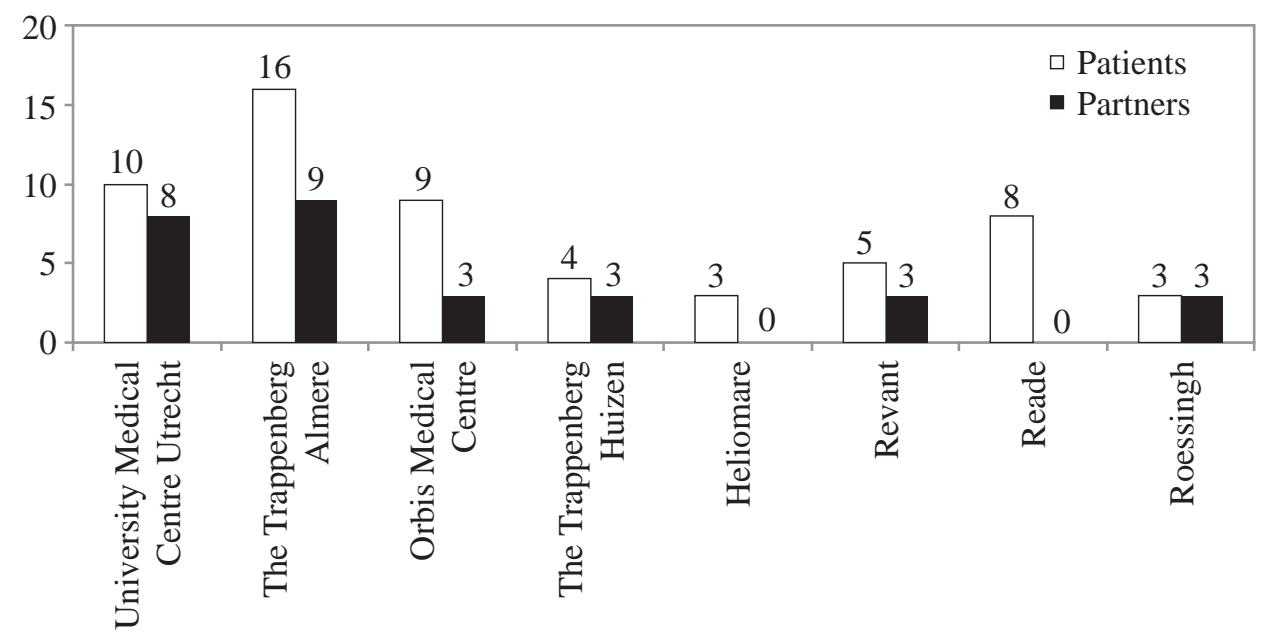

Figure 6.1 Numbers of patients and partners assigned to the self-management intervention in each institute

Recording forms were completed by therapists for 53 out of 58 patients (91\%) and 26 out of 29 partners (90\%) who attended at least one session of the self-management intervention. Characteristics of these patients and partners are presented in table 6.2. No recording form data was collected for 5 out of 58 patients (9\%), as they did not attend any of the sessions due to their physical condition $(n=1)$ or for unknown reasons $(n=1)$, or quit the study due to dissatisfaction with the intervention $(n=2)$ or communicative impairment $(n=1)$. No recording form data was collected for 3 out of 29 partners (10\%), as they did not attend any of 
the sessions due to other commitments $(\mathrm{n}=1)$, patients' inability to take part in the intervention $(\mathrm{n}=1)$, or unknown reasons $(\mathrm{n}=1)$. In total, 52 out of 53 patients (98\%) and 25 out of 26 partners (96\%) returned the evaluation form sent to them. One patient and partner did not return the evaluation form, for unknown reasons.

Table 6.2 Background characteristics of patients and partners

\begin{tabular}{|c|c|c|}
\hline & Patients $(n=53)$ & Partner $(n=26)$ \\
\hline \multicolumn{3}{|l|}{ Demographic characteristics } \\
\hline Sex: male & $24(45.3)$ & $23(50.0)$ \\
\hline Age (years) & $55.5 \pm 9.1(36-68)$ & $57.3 \pm 7.9(45-70)$ \\
\hline Education level: <higher general education & $35(68.6)^{*}$ & $4(17.4)^{*}$ \\
\hline Employment status: having a job & $12(22.6)$ & $14(53.8)$ \\
\hline Living with partner & $38(71.7)$ & $26(100.0)$ \\
\hline \multicolumn{3}{|l|}{ Stroke characteristics } \\
\hline Mean time after stroke in months & $14.5 \pm 19.1(1-113)^{\dagger}$ & \\
\hline Stroke history: $>1$ stroke & $7(13.2)^{\dagger}$ & \\
\hline Barthel Index (0-20) & $19.0 \pm 2.5(4-20)$ & \\
\hline $\begin{array}{l}\text { Values are } \mathrm{n}(\%) \text { or mean } \pm \\
* \mathrm{n}=51 ;{ }^{\dagger} \mathrm{n}=52 ;{ }^{\star} \mathrm{n}=23\end{array}$ & (range) & \\
\hline
\end{tabular}

Table 6.3 Background characteristics of therapists

\begin{tabular}{lcc}
\hline & $\begin{array}{c}\text { All therapists } \\
(\mathrm{N}=19)\end{array}$ & $\begin{array}{c}\text { Focus group } \\
\text { therapists } \\
(\mathrm{n}=9) \mathrm{w}\end{array}$ \\
\hline Sex: female & $19(100.0)$ & $9(100.0)$ \\
Age (years) & $42.8 \pm 10.0$ & $41.7 \pm 10.9$ \\
Institute: hospital & $8(42.1)$ & $6(66.7)$ \\
Healthcare profession & & \\
$\quad$ Occupational therapist & $7(36.8)$ & $2(22.2)$ \\
$\quad$ Psychologist assistant/trainer & $4(21.1)$ & $3(33.3)$ \\
$\quad$ Psychologist & $3(15.8)$ & $2(22.2)$ \\
$\quad$ Social worker & $3(15.8)$ & $2(22.2)$ \\
$\quad$ Nurse & $2(10.5)$ & $0(0.0)$ \\
Years of experience working with ABI patients & $9.9 \pm 6.3$ & $8.2 \pm 3.9$ \\
Offered intervention more than once & $8(42.1)$ & $5(55.6)$ \\
\hline
\end{tabular}


All 19 therapists delivering the self-management intervention completed the evaluation form for therapists and the recording forms for the 53 patients and 26 partners who completed the intervention. Out of 19 therapists approached for participation in the focus group, 9 consented (47\%) (i.e., 5 participated in the central focus group and 4 in a local centre-specific focus group). Reasons for therapists not to participate in one of the focus groups were holidays $(n=4)$, another therapist at their institute already participating in a focus group $(n=4)$, their own physical condition $(n=1)$ and other commitments $(n=1)$. Therapists' characteristics are presented in table 6.3.

\section{Reach}

In all, 16 intervention groups took part in the Restore4Stroke Self-Management study. Each institute served an average of 2.0 intervention groups (SD 1.1; range 1-4). Groups had a median size of 4 patients (range 2-5) and 2 partners (range $0-3)$.

As described above, two of the 58 patients (3\%) and three of the 29 partners (10\%) did not attend any of the sessions. Three of the 58 patients $(5 \%)$ quit the intervention.

Fifty-three patients attended at least one session of the intervention, with 33 of them (62\%) attending all 7 sessions and 46 of them (87\%) attending at least three quarters of the sessions (i.e., 5 or more sessions). More specifically, these 53 patients attended an average of 5.5 of the 6 regular sessions in the first six weeks (SD.7; range 3-6), and 50 of them (94\%) attended the booster session.

Twenty-six partners attended at least one session of the intervention, with 15 of them (58\%) attending all 7 sessions and 24 of them (92\%) attending at least three quarters of the sessions (i.e., 5 or more sessions). More specifically, these 26 partners attended an average of 5.2 of the 6 regular sessions in the first six weeks (SD 1.3; range 1-6), and 24 of them (92\%) attended the booster session.

\section{Dose delivered}

All participating hospitals and rehabilitation centres provided all sessions, resulting in a total of 112 sessions provided in all institutes (16 interventions times 7 sessions). In 6 of the 112 sessions (5\%), one therapists was absent. 
In 5 of the 7 sessions, participants were asked to work on their proactive action plan, that is, a total of 96 of the 112 sessions held in all institutes (16 interventions times 5 sessions). However, the proactive action planning tool was inadequately applied in 20 of the 96 sessions (20\%). More specifically, in 4 of the 96 sessions (4\%) groups were not split up while they were working out the proactive action planning tool, and in 16 of the 96 sessions (17\%), proactive action plans were not worked out in sufficient detail. In addition, therapists in all focus groups found it hard to integrate the content of the themes with the proactive action planning by participants.

\section{Dose received - Exposure}

The overall level of engagement in the intervention groups was assessed by the therapists as good in 13 of the 16 groups (81\%), and as sufficient in three groups (19\%) The overall atmosphere in the intervention groups was assessed by the therapists as pleasant in 13 of the 16 intervention groups (81\%) and as acceptable in three groups (19\%). The overall level of trust between participants was assessed by the therapists as very high in three of the 16 intervention groups (19\%), high in 11 (69\%), and sufficient in two (13\%).

Figure 6.2A graphically presents the percentage of participants engaging in active goal setting for each session, as reported by the therapists on the recording forms. Twenty-five of the 53 patients (47\%) worked on their goals during all five sessions requiring goal setting, and 16 of them (30\%) did so during at least three of these sessions. Thirteen of the 26 partners (50\%) worked on their goals during all five sessions requiring goal setting, and another four (15\%) did so during at least three of these sessions.

Figure 6.2B graphically presents the percentage of participants' doing homework assignments for each session, as reported by the therapists on the recording forms. A total of 12 patients (23\%) did all of their homework assignments, and another $25(47 \%)$ completed at least three quarters of the assignments. Seven of the 26 partners (27\%) did all of their homework assignments, and another $10(39 \%)$ completed at least three quarters of their homework assignments. At session four, the therapists reported a considerable decline in the percentage of patients and partners doing their homework assignments. 
A.
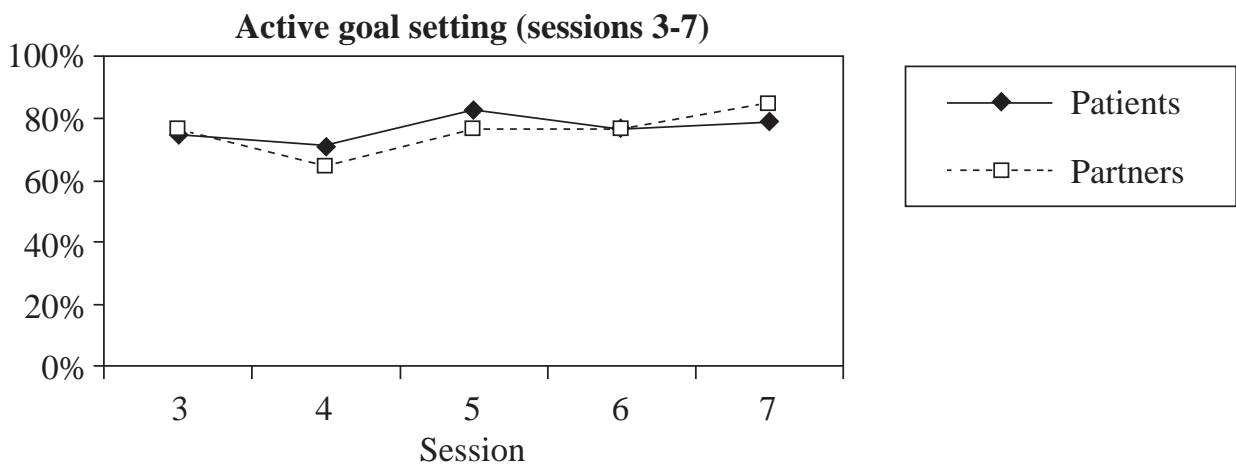

B.

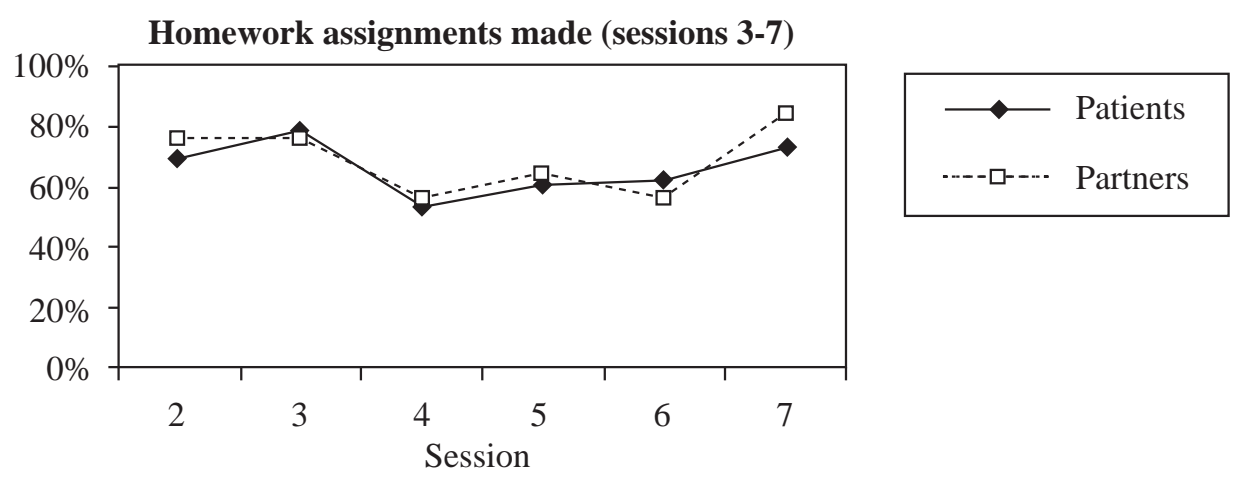

Figure 6.2 Overview of the level of engagement among the intervention groups in the various sessions. (A) Percentage of participants engaging in active goal setting, and (B) Percentage of participants' doing homework assignments

\section{Dose received - Satisfaction}

On a scale from 1 to 10 , patients, partners, and therapists rated the intervention with mean scores of 7.5 (SD 1.6; range 2-10), 7.8 (SD .7; range 7-9), and 7.4 (SD .7; range 5.5-8.5) respectively.

As regards the structure of the intervention, 13 of the 19 therapists assessed the number of sessions (68\%), 16 the frequency (84\%) and 11 the length of the sessions $(58 \%)$ as appropriate. 
With regard the intervention content, 47 of the 52 patients (90\%), and all 25 partners and 19 therapists considered the intervention to be somewhat to very useful (see table 6.4) Continued delivery of the intervention after the research project was preferred by 18 of the 19 therapists $(95 \%)$.

Table 6.4 Usefulness of the self-management intervention according to patients $(\mathrm{n}=52)$, partners $(\mathrm{n}=26)$ and therapists $(\mathrm{n}=19)$.

\begin{tabular}{lccc}
\hline & Patients $(\mathrm{n}=52)$ & Partners $(\mathrm{n}=26)$ & Therapists $(\mathrm{n}=19)$ \\
\hline Very useful & $15(28.8)$ & $8(32.0)$ & $3(15.8)$ \\
Useful & $24(46.2)$ & $10(40.0)$ & $12(63.2)$ \\
Somewhat useful & $8(15.4)$ & $7(28.0)$ & $4(21.1)$ \\
Not useful & $5(9.6)$ & $0(0)$ & $0(0)$ \\
\hline
\end{tabular}

Note: $\quad$ Values are $\mathrm{n}(\%)$

Figure 6.3 presents the elements of the intervention that were most often rated as valuable by patients, partners and therapists.

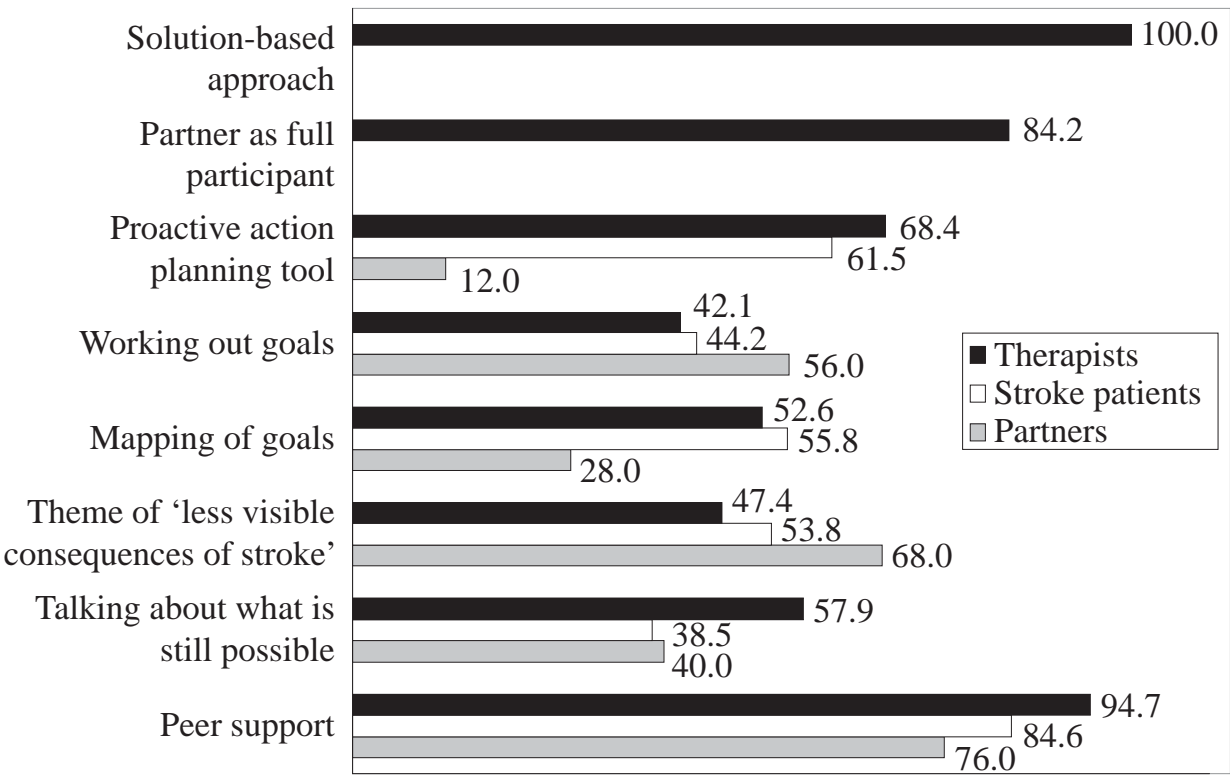

Figure 6.3 Proportion of participants indicating components as valuable 
Fifteen of the 19 therapists (79\%) attended the group training course. All of them reported that the course had helped them to deliver the intervention. The other four therapists were individually trained, as they were not able to attend the group training course.

Important barriers for the implementation of the intervention mentioned in all three focus groups resulted from existing interventions being used in a given centre, with overlapping content. An additional barrier mentioned in two of the focus groups was the challenge of fitting a group intervention into existing timetables of healthcare professionals and facilities.

Suggested improvements of the intervention content in two focus groups including abandoning the obligatory link between the themes and the proactive action plan, adding one session without a fixed theme, and having the booster session at a later moment.

A suggested improvement to the inclusion criteria of the intervention in two focus groups was to include patients with other forms of acquired brain injury. Broadening of the inclusion criteria for partners allowing non-cohabiting partners and other relatives to take part in the intervention as well, was recommended in all three focus groups.

A suggested improvement to the criteria for therapists in all three focus groups was that the two therapists should have a different professional background, share the preparation, and collaborate closely. In two focus groups it was recommended that at least one of the therapists should have a professional background in the psychosocial domain, and that therapists should receive a more elaborate training course, provided nearer to the provision of the first session.

\section{Recruitment}

In the Restore4Stroke Self-Management study, rehabilitation physicians and nurse practitioners selected eligible stroke patients through case finding. These patients were verbally informed about the study by the rehabilitation physician or nurse practitioner during their regular consultations at the outpatient facility of the participating institute. If patients were interested in participating in the study, they received an information letter and their partners were asked to take part in the study as well. After five days, the researcher called them to ask if they still wanted to participate in the study after having read the information letter. If 
patients consented, they were put on a list until eight patients in the same institute had consented to participate.

No barriers regarding the recruitment of patients were reported by the therapists during the focus groups. A barrier in the recruitment of partners reported in all focus groups was a lack of emphasis during the intake procedures on the possibility for partners to take part in the intervention. Other activities of partners such as work were reported in two focus groups as important barriers in the recruitment of partners.

Important barriers for keeping participants' engagement reported in all focus groups were the presence of considerable cognitive impairments, a lack of intrinsic motivation to take part in the intervention, and a lack of awareness of the active role required of them during the intervention. Other factors mentioned in two focus groups were participants' limited experience with the consequences of stroke in daily life, and the absence of a therapist during the intake procedure.

\section{Discussion}

This process evaluation study showed that intended participants were indeed reached and that participants and therapists were satisfied with the intervention. However, we also found that degree to which the intervention was performed conform the treatment protocol, and participants' engagement level in the intervention, were not optimal. In particular, activities related to the proactive action planning tool, such as working with the proactive action planning tool during the sessions and homework assignments, were carried out less completely than intended.

Peer support was reported to be of great value to patients, partners and therapists. This finding is in line with beneficial effects reported in earlier research in terms of increased awareness of the consequences of stroke and the opportunities for peer comparisons among stroke patients and their partners. ${ }^{137,138}$

Most patients and therapists considered the proactive action planning tool to be valuable. Nevertheless, therapists found it complex to teach the use of this tool and preferred more extensive training for themselves. Therefore, they might not have been skilled enough to teach the use of this tool. However, abandoning the obligatory link between the themes and the proactive action plan may also 
help. Learning to use proactive action planning strategies might be difficult for participants as well, as participants' homework assignments declined after introduction of the proactive action plan. Homework assignment completion may be enhanced by addressing barriers mentioned for maintaining participant engagement, such as a lack of intrinsic motivation to take part in the intervention, and a lack of knowledge about the active role required during the intervention.

Remarkably, the theme of 'less visible stroke consequences' was reported as valuable by a larger proportion of partners than therapists and patients. The interest in this theme can be explained by the distressing impact of less visible stroke consequences on partners. ${ }^{139}$

Although the intervention uses a family-centred approach and therapists valued this approach, therapists indicated that this was not sufficiently emphasized in the intake procedures with the participants. This may reflect their traditional tendency towards a patient-centred focus, rather than one focusing on problems of partners as well. ${ }^{140-142} \mathrm{Next}$, broadening of the inclusion criteria was recommended allowing non-cohabiting partners, other relatives, and other acquired brain injuries patients to take part in the intervention as well.

Important strengths of this process evaluation study were the very high response rates and the considerable number of institutes that participated, yielding a reliable reflection of clinical practice at least in the Netherlands, and the use of both qualitative and quantitative research methods. Furthermore, the outcomes of the process evaluation were not biased by the outcomes of the trial, as these were not known yet.

The most important limitation of our process evaluation was its lack of attention to the fidelity of the intervention implementation, i.e., degree to which each element of the intervention was correctly implemented. ${ }^{135}$ Next, the outcomes may have been biased by participants giving socially desirable answers. In order to reduce this bias, therapists and participants were asked to complete the questionnaires in the absence of the researcher, and interviewers were conducted by a research assistant who did not take part in the effectiveness study.

In summary, although it seems that the target audience was reached, and patients, partners and therapists were satisfied with the intervention, there is still room for improvement. In particular, as the proactive action planning tool forms the core of what distinguishes the current intervention from existing 
evidence-based self-management interventions for stroke patients, increasing the delivery rate of this intervention element deserves high priority. Based on our study outcomes, researchers and policy makers should be aware that adequate implementation of interventions such as ours is complex and needs time, as both healthcare professionals and participants had to get used to participants' active role in the management of their own situation.

\section{Clinical messages}

- To improve the intervention implementation participants should be selected on their intrinsic motivation to change their behaviour

- More extensive training and assistance is needed for therapists in adequate delivery of the intervention conform the treatment protocol.

- Therapists need to address caregivers' own problems and goals, and need for peer support 




\section{CHAPTER 7 Effectiveness of the Restore4Stroke self- management intervention 'Plan Ahead!': A randomized controlled trial in stroke patients and partners}

Nienke S. Tielemans Johanna M.A. Visser-Meily

Vera P.M. Schepers

Patricia E. Passier Ingrid G.L. van de Port Judith D.M. Vloothuis Pieter A.A. Struyf

Caroline M. van Heugten 


\section{Abstract}

Objective: To investigate the effectiveness of a self-management intervention aimed at proactive coping for stroke patients and partners, compared to an education intervention.

Design: Multicentre randomized controlled trial

Participants: The study included 113 stroke patients (mean age 57.0 years (SD 9.0), mean of 18.8 months after stroke (SD 28.4)) and 57 partners (mean age 59.2 (SD 8.3)).

Methods: Stroke patients and partners were randomized to a ten-week outpatient, stroke-specific, group-based self-management intervention, or a ten-week outpatient, stroke-specific, group-based education intervention. Main patient inclusion criteria were symptomatic stroke ( $\geq 6$ weeks ago), and reporting $\geq 2$ restrictions on the Restriction subscale of the Utrecht Scale for Evaluation of Rehabilitation Participation. Measurements were performed immediately after the intervention and at three and nine months of follow-up. Primary outcomes for patients and partners were proactive coping and participation restrictions. Analyses were based on linear mixed modelling. Results: No significant differences in proactive coping or participation restrictions were demonstrated between the two interventions, neither in patients nor in partners. Some beneficial trends were found favouring the self-management intervention.

Conclusion: No superiority was found for the self-management intervention over the education intervention. Due to ineffectiveness, the intervention should not be implemented in its current form. 


\section{Introduction}

The worldwide incidence of stroke is high, with 257.96 new cases per 10,000 people in $2010 .{ }^{60} \mathrm{~A}$ growing number of patients survive a stroke. ${ }^{143}$ Many of these patients are confronted with lasting impairments in physical, cognitive, emotional, and/ or social functioning. ${ }^{5}$ This puts heavy demands on patients living at home and their partner, as they are required to integrate the stroke consequences in their daily lives. It is therefore important to enhance the self-management abilities of stroke patients and partners, to enhance their ability to deal with these stroke consequences.

Self-management abilities refers to someone's abilities to manage the medical, lifestyle, physical, emotional, and psychosocial consequences of a chronic condition, and its impact on daily life. ${ }^{25}$ Although patients need some management of lifestyle and the medical condition, a major self-management task post stroke is to adjust life to invisible stroke consequences regarding cognitive, emotional, and behavioural functioning. ${ }^{26}$

In the past, education-based interventions have been developed to support stroke patients and their partners. However, these interventions did not result in actual behavioural changes, even though they can improve stroke patients' and partners' knowledge and satisfaction. ${ }^{144}$ Other approaches are therefore needed to teach patients and their partners strategies to support them in adapting to the stroke consequences in daily life. Self-management interventions are a likely candidate, as their effectiveness has been shown in other diseases..$^{25}$

Most effective stroke-specific self-management interventions aim at adjusting life goals and underlying psychological processes such as self-efficacy and self-control. 27,28,30,92,145 Nevertheless, patients often fail to achieve their adjusted goals, as unanticipated stroke consequences such as cognitive problems hamper them. ${ }^{31}$ In such situations stroke patients are easily overwhelmed, due to cognitive impairments such as mental slowness and reduced flexibility. ${ }^{84}$ It therefore seems better to teach stroke patients strategies that support them to anticipate on potential difficulties before undertaking an activity.

Proactive coping strategies post stroke are efforts made by patients and partners to anticipate potentially hampering consequences of the stroke during the goal-setting process and, if necessary, to undertake actions to prevent the 
occurrence or adjust the outcome of the hampering consequences beforehand. ${ }^{35}$ Studies among healthy elderly people and people with type 2 diabetes have shown potential benefits of teaching people proactive coping strategies when confronted with a chronic condition. ${ }^{33,34}$ As stroke patients and partners might benefit from such strategies as well, we developed the stroke-specific intervention entitled 'Plan Ahead!', a group-based self-management intervention aimed at teaching stroke patients and their partners action planning strategies for proactive coping. ${ }^{130}$

This study examined the effectiveness of our stroke-specific self-management intervention, based on teaching proactive coping action planning strategies to stroke patients and partners, compared to a stroke-specific, education-based intervention. Primary outcomes measures for both stroke patients and partners were proactive coping and participation restrictions. The study was part of the Dutch national consortium Restore4Stroke which aims to improve the quality of life of stroke patients and their partners.

\section{Method}

\section{Study design}

This multicentre randomized controlled trial had a two-group parallel design, using a balanced randomization stratified by institute (1:1 ratio). The study was approved by the Medical Ethics Committee of the University Medical Center Utrecht and the ethics committees of the participating institutes. All patients and partners provided written informed consent. The study was registered in the Dutch Trial Register as NTR3051. Study details are described elsewhere. ${ }^{38}$

\section{Participants}

The study was conducted at the outpatient facilities of three hospitals and five rehabilitation centres in the Netherlands, between February 2012 and May 2014.

Eligible stroke patients were adults ( $\geq 18$ years) who had suffered a first or recurrent symptomatic stroke (i.e. ischemic or intracerebral hemorrhagic lesion) as confirmed by a neurologist. The patients had to experience participation problems as confirmed by a rehabilitation physician or nurse by endorsing at least two items on the Restriction scale of the Utrecht Scale for Evaluation of Rehabilitation-Participation (USER-Participation) $)^{70}$. Exclusion criteria comprised 
being clinically judged as having insufficient mental abilities to understand and benefit from the intervention, disturbance in the production or comprehension of language (score below 5 on the Shortened version of the Aphasia Scale of the Dutch Aphasia Foundation, $\mathrm{SAN}^{49}$ ), behavioural problems hampering group functioning, major depression, or receiving structured psychological counselling aimed at proactive coping post stroke at the time of recruitment. Patients could take part in the study without a partner.

Partners were invited to partake in the study if they were adults $(\geq 18$ years), and cohabited with a stroke patient participating in the study. Partners were excluded if they were clinically judged as having behavioural problems hampering group functioning, or insufficient command of Dutch to understand the intervention and/ or complete questionnaires.

\section{Interventions}

The study compared the effectiveness of a self-management intervention with that of an education intervention in stroke patients and partners.

The 10-week self-management intervention consisted of six two-hour sessions in the first six weeks and one two-hour booster session in the tenth week. It was provided in groups of four to eight participants (i.e. four stroke patients and their partners, if applicable) by two rehabilitation professionals (e.g. psychologist or occupational therapist) at outpatient facilities of hospitals and rehabilitation centres. The intervention aimed to teach proactive action planning strategies embedded into four themes: 'handling negative emotions', 'social relations and support', 'participation in society', and 'less visible stroke consequences'. A more detailed description of the rationale and the intervention itself can be found elsewhere. ${ }^{130}$

The 10-week education intervention consisted of three one-hour sessions in the first six weeks and one one-hour booster session in the tenth week. It was provided in groups of four to eight participants (i.e. four stroke patients and their partners) by one rehabilitation professional (e.g. occupational therapist or psychologist) at outpatient facilities of the hospitals and rehabilitation centres. This intervention aimed to provide information about 'the brain and a stroke', 'general stroke consequences', and 'preventing a recurrent stroke'. ${ }^{38}$ 


\section{Procedure}

Eligible stroke patients were selected through case finding by rehabilitation physicians and nurse practitioners. Patients were invited to participate in the study during their regular consultation at the outpatient facility of participating centres. If patients were interested to partake in the study, they received an information letter, and their partners were also invited to participate in the study. After five days, the researcher called the patients and partners to find out if they wanted to participate. If eight patients in a centre consented, the researcher/ research assistant conducted baseline measurements at the patient's home or participating centre. After these measurements, patients were randomized to either the selfmanagement intervention or education intervention, with partners placed in the same group as patients. Subsequently, the allocated intervention was provided. Upon intervention completion, measurements were performed immediately (T1) and at three (T2) and nine months (T3) of follow-up. Participants could complete a digital or paper version of these questionnaires autonomously at home within two weeks, or make an appointment with a research assistant if necessary.

\section{Measurements}

\section{Baseline characteristics}

At baseline, patients' and partners' demographic characteristics were collected using open questions about age, sex, educational level, marital status, employment status, and ethnicity. Patients' stroke characteristics were collected using a questionnaire for rehabilitation physicians about the number of months since stroke, and type of stroke. During the baseline measurements, the researcher or research assistant assessed patients' activities of daily living (Barthel Index, $0-20)^{50}$, general cognitive functioning with the Montreal Cognitive Assessment ${ }^{76}$, and communicative abilities with the $\mathrm{SAN}^{49}$.

\section{Primary outcomes}

Proactive coping was used as a process-oriented primary outcome measure, assessed with the Utrecht Proactive Coping Competence (UPCC) scale in both patients and partners. This self-assessment scale consists of 21 items scored on a 4-point scale ranging from 'not competent at all' to 'competent'. A total score was 
computed by averaging all item scores (range 1-4). Higher scores indicate higher proactive coping levels. Good psychometric properties of this scale were shown for stroke patients and healthy elderly people (mean age 62.3 years (SD 5.4)). ${ }^{48,66}$

Participation, measured with the Restriction subscale of the USERParticipation instrument, was used as a primary outcome measure to assess intervention benefits for both patients and partners. This self-assessment scale consists of 11 items scored on a 4-point scale ranging from 'not possible at all' to 'independent without difficulty'. A total score was calculated by adding all items and transforming the resulting sum to a 0-100 scale. Participants could also choose 'not applicable' for specific activities that did not apply to them, or experienced restrictions unrelated to stroke. Higher scores indicated lower participation restriction levels, i.e. better participation. The psychometric properties of this scale have proved to be satisfactory for rehabilitation outpatients, including stroke patients. ${ }^{70}$

\section{Secondary outcomes}

Both patients' and partners' general self-efficacy was assessed with the Dutch version of the General Self-Efficacy scale (GSES). This self-assessment scale comprises ten items scored on a 4-point scale ranging from 'completely incorrect' to 'completely correct'. A total score was computed by adding all item scores (range 10-40). Higher scores indicated greater self-efficacy. ${ }^{71}$

Patients' disease-specific health-related quality of life was assessed with the short version of the Stroke-Specific Quality of Life Scale (SS-QoL-12). This selfassessment scale comprises six items covering the physical domain and six items covering the psychosocial domain. Total scores were computed by averaging item scores (range 1-5). Higher scores indicated higher quality of life. ${ }^{52}$

Patients' and partners' frequency of and satisfaction with participation were assessed with the two remaining USER-Participation self-assessment subscales, with 11 and 10 items, respectively. Total scores were calculated for each subscale by adding all items belonging to the subscale and transforming the resulting sum to a $0-100$ scale. Higher scores represented greater frequency of and satisfaction with participation. ${ }^{70}$ 
Patients' and partners' emotional functioning were assessed with the Hospital Anxiety and Depression Scale (HADS). This self-assessment scale consists of seven items assessing anxiety symptoms and seven items assessing depression symptoms. Scores for both subscales and the overall total score were computed by adding all item scores (range of subscales 0-31; range of total score 0-42). Higher scores represented greater anxiety or more depressive symptoms. ${ }^{74}$

Patients' subjective well-being was assessed with two self-assessment questions measuring patient's perception of their current life satisfaction (6-point scale ranging from 'very unsatisfactory' to 'very satisfactory'), and the difference with pre-stroke life satisfaction (7-point scale ranging from 'much worse' to 'much better'). Adding these two questions resulted in the total score (range 2-13), referred to in this article as 2LS. Higher scores indicated greater life satisfaction. ${ }^{75}$ Contrasting the intentionin our original study protocol, and in consultation with the scale developer, we decided not to use the question asking patients to assess satisfaction level before stroke. ${ }^{38}$

Partners' burden was assessed with the Caregiver Strain Index (CSI).146 Adding all 13 item scores resulted in a total score (range 0-13). Higher scores indicated greater burden. We decided not to use the expanded Caregiver Strain Index as proposed in our study protocol, because recent research has found a lower validity of the subscale measuring positive caregiving aspects in stroke patients' partners. ${ }^{147}$

\section{Sample size}

Sample size calculations based on UPCC indicated that a minimum of 45 stroke patients per treatment group were needed to demonstrate standardized differences of .6 on the UPCC, with $\mathrm{p}=.05$ and a power of $80 \% .^{48,99}$ This number of patients was also enough to demonstrate a standardized difference of .5 on the Restriction subscale of USER-Participation, with a $\mathrm{p}=.05$ and a power of $80 \% . .^{72}$ As a dropout rate of $15 \%$ was expected, at least 106 patients had to be recruited.

\section{Randomization}

When eight stroke patients were recruited at the same centre, patients selected one out of eight blank envelopes containing an invitation for either the selfmanagement intervention or the education intervention (1:1 ratio). Partners were assigned to the same intervention as the patient. 


\section{Blinding}

Participants were told that two education-based interventions were being compared. Randomization took place directly after the first measurement. The post-treatment measurements were performed with or without help from a research assistant blinded to the assigned condition.

\section{Statistical Analysis}

Differences between self-management and education intervention groups at baseline were checked with independent t-tests, Mann Whitney U-tests and Chi-square tests. For patients, baseline differences were checked in terms of demographic characteristics, general functioning and stroke characteristics, and outcome measures. For partners, baseline differences were checked in terms of demographic characteristics and outcome measures. In case of a significant between-group difference $(\mathrm{p}<.05)$, the corresponding variable was included as a covariate in the effectiveness analyses. The same tests were used to check if participants who dropped out from the study differed from participants who did not $(\mathrm{p}<.05)$.

Unlike our original study protocol, we used linear mixed modelling to determine the differences in effectiveness of the two interventions. ${ }^{38}$ Linear mixed modelling is more sophisticated than repeated measures of variance, and includes participants with incomplete data sets. ${ }^{148}$ For patients 12 models were calculated, each with one of the two primary outcome measures or one of the 10 secondary

outcome measures as dependent variable. For partners nine models were calculated, each with one of the two primary outcome measures or one of the seven secondary outcome measures as dependent variable.

Effectiveness of the intervention was determined according to the intentionto-treat principle. Effectiveness was also examined using 'on-treatment analysis', including only patients and partners who took part in at least 5 sessions of the self-management intervention or at least 3 sessions of the education intervention (i.e. $>75 \%$ attendance). Time, group, covariate(s) and the time $\mathrm{x}$ group interaction term were added as fixed terms to the models. Time and group were considered as categorical variables, and age as a continuous variable. The primary and secondary outcome measures were included as dependent variables. Parameters were estimated with the REML maximum likelihood estimation method. 
The need for random slopes and appropriate covariance structures was estimated based on Akaike's Information Criterion (AIC). Lower AIC values indicated a better model given the data.

Data were analysed with IBM SPSS Statistics 21. Statistical tests were performed two-sided. A $p<.0042$ for patients was considered to be statistically significant, based on a Bonferroni correction to control for multiple outcomes. For partners, an uncorrected $\mathrm{p}<.05$ was considered statistically significant, as sample size calculations were performed for patients only.

\section{Results}

\section{Participant Characteristics}

Figure 7.1 depicts the flowchart of 113 stroke patients and 57 partners included in this study. Out of 58 patients assigned to the self-management intervention, 56 started the intervention and 46 attended at least three quarters of the intervention sessions (i.e. $\geq 5$ sessions). Out of 55 patients assigned to the education intervention, 53 started the intervention and 38 attended at least three quarters of the intervention sessions (i.e. $\geq 3$ sessions).

Out of 29 partners assigned to the self-management intervention, 25 actually started the intervention and 24 attended at least three quarters of the intervention sessions. Out of 28 partners assigned to the education intervention, 26 actually started the intervention and 23 attended at least three quarters of the intervention sessions (i.e. $\geq 3$ sessions). 


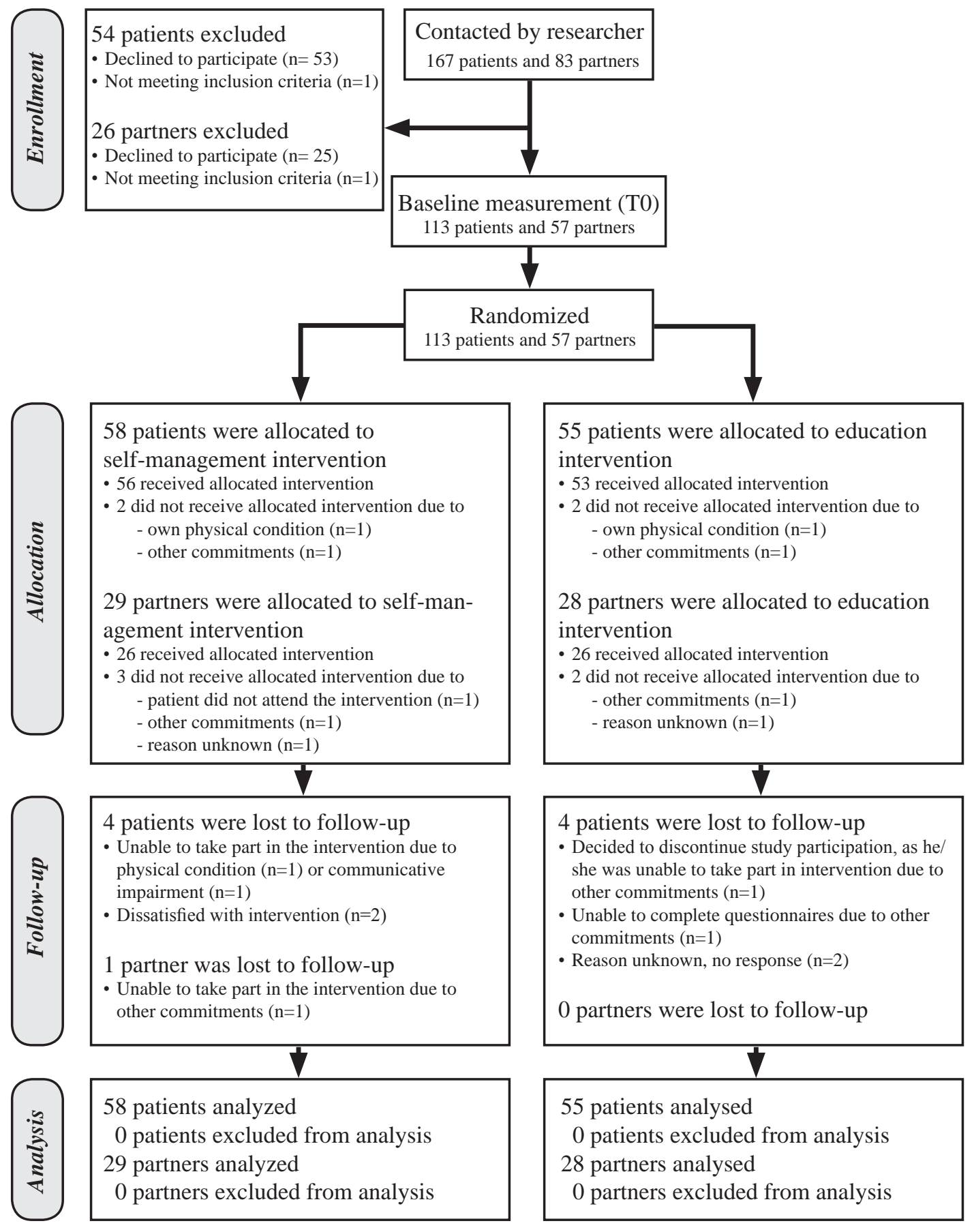

Figure 7.1 Flow-chart of patients and partners through the study 
Table 7.1 presents participating patients' and partners' characteristics. At baseline, patients in the self-management intervention condition were significantly younger than patients in the education intervention condition $(\mathrm{F}=.58 ; \mathrm{p}=.034)$. On all other demographic and stroke characteristics, general functioning and outcome measures, patients in the two conditions were comparable. At baseline, no significant differences were found between partners in the self-management intervention condition and the education intervention condition in terms of demographic characteristics or outcome measures.

Patients who were lost to follow-up $(n=8)$ during the study had lower levels of self-efficacy $(F=16.6 ; p<.001)$, health-related quality of life $(F=4.7 ; p=.033)$, psychological quality of life $(\mathrm{F}=5.9 ; \mathrm{p}=.016)$, and cognitive functioning $(\mathrm{F}=5.0$; $\mathrm{p}=.028$ ) than those who did not. As only one partner was lost to follow-up, it was not necessary to calculate if this person differed from the partners who completed the study.

Table 7.1 Patients' and partners' characteristics $(\mathrm{n}=113)$

\begin{tabular}{|c|c|c|c|c|c|c|c|c|}
\hline & \multicolumn{4}{|c|}{ Patient } & \multicolumn{4}{|c|}{ Partner } \\
\hline & \multicolumn{2}{|c|}{$\begin{array}{c}\text { Self-management } \\
\text { intervention } \\
(\mathrm{n}=58)\end{array}$} & \multicolumn{2}{|c|}{$\begin{array}{c}\text { Education } \\
\text { intervention } \\
\quad(\mathrm{n}=55)\end{array}$} & \multicolumn{2}{|c|}{$\begin{array}{c}\text { Self-management } \\
\text { intervention } \\
(n=29)\end{array}$} & \multicolumn{2}{|c|}{$\begin{array}{c}\text { Education } \\
\text { intervention } \\
(\mathrm{n}=28)\end{array}$} \\
\hline & $\mathrm{n}$ & & $\mathrm{n}$ & & $\mathrm{n}$ & & $\mathrm{n}$ & \\
\hline \multicolumn{9}{|l|}{ Demographic characteristics } \\
\hline Age (years) & 58 & $55.2 \pm 8.9 *$ & 55 & $58.8 \pm 8.7 *$ & 29 & $57.2 \pm 7.8$ & 28 & $61.1 \pm 8.5$ \\
\hline Sex: male & 58 & 44.8 & 55 & 60.0 & 29 & 50.0 & 28 & 37.9 \\
\hline Educational level: low & 56 & 69.6 & 54 & 63.0 & 25 & 24.0 & 28 & 31.0 \\
\hline Living with partner & 57 & 73.7 & 55 & 76.9 & 29 & 100 & 28 & 100 \\
\hline $\begin{array}{l}\text { Employment status: } \\
\text { employed after stroke }\end{array}$ & 58 & 22.4 & 55 & 23.6 & 29 & 57.1 & 28 & 51.7 \\
\hline Ethnicity: Dutch nationality & 58 & 98.3 & 54 & 100.0 & 29 & 100 & 28 & 100 \\
\hline $\begin{array}{l}\text { Participating with partner in } \\
\text { intervention }\end{array}$ & 58 & 48.3 & 55 & 54.5 & 29 & 100 & 28 & 100 \\
\hline \multicolumn{9}{|l|}{ Functioning } \\
\hline Barthel Index (0-20) & 58 & $18.9 \pm 2.7$ & 54 & $18.4 \pm 2.8$ & - & - & - & - \\
\hline $\begin{array}{l}\text { Cognitively impaired: MoCA } \\
<26\end{array}$ & 58 & 55.2 & 54 & 63.0 & - & - & - & - \\
\hline $\begin{array}{l}\text { Communicatively impaired: } \\
\text { SAN }<7\end{array}$ & 58 & 43.1 & 55 & 50.9 & - & - & - & - \\
\hline
\end{tabular}




\begin{tabular}{|c|c|c|c|c|c|c|c|c|}
\hline & \multicolumn{4}{|c|}{ Patient } & \multicolumn{4}{|c|}{ Partner } \\
\hline & \multicolumn{2}{|c|}{$\begin{array}{c}\text { Self-management } \\
\text { intervention } \\
(\mathrm{n}=58)\end{array}$} & \multicolumn{2}{|c|}{$\begin{array}{c}\text { Education } \\
\text { intervention } \\
(\mathrm{n}=55)\end{array}$} & \multicolumn{2}{|c|}{$\begin{array}{c}\text { Self-management } \\
\text { intervention } \\
(n=29)\end{array}$} & \multicolumn{2}{|c|}{$\begin{array}{c}\text { Education } \\
\text { intervention } \\
(\mathrm{n}=28)\end{array}$} \\
\hline \multicolumn{9}{|l|}{ Stroke characteristics } \\
\hline Time after stroke in months & 54 & $15.6 \pm 20.9$ & 55 & $21.9 \pm 34.1$ & - & - & - & - \\
\hline Type of stroke: infarction & 55 & 78.2 & 55 & 87.3 & - & - & - & - \\
\hline Affected hemisphere: right & 54 & 44.4 & 55 & 45.5 & - & - & - & - \\
\hline Stroke history: recurrent & 54 & 13.0 & 55 & 21.8 & - & - & - & - \\
\hline \multicolumn{9}{|l|}{ Outcome measures } \\
\hline UPCC (1-4) & 58 & $2.9 \pm .6$ & 55 & $2.9 \pm .5$ & 28 & $3.1 \pm .4$ & 29 & $3.1 \pm .4$ \\
\hline $\begin{array}{l}\text { USER-Participation } \\
\text { restriction }(0-100)\end{array}$ & 58 & $70.9 \pm 15.5$ & 54 & $73.4 \pm 16.6$ & 26 & $86.6 \pm 16.0$ & 28 & $86.6 \pm 14.0$ \\
\hline GSES (1-40) & 58 & $28.4 \pm 6.5$ & 54 & $27.9 \pm 6.4$ & 28 & $32.2 \pm 4.3$ & 29 & $32.1 \pm 4.0$ \\
\hline $\begin{array}{l}\text { USER-Participation } \\
\text { Frequency (0-100) }\end{array}$ & 58 & $31.2 \pm 10.3$ & 54 & $30.4 \pm 10.2$ & 28 & $36.1 \pm 9.9$ & 29 & $34.0 \pm 8.7$ \\
\hline $\begin{array}{l}\text { USER-Participation } \\
\text { Satisfaction (0-100) }\end{array}$ & 58 & $59.1 \pm 16.1$ & 54 & $62.6 \pm 18.1$ & 28 & $69.3 \pm 14.5$ & 29 & $68.6 \pm 17.1$ \\
\hline HADS depression (0-21) & 58 & $6.3 \pm 3.8$ & 54 & $6.6 \pm 3.6$ & 28 & $4.2 \pm 4.0$ & 29 & $5.2 \pm 4.2$ \\
\hline HADS anxiety (0-21) & 58 & $6.7 \pm 4.2$ & 54 & $6.7 \pm 4.0$ & 28 & $6.7 \pm 4.1$ & 29 & $6.8 \pm 4.6$ \\
\hline HADS total $(0-42)$ & 58 & $12.9 \pm 7.1$ & 54 & $13.3 \pm 6.7$ & 28 & $10.9 \pm 7.5$ & 29 & $12.0 \pm 8.3$ \\
\hline 2LS (2-13) & 58 & $6.4 \pm 2.7$ & 54 & $7.0 \pm 2.4$ & - & - & - & - \\
\hline SS-QOL-12 physical (1-5) & 58 & $3.9 \pm .6$ & 54 & $3.8 \pm .7$ & - & - & - & - \\
\hline $\begin{array}{l}\text { SS-QOL-12 psychological } \\
(1-5)\end{array}$ & 58 & $3.2 \pm 1.1$ & 54 & $3.4 \pm 1.0$ & - & - & - & - \\
\hline SS-QOL-total (1-5) & 58 & $3.6 \pm .8$ & 54 & $3.6 \pm .8$ & - & - & - & - \\
\hline CSI (0-13) & - & - & - & - & 28 & $4.9 \pm 3.5$ & 29 & $6.2 \pm 3.1$ \\
\hline
\end{tabular}

$\begin{array}{ll}\text { Note: } & \text { Values are } \mathrm{n}(\%) \text { or mean } \pm \mathrm{SD} \text { (range); } \\ & * \text { p-value }<.05 \text { was considered statistically significant }\end{array}$

Abbreviations: $\quad \mathrm{BI}=$ Barthel Index; MoCA = Montreal Cognitive Assessment; $\mathrm{SAN}=$ Shortened version of the Aphasia Scale of the Dutch Aphasia Foundation; UPCC = Utrecht Proactive Coping Competence scale; GSES = General Self Efficacy Scale; USER-Participation Restriction= Restriction subscale of the Utrecht Scale for Evaluation of Rehabilitation-Participation; USER-Participation Frequency = Frequency scale of the Utrecht Scale for Evaluation of Rehabilitation-Participation; USER-Participation Satisfaction = Satisfaction scale of the Utrecht Scale for Evaluation of Rehabilitation-Participation; HADS Depression $=$ Depression subscale of the Hospital Anxiety and Depression Scale; HADS Anxiety = Anxiety subscale of the Hospital Anxiety and Depression Scale; HADS Total = Total scale of the Hospital Anxiety and Depression Scale; 2LS = two life satisfaction questions; SS-QOL-12 Physical = Physical subscale of the Short Stroke-Specific Quality of Life scale; SS-QOL-12 Psychosocial = Psychosocial subscale of the Short Stroke-Specific Quality of Life scale; SS-QOL-12 Total= total scale of the Short Stroke-Specific Quality of Life scale; CSI = Caregiver Strain Index 


\section{Treatment effects}

Tables 7.2 and 7.3 present the estimated mean differences and treatment effects of the self-management intervention for all primary outcome measures, compared to the education intervention, at $\mathrm{T} 1, \mathrm{~T} 2$, and $\mathrm{T} 3$.

As regards the patients, the intention-to-treat analyses showed no significant differences between the self-management intervention and the education intervention, neither on the primary nor on the secondary outcome measures (all p>.0042). Nevertheless, a trend toward a difference was seen regarding the USER-Participation Restriction subscale at T3 (estimated mean difference 6.5; $\mathrm{p}=.016$ ). That is, patients in the self-management group reported a decrease in their participation restrictions at T3, while patients in the education intervention group reported an increase in their participation restrictions.

On-treatment analyses for patients showed no significant differences between self-management intervention and education intervention either, whether on primary or secondary outcome measures (all p>.0042). Again, a trend toward a difference was seen at $\mathrm{T} 3$ regarding the USER-Participation Restriction subscale (estimated mean difference $6.7 ; \mathrm{p}=.022$ ) and the total score on the SS-QoL-12

(estimated mean difference .3; $\mathrm{p}=.027$ ). That is, patients in the selfmanagement group reported a decrease in participation restrictions and an increase in health-related quality of life at T3 (mean T0 (SD)= $3.6(.7)$; mean T3 $(\mathrm{SD})=3.8(.8)$ ), while patients in the education intervention reported an increase in participation restrictions and a decrease in overall quality of life (mean T0 $(\mathrm{SD})=.3 .6(.8)$; mean $\mathrm{T} 3(\mathrm{SD})=3.5(.9))$.

As regards the partners, intention-to-treat analyses showed no significant differences between self-management intervention and education intervention, neither on primary nor on secondary outcome measures (all p>.05).

On-treatment analyses showed no significant differences between selfmanagement intervention and education intervention either, for both primary outcome measures ( $\mathrm{p}>.05$ for both). However, a statistically significant difference was found at T2 regarding the GSES (estimated mean difference 2.5; $\mathrm{p}=.028$ ). That is, at T2, partners of the self-management intervention group reported an increase in self-efficacy (mean T0 $(\mathrm{SD})=32.3(4.5)$; mean T2 $(\mathrm{SD})=34.6$ (4.9)), while partners in the education intervention group reported a decrease in self-efficacy (mean T0 $(\mathrm{SD})=32.1(4.0)$; mean $\mathrm{T} 2(\mathrm{SD})=31.9(4.7))$. All other secondary outcomes showed equal effectiveness of the self-management intervention compared to the education intervention (all $p>.05$ ). 
Table 7.2 Mean scores and treatment effects on the primary outcome measures for patients

\begin{tabular}{|c|c|c|c|c|c|c|}
\hline & $\begin{array}{c}\text { Self-management } \\
\text { intervention }\end{array}$ & $\begin{array}{c}\text { Education } \\
\text { intervention }\end{array}$ & & & & \\
\hline & Mean \pm SD & Mean \pm SD & $\begin{array}{l}\text { Estimated mean } \\
\text { difference }\end{array}$ & $\begin{array}{c}\text { Lower } \\
95 \%\end{array}$ & $\begin{array}{l}\text { Upper } \\
95 \%\end{array}$ & p-value \\
\hline \multicolumn{7}{|c|}{$\begin{array}{l}\text { Intention-to-treat } \\
\text { analyses }(n=113)\end{array}$} \\
\hline \multicolumn{7}{|c|}{ UPCC } \\
\hline - T0 & $2.9 \pm .6$ & $2.9 \pm .5$ & & & & \\
\hline - T1 & $2.9 \pm .6$ & $2.9 \pm .6$ & .0 & -.2 & .2 & .863 \\
\hline - $\mathrm{T} 2$ & $3.0 \pm .6$ & $2.9 \pm .5$ & .1 & -.1 & .3 & .245 \\
\hline - T3 & $3.0 \pm .7$ & $2.9 \pm .6$ & .1 & -.1 & .3 & .398 \\
\hline \multicolumn{7}{|c|}{$\begin{array}{l}\text { USER-Participation } \\
\text { restriction }\end{array}$} \\
\hline - T0 & $70.9 \pm 15.5$ & $73.4 \pm 16.6$ & & & & \\
\hline$-\mathrm{T} 1$ & $70.9 \pm 15.1$ & $71.5 \pm 18.8$ & 1.3 & -4.0 & 6.5 & .636 \\
\hline - T2 & $70.3 \pm 16.2$ & $70.5 \pm 18.4$ & 1.2 & -4.0 & 6.4 & .655 \\
\hline - T3 & $73.1 \pm 17.0$ & $67.6 \pm 20.2$ & 6.5 & 1.2 & 11.7 & .016 \\
\hline \multicolumn{7}{|c|}{$\begin{array}{l}\text { On-treatment analyses } \\
(n=84)\end{array}$} \\
\hline \multicolumn{7}{|c|}{ UPCC } \\
\hline - T0 & $2.8 \pm .6$ & $2.9 \pm .5$ & & & & \\
\hline$-\mathrm{T} 1$ & $2.9 \pm .6$ & $2.9 \pm .6$ & .1 & -.1 & .2 & .520 \\
\hline - T2 & $3.0 \pm .6$ & $2.9 \pm .5$ & .1 & -.1 & .3 & .178 \\
\hline - T3 & $3.0 \pm .7$ & $2.8 \pm .6$ & .1 & -.1 & .3 & .206 \\
\hline \multicolumn{7}{|c|}{$\begin{array}{l}\text { USER-Participation } \\
\text { restriction }\end{array}$} \\
\hline - T0 & $69.8 \pm 15.8$ & $73.4 \pm 16.4$ & & & & \\
\hline - T1 & $69.1 \pm 14.9$ & $71.5 \pm 17.6$ & .5 & -5.3 & 6.2 & .874 \\
\hline - T2 & $69.3 \pm 16.5$ & $69.8 \pm 18.8$ & 1.4 & -4.3 & 7.1 & .636 \\
\hline - T3 & $72.7 \pm 17.3$ & $67.4 \pm 20.0$ & 6.7 & 1.0 & 12.5 & .022 \\
\hline
\end{tabular}

Note:

$*$ p-value $<.0042$ was considered statistically significant

Abbreviations: $\quad$ UPCC $=$ Utrecht Proactive Coping Competence scale; USER-Participation restrictions $=$ restriction subscale of the Utrecht Scale for Evaluation of Rehabilitation-Participation; T0 = baseline measurement; $\mathrm{T} 1$ = post treatment measurement; $\mathrm{T} 2$ = first follow-up measurement; $\mathrm{T} 3=$ second follow-up measurement 
Table 7.3 Mean scores and treatment effects on the primary outcome measures for partners

\begin{tabular}{ccccccc}
\hline & $\begin{array}{c}\text { Self-management } \\
\text { intervention }\end{array}$ & $\begin{array}{c}\text { Education } \\
\text { intervention }\end{array}$ & & & & \\
\cline { 2 - 6 } & Mean \pm SD & Mean \pm SD & Estimated mean & Lower & Upper & p-value \\
& & difference & $95 \%$ & $95 \%$ & \\
\hline
\end{tabular}

Intention-to-treat

analyses $(\mathrm{n}=113)$

UPCC

- T0

$3.1 \pm .4$

$3.1 \pm .5$

- T1

$3.3 \pm .5$

$3.3 \pm .3$

$-.2$

953

- T2

$3.4 \pm .5$

$3.1 \pm .5$

$\begin{array}{ll}-.0 & .4\end{array}$

.065

- T3

$3.3 \pm .6$

$3.3 \pm .5$

$\begin{array}{ll}-.2 & .2\end{array}$

.653

USER-Participation

restriction

- T0

$86.6 \pm 16.0$

$86.6 \pm 14.0$

- T1

$91.5 \pm 9.2$

$88.7 \pm 11.9$

3.0

$-2.4 \quad 8.4$

.277

- T2

$89.1 \pm 12.3$

$83.0 \pm 16.3$

6.3

$\begin{array}{lll}-.8 & 13.4 \quad .083\end{array}$

- T3

$87.9 \pm 18.8$

$85.3 \pm 16.3$

2.7

$\begin{array}{lll}-4.9 & 10.4 & .476\end{array}$

On-treatment analyses

$(\mathrm{n}=84)$

UPCC

- T0

$3.0 \pm .4$

$3.1 \pm .4$

- T1

$3.3 \pm .5$

$3.3 \pm .4$

.0

$\begin{array}{ll}-.2 & .2\end{array}$

.888

- T2

$3.3 \pm .6$

$3.1 \pm .5$

$\begin{array}{ll}-.0 & .4\end{array}$

.076

- T3

$3.3 \pm .5$

$3.3 \pm .5$

.2

$-.2 \quad .3$

.784

USER-Participation

restriction

- T0

$86.4 \pm 16.0$

$86.8 \pm 14.8$

- T1

$90.3 \pm 9.8$

$89.1 \pm 11.2$

1.3

$-4.8$

$7.4 \quad .675$

- $\mathrm{T} 2$

$86.5 \pm 13.1$

$81.3 \pm 17.3$

5.3

$-3.4$

$14.0 \quad .224$

- T3

$86.9 \pm 20.8$

$85.5 \pm 14.6$

1.4

$\begin{array}{lll}-8.2 & 11.0 & .769\end{array}$

Note:

$*$ p-value $<.05$ was considered statistically significant

Abbreviations:

UPCC $=$ Utrecht Proactive Coping Competence scale; USER-Participation restrictions = restriction subscale of the Utrecht Scale for Evaluation of Rehabilitation-Participation; T0 = baseline measurement; $\mathrm{T} 1$ = post treatment measurement; $\mathrm{T} 2$ = first follow-up measurement; $\mathrm{T} 3=$ second follow-up measurement 


\section{Discussion}

Our study found no evidence in favour of our self-management intervention compared to the education intervention among stroke patients. As for partners, the self-management intervention was effective in terms of self-efficacy levels three months after the intervention ended. That is, partners who had attended at least three quarters of the intervention sessions reported higher levels of selfefficacy compared to partners in the education intervention.

The outcomes of our study do not correspond to earlier studies showing effectiveness of stroke-specific self-management interventions in stroke patients. 27,28,30,92,145 Our study differed from earlier studies in our aim to teach stroke patients proactive coping strategies. Reduced self-awareness, a common stroke consequence, may have hampered our patients in learning these strategies. ${ }^{149}$ That is, stroke patients' reduced self-awareness may have hampered their selfregulation behaviours, which are required for learning complex abilities such as proactive coping. ${ }^{150}$ Consequently, patients may have been unable to adopt proactive coping strategies.

As for partners, our study differed from a study aimed at enhancing healthy adults' proactive coping strategies in dealing with own future problems. ${ }^{34}$ In contrast, partners in our study were invited due to the patients' post-stroke participation problems, instead of their own problems. As such, partners might have been less motivated to learn proactive coping strategies. Moreover, partners in our study reported low participation restrictions at the study onset, which may also imply less motivation and less room for improving their participation.

Therapists indicated their difficulty in supporting partners adequately during the intervention, due to the relatively novel position of partners as full participants in our intervention. ${ }^{151}$ Although partners are increasingly involved in the care for stroke patients, professionals still pay little attention to partners' goals and problems when patients are living at home. ${ }^{140}$ In addition, therapists in our study experienced difficulty in supporting participants adequately during the intervention, as the proposed therapeutic approach was relatively new to most of them. ${ }^{151}$ This is in agreement with earlier research, which showed therapists' reluctance towards patient empowerment to be an important barrier to implementation of self-management interventions. ${ }^{152}$ 
However, earlier studies showing effectiveness of stroke-specific selfmanagement interventions and interventions aimed at increasing proactive coping strategies compared these interventions with care as usual conditions or a waiting list, instead of a control intervention. ${ }^{27,28,30,92,145}$ Therefore, these studies might not have controlled for a-specific effects due to general therapeutic approaches, such as peer support or stroke-related information provision, to patients in the control condition. As a result it could be that these generic components were responsible for the effectiveness of these earlier self-management interventions, rather than specific self-management components. In line with this idea, our process evaluation study showed that in our self-management intervention, peer support was most often indicated as valuable by both patients and partners. ${ }^{151}$

The current study showed a favourable trend for our self-management intervention compared to the education intervention, among patients and partners. Nevertheless, proactive coping does not seem to be the effective ingredient in this case. Therefore, on the one hand, we recommend further research into facilitators of proactive coping in stroke patients and partners, as proactive coping is associated with quality of life post stroke. ${ }^{66}$ On the other hand we think, in line with other researchers, that there is insufficient knowledge about factors explaining the success of self-management interventions, such as contextual factors, therapeutic approaches, and patient characteristics. ${ }^{153,154}$ Hence, we recommend further research into these factors, to identify the conditions needed to successfully provide self-management interventions to stroke patients and partners.

Strong points of our study included the considerable patient sample size, and the recruitment of patients and partners at multiple sites. Additionally, both patients and partners were blinded for the condition. Also, the number of dropouts during the study was low. Finally, our results were analysed using linear mixed modelling, allowing for inclusion of incomplete datasets.

Our study was limited due to patients not being selected based on their own experiences and intrinsic motivation to change their situation.151 Instead, physicians and specialized nurses assessed whether patients experienced participation problems and were eligible for the study. Secondly, the trial was conducted in addition to usual care in the participating hospitals and rehabilitation centres, so our outcomes may have been influenced by the care-as-usual treatment 
programs, as we were unable to control for the content of these programs.

In conclusion, no compelling evidence was found in favour of our selfmanagement intervention compared to the education intervention among the stroke patients. Therefore, the self-management intervention should not be implemented in its current form in clinical practice. Further research is needed into ways to facilitate proactive coping in stroke patients, and into contextual and personal factors influencing outcomes of interventions such as ours. 



\section{CHAPTER 8 \\ General discussion}


The present thesis describes the Restore4Stroke Self-Management study, in which we examined the use of proactive coping strategies by stroke patients. The main objective of the Restore4Stroke Self-Management study was to examine the effectiveness of a stroke-specific, group-based self-management intervention aimed at teaching stroke patients and their partners proactive coping strategies, compared to a group-based, education intervention. In addition, we investigated the psychometric properties of our primary outcome measure the Utrecht Proactive Coping Competence Scale, in stroke patients, and the potential benefits of proactive coping for stroke patients' psychosocial functioning. This chapter discusses the main findings and the methodological strengths and limitations of our study. In addition, it presents clinical implications and recommendations for future research.

\section{Main findings reported in this thesis}

Most existing stroke-specific self-management interventions reported on in the literature have been based on self-efficacy principles. However, convincing evidence for the effectiveness of these interventions has been lacking ${ }^{28,30}$, and no alternative and possibly better mechanisms to enhance the self-management abilities of stroke patients were known. We investigated whether enhancing proactive coping strategies would be a more effective strategy to improve selfmanagement abilities in stoke patients. As proactive coping had not yet been investigated in stroke patients, we first explored the construct of proactive coping in some more detail in stroke patients.

We examined the psychometric properties of the Utrecht Proactive Coping Competence scale (UPCC) (Chapter 2). Our study showed that the UPCC had excellent reliability (Cronbach's $\alpha=.95$ ). Convergent validity of the UPCC was shown by moderate positive relations with the active problem solving subscale of the Utrecht Coping List (UCL) $(r=.38)$ and moderate negative relations with the UCL subscales for passive reactions $(r=-.50)$, avoidance $(r=-.40)$, and expression of emotions $(r=-.42)$. Thus, the UPCC was found suitable for the exploration of the construct of proactive coping in stroke patients.

Next, we investigated the associations between proactive coping and healthrelated quality of life in stroke patients (Chapter 2). We showed that proactive coping was positively associated with the physical, psychosocial and overall 
health-related quality of life domains post stroke $(\mathrm{r}=.48-.61)$ as measured with the short Stroke Specific Quality of Life scale. Moreover, its association with health-related quality of life was stronger than with other coping strategies (i.e. active problem solving, passive reactions, palliative reactions, seeking social support, avoidance, expression of emotions, and reassuring thoughts).

We also investigated if the construct of proactive coping differed sufficiently from that of self-efficacy to justify our assumption that it would be an alternative target for stroke-specific self-management interventions. Hence, we investigated the associations between proactive coping, self-efficacy and psychosocial outcomes post-stroke (Chapter 3). We showed that although self-efficacy and proactive coping were highly correlated, their associations with psychosocial outcomes differed. Proactive coping was positively associated with psychosocial outcomes related to emotional acceptance (i.e., satisfaction with participation, health-related quality of life, emotional functioning and life satisfaction), but was not associated with participation restrictions. It seemed that greater use of proactive coping strategies in stroke patients resulted in better emotional acceptance, but not in actual reductions of restrictions of daily life. In addition, the influence of self-efficacy on life satisfaction was fully mediated by proactive coping, while self-efficacy had a direct influence on emotional functioning and health-related quality of life. Finally, self-efficacy did not moderate the association between proactive coping and the psychosocial outcomes. Thus, the level of self-efficacy did not influence the strength of the relationship between proactive coping and psychosocial outcomes post stroke.

In the Restore4Stroke Self-management study we investigated if a groupbased, stroke-specific self-management intervention aimed at teaching stroke patients and their partners proactive coping strategies was more effective than a group-based, stroke-specific education intervention (see Chapter 4 for the study protocol). Chapter 5 presents the rationale behind, and the description of, the group-based self-management intervention called 'Plan Ahead!', which was developed for stroke patients and their partners. The self-management intervention was based on the proactive coping theory, the Health Action Process Approach model, existing interventions, expert consultations, feedback derived from pilot studies, and solution-based therapeutic techniques. 
The process evaluation study showed that the self-management intervention reached the target audience, and that both participants and therapists were satisfied with the intervention (Chapter 6). However, the implementation of the intervention during the trial was not optimal, both in terms of the compliance of the therapists with the treatment protocol and the engagement of participants. The suboptimal implementation of the intervention may have influenced its effectiveness, as the activities related to the proactive action planning tool in particular were not fully carried out. With our multicentre randomized controlled trial we showed that the self-management intervention was not superior to the education intervention, as proactive coping strategies were not significantly enhanced and participation restrictions were not significantly reduced in either stroke patients or their partners by the self-management intervention compared to the education intervention (Chapter 7). Nevertheless, compared to patients in the education intervention, those in the self-management intervention showed beneficial trends in terms of restriction levels of participation among patients, and significantly higher levels of self-efficacy among partners, three months after the last session of the intervention had been completed.

\section{Proactive coping post stroke}

Folkman, Lazarus, Gruen and DeLongis defined coping as 'the person's cognitive and behavioural efforts to manage (reduce, minimize, master, or tolerate) the internal and external demands of the person-environment transaction that is appraised as taxing or exceeding the person's resources' ${ }^{65(\mathrm{p} .572)} \mathrm{A}$ screening of the literature showed that most of the studies in stroke patients have focused on coping responses adopted after a stressful situation occurred, i.e. on reactive coping. Recent research in elderly people and people with chronic conditions has started to investigate proactive coping, i.e. coping strategies adopted to prevent or modify a potential problem situation before it actually arises. ${ }^{33-35,155,156}$ To the best of our knowledge, we were the first to investigate proactive coping strategies in stroke patients, as we thought that such strategies might enhance their abilities to deal with the long-term consequences of stroke. Many stroke patients are hampered in their daily life by consequences of stroke, such as fatigue, emotional changes, and problems with initiating activities. ${ }^{31,157}$ Proactive coping strategies should enable these patients to anticipate stroke-related barriers 
in daily life activities, so they can prepare themselves to prevent or master these consequences.

Traditionally, coping strategies are dichotomized into problem-based or emotion-based coping strategies. Problem-based coping strategies are aimed at changing the situation, while emotion-based coping strategies are adopted in an attempt to regulate the emotions elicited by the situation at hand. ${ }^{65}$ The studies in this thesis pointed at the difficulty of fitting proactive coping into the traditional dichotomization into problem-based and emotion-based coping strategies. On the one hand, our conceptualisation of proactive coping reflects a problembased coping strategy, as it meant proactive coping aimed at actively preventing or modifying a potentially stressful situation. In line with this view, our study showed that proactive coping was positively associated with the problem-based, reactive coping strategy of active coping in stroke patients. On the other hand, contradicting the problem-based nature of proactive coping, we found that it was positively associated with outcomes related to emotional acceptance (i.e. healthrelated quality of life, life satisfaction, satisfaction with participation, emotional functioning). This finding seems to suggest that proactive coping can be classified as an emotion-based coping strategy. Moreover, problem-based coping strategies are expected to enhance participation, as such strategies should enhance patients' abilities to deal with stroke-related barriers regarding an activity. However, these expected associations were not found in our study.

An explanation for these findings might be provided by the goal adjustment process taking place after stroke, as depicted in figure 8.1. That is, the association between proactive coping and emotional acceptance could in fact be the result of the associations between goal adjustment and both of these processes. As such, the association between proactive coping and emotional acceptance might not really exist. Specifically, many stroke patients have to adjust their goals, as their previous goals have become unattainable due to the consequences of stroke..$^{31,157}$ Proactive coping seems to be related to goal adjustment, as it is associated with realistic goal setting. ${ }^{34}$ In addition, a study among adult caregivers of people with a mental illness provided evidence for an association between goal adjustment and emotional acceptance, as it was associated with greater well-being and less emotional problems. ${ }^{158} \mathrm{An}$ example of this explanation is given by case 1 in Box 8.1 . 


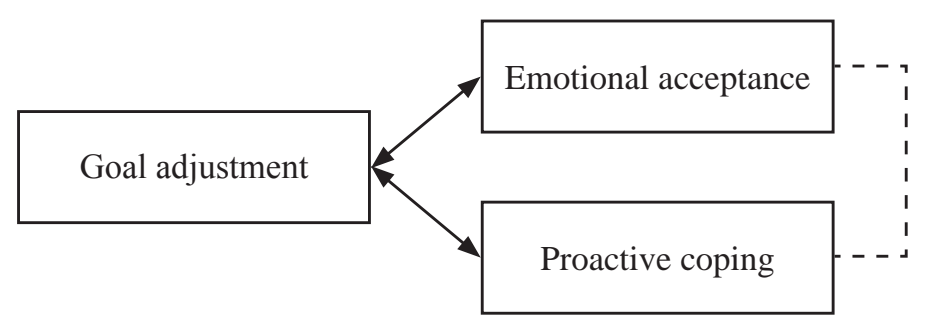

Figure 8.1 Schematic representation of the potential relations between goal adjustment, proactive coping and emotional acceptance.

Box 8.1 Case 1.

\begin{tabular}{|c|c|c|}
\hline & & eali \\
\hline Pre-stroke & $\begin{array}{l}\text { ng a busy social life, including } \\
\text { parties at the hockey club and } \\
\text { matches at the arena }\end{array}$ & intolerance to noisy places \\
\hline e & & $\begin{array}{l}\text { Yes, if Mr P. and his friend opt for } \\
\text { short activities in quiet places, and } \\
\text { at times of the day when Mr P. has }\end{array}$ \\
\hline & \multicolumn{2}{|c|}{$\begin{array}{l}\text { Mr P's social goal is adjusted because he realizes that that his previous } \\
\text { social life is no longer sustainable. That is, reduced energy levels and } \\
\text { intolerance to noisy places result in exhaustion lasting several days after } \\
\text { undertaking activities in noisy places. He realizes that his former social } \\
\text { life is no longer realistic, and decides to focus on the most worthwhile } \\
\text { part of his social life only: his contact with his friend. }\end{array}$} \\
\hline & \multicolumn{2}{|c|}{$\begin{array}{l}\text { His former social life required Mr P. to visit noisy places at fixed times. } \\
\text { His intolerance to noisy places and reduced energy levels are almost } \\
\text { insurmountable barriers in these situations. In his new, adjusted goal, } \\
\text { these stroke-related barriers become manageable, as he is able to influence } \\
\text { the location and timing of the activities. In other words, he is able to } \\
\text { overcome these stroke-related barriers before undertaking the activity, and } \\
\text { can thus could proactively cope to reach this goal. }\end{array}$} \\
\hline & \multicolumn{2}{|c|}{$\begin{array}{l}\text { As Mr P. accepts that he has to adjust his goal, he allows himself to set a } \\
\text { more achievable goal. On the other hand, as his new goal is more realistic, } \\
\text { he is able to reach it. As a result, he becomes less frustrated about the } \\
\text { situation post stroke, and is more satisfied with his life. }\end{array}$} \\
\hline
\end{tabular}


Another explanation for our results might be the fatigue many patients report post stroke. ${ }^{11}$ Briefly, we suggest that patients who proactively deal with their fatigue might be better able to achieve valued goals at the cost of lower priority goals. As a result, stroke patients may experience greater emotional acceptance of their situation, even though their overall participation restrictions do not change. An example of this explanation is given by case 2 in Box 8.2. Supporting this explanation, a qualitative study found that many stroke patients try to proactively cope with the barrier of limited energy by sacrificing other activities for the pursuit of valued goals. ${ }^{159}$ So although stroke patients' participation remains restricted by fatigue, it seems that patients are still relatively well able to achieve these valued goals. A recent study among patients with acquired brain injury showed that more achievement of valued goals was associated with greater life satisfaction, and indirectly with better emotional functioning. ${ }^{160}$ Thus, while patients' overall restrictions of participation do not change, we think their degree of emotional acceptance of their situation can still be relatively high, raised through proactive coping. Support for this idea was found in a study among chronic stroke patients which showed that fatigue was associated with the restrictions of participation they experience, but not with the satisfaction with participation, which we consider to be a component of emotional acceptance. ${ }^{161}$

Box 8.2 Case 2.

\begin{tabular}{ll}
\hline $\begin{array}{l}\text { Valued goal } \\
\text { Lower priority goals }\end{array}$ & $\begin{array}{l}\text { Visiting her son's graduation ceremony } \\
\text { Household activities such as cleaning the kitchen and using the } \\
\text { vacuum cleaner }\end{array}$ \\
Decision & $\begin{array}{l}\text { Mrs U. deals proactively with this situation by not performing } \\
\text { household activities the day before the graduation ceremony, } \\
\text { to save energy for the next day }\end{array}$ \\
Instead of being exhausted on the day of the ceremony, Mrs \\
U. has saved sufficient energy to fully enjoy the graduation \\
ceremony.
\end{tabular}




\section{Self-efficacy post stroke}

Self-efficacy is defined as the confidence someone has in their own competence to successfully accomplish actions or reach goals. ${ }^{67}$ According to the social cognitive theory by Bandura (1977) self-efficacy is an important determinant of the initiation and persistence of behaviour, and of the amount of effort spent on this behaviour. ${ }^{67}$ Our finding that higher self-efficacy was associated with greater life satisfaction and health-related quality of life and less emotional problems was in line with recent studies among patients with acquired brain injury and specifically among stroke patients. ${ }^{160,162}$ However, our finding that self-efficacy was not associated with participation contradicts earlier findings among spinal cord injury patient. This can be explained by the theory of planned behaviour. ${ }^{80,163} \mathrm{~A}$ schematic representation of this theory is depicted in figure 8.2.

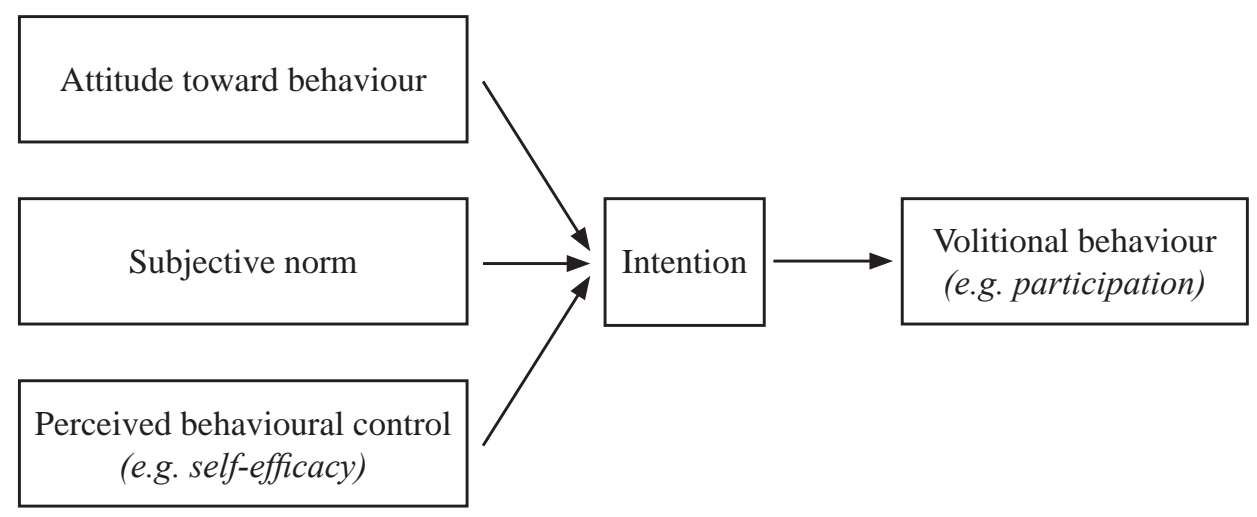

Figure 8.2 The theory of planned behaviour.

According to the theory of planned behaviour, volitional behaviour is the result of an intention to perform a particular behaviour. Such intentions are influenced by 1) someone's own attitude towards a particular behaviour (i.e., someone's personal opinion about performing a particular behaviour), 2) the subjective norm (i.e., perceived social pressure to act in a particular way), and 3) perceived behavioural control (i.e., perceived ability to perform the behaviour effectively). ${ }^{163}$ Based on this theory, self-efficacy can be considered as a determinant in someone's perceived behavioural control. 
As seen in figure 8.2, other factors than self-efficacy alone influence the intention to adopt a specific behaviour. For example, spinal cord injury often affects patients' motor functioning, resulting in clearly visible consequences such as reduced arm or leg functioning. ${ }^{81}$ In contrast, stroke patients living at home often report behavioural, cognitive and emotional consequences of stroke which are largely invisible from the outside. ${ }^{82-85}$ Due to the lack of visibility of these consequences, the stroke patients' environment (i.e., relatives and people in the community) could easily have unrealistic expectations about their post-stroke capacities and make unrealistic demands on their participation. ${ }^{31,164}$ Therefore, social pressure might have a greater influence on behaviour in stroke patients than in spinal cord injury patients.

However it could also be that the abilities needed to construct adequate self-efficacy beliefs are affected by a stroke. According to the theory of planned behaviour, higher levels of self-efficacy are related to increased chances of performing a particular behaviour. However, a frequently reported stroke-specific impairment is reduced self-awareness, that is, a reduced ability to assess one's abilities in daily life. ${ }^{149}$ As a result, patients often overestimate their own abilities, which could result in unrealistically high self-efficacy levels. ${ }^{31,86}$ As such, there can be a mismatch between perceived self-efficacy and the actual abilities to perform participation oriented behaviour. This mismatch might be reflected by the lack of association we found between self-efficacy and participation.

A final explanation of our finding that higher self-efficacy was not associated with greater participation could be that stroke-specific cognitive impairments impede the translation of intentions into actual behaviour that is proposed by the theory of planned behaviour. Executive functioning in particular has been suggested to be essential in the translation of intentions into actual, volitional behaviour, as such behaviour requires adequate selection of goals, planning, and the initiation of behaviour. ${ }^{165}$ However, since many stroke patients report cognitive problems of executive functioning ${ }^{12}$, the influence that self-efficacy might have on their intentions is not reflected in actual behaviour, as the translation of intentions into actual behaviour might fail in these patients. 


\section{The 'Plan Ahead!' self-management intervention for stroke patients}

Self-management refers to someone's abilities to deal with the medical, lifestyle, physical and psychosocial consequences of a condition, and their impact on daily life. ${ }^{25}$ In recent years, a growing number of interventions have been developed to enhance self-management abilities in stroke patients. However, studies investigating the effectiveness of such interventions have shown mixed outcomes, and their methodological quality has often been compromised. ${ }^{47}$

Our trial showed that our stroke-specific self-management intervention, 'Plan Ahead!', was not more effective among patients than an education intervention. This finding was not in line with earlier studies, which found effectiveness of either stroke-specific self-management interventions or interventions aimed at increasing proactive coping strategies. ${ }^{27-30,33,34}$ Our process evaluation study showed that the degree to which the intervention was performed according to the treatment protocol during the trial was not optimal, and the same was true for the level of engagement of patients and partners during activities related to the proactive action planning tool of the intervention. Therefore, the lack of effectiveness of our intervention that we found might be explained by insufficient implementation.

However, there may be other explanations possible. We have described above the associations between personal factors such as self-efficacy and the psychosocial outcomes post stroke. Personal factors such as self-efficacy may also have influenced the outcomes of our trial. Self-efficacy has been proposed as an important determinant of the adoption of behaviour, as reflected in the theory of planned behaviour. ${ }^{67,163}$ Our self-management intervention does not devote a great deal of attention to participants' self-efficacy, which may have impeded actual change in coping behaviour in our stroke patients. If this lack of attention to self-efficacy is the cause, a more comprehensive intervention might be needed to teach stroke patients proactive coping strategies, one which includes cognitive behavioural therapeutic principles for changing personal factors such as selfefficacy.

In addition to the potential influence of self-efficacy, another personal factor that might have influenced the outcomes of our trial is a patient's intrinsic motivation to change their behaviour in order to achieve better outcomes post stroke. Patients in our trial were selected by their rehabilitation physician or a 
specialized nurse, who assessed whether patients were experiencing participation problems. As a result, intrinsic motivation to change their behaviour was not a necessary criterion for participating in the intervention. According to the transtheoretical model, however, changing a behaviour is a process of six interrelated stages: precontemplation (i.e., patients do not have the intention to change), contemplation (i.e., they have the intention to change within six months), preparation (i.e., they have the intention to change in the near future), action (i.e., they have made changes), maintenance (i.e., they try to sustain their behaviour change), and termination (i.e., the behaviour change has become part of their behaviour pattern). ${ }^{166}$ Hence, a patient's level of motivation depends on the stage they are in. For example, the required level of motivation to change behaviour is absent in the precontemplation phase, while in the action phase patients may be highly motivated to change their behaviour. Support for the idea that motivation played a part in our findings could be found in our process evaluation study, as the therapists indicated that a lack of motivation to change one's situation was an important barrier preventing patients from benefitting from our self-management intervention.

In addition to personal factors, stroke-specific impairments might have influenced the outcomes of our trial. For instance, as described above, stroke patients often report reduced self-awareness, resulting in an overestimation of their own capacities..$^{31,86}$ As associations between realistic goal setting and proactive coping have been reported in healthy adults, it could be that unrealistic goal setting hampered our stroke patients in proactively coping with their goals. ${ }^{34}$ Another stroke-specific impairment that might have influenced the outcomes of our trial is the frequently reported impaired executive functioning, limiting stroke patients' abilities to learn proactive coping strategies. ${ }^{12}$ Gross and Schutz (1986) proposed a hierarchical framework to categorize neuropsychological interventions based on the learning abilities required of patients. ${ }^{150,167}$ This framework is presented in figure 8.3. 


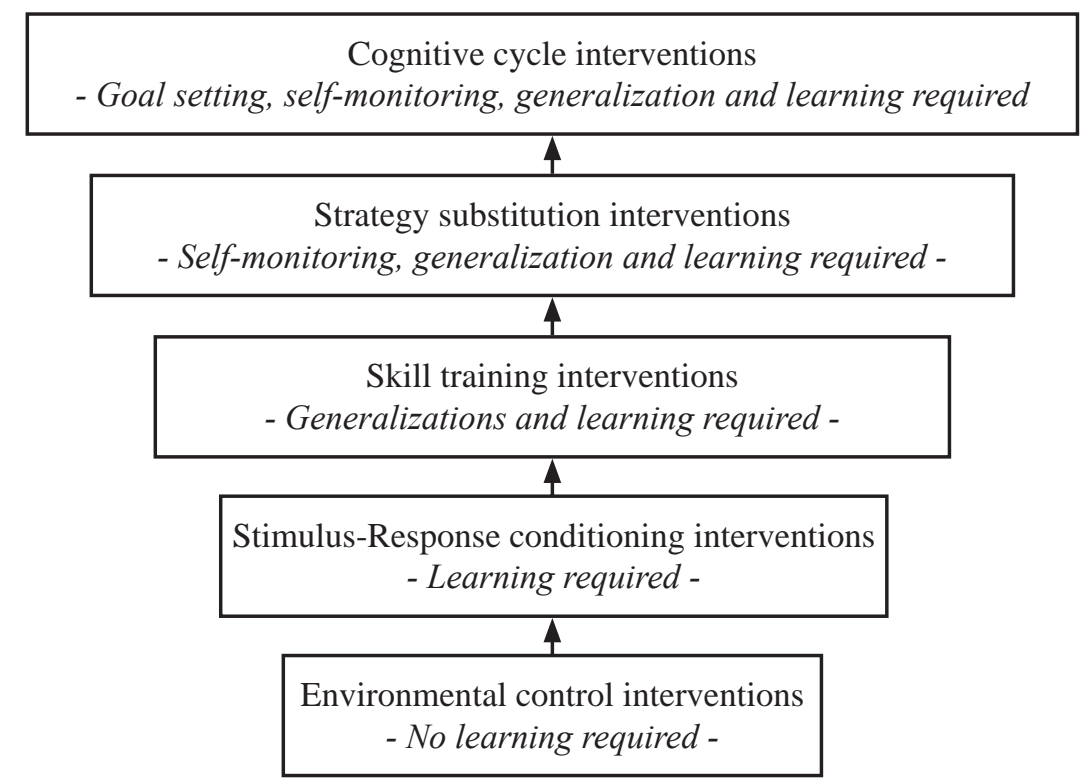

Figure 8.3 Framework by Gross \& Schultz (1986) to categorize neuropsychological interventions and the required learning abilities.

As depicted in figure 8.3, the higher the level at which an intervention is situated in this framework, the greater the demands made on a patient's executive functioning and self-awareness. Proactive action planning requires patients to set goals, think of potential barriers and requirements for goal achievement, formulate action plans, undertake action, and evaluate the outcomes of the proactive action planning process. ${ }^{35}$ Thus, it requires of patients the abilities to set goals, selfmonitor, generalize and learn. As such, proactive action planning operates at the highest level of the Gross and Schutz (1986) framework. As a result, the potential impairments of executive functioning among stroke patients and their potentially reduced self-awareness may have prevented them from learning proactive coping strategies. Our process evaluation study provided some support for this idea, as the therapists indicated that the presence of cognitive impairments would be an important barrier for patients to benefit from our self-management intervention. In addition, a study has found that self-awareness was positively associated with goal setting ability and rehabilitation outcome in stroke patients. ${ }^{168}$ Another study, among patients with schizophrenia, showed that proactive coping was positively associated with cognitive functioning. ${ }^{155}$ 
Finally, the difference in effectiveness between our self-management intervention and earlier interventions might be caused by methodological factors. Earlier studies compared the intervention of interest with a care as usual condition or a waiting control list. In contrast, the education intervention used as a control condition in our trial only differed from our self-management intervention by not teaching participants proactive action planning. As a consequence, the effectiveness of interventions in earlier studies could also be attributed to generic, non-intervention specific components, such as peer support and information provision. Some support for this idea was provided by explorative analyses of the satisfaction data of our process evaluation study. First, for the patients, peer support was the most frequently valued component of both interventions. Next, patients' satisfaction rates did not differ significantly between the selfmanagement intervention and the education intervention (both p-values $>.05$ ). This latter finding was in line with earlier research among acquired brain injury patients, which showed that patients' level of satisfaction with an intervention did not reflect its effectiveness: although this study with acquired brain injury patients found the experimental intervention to be more effective in improving executive functioning than a control intervention, patients were equally satisfied with the experimental and control interventions. ${ }^{169}$

In short, the absence of superiority of the self-management intervention over the education intervention might be explained by insufficient implementation of our intervention. However, also personal factors (e.g. self-efficacy and intrinsic motivation) and stroke-specific factors (e.g. reduced self-awareness or impaired executive functioning) might influence stroke patients' ability to learn proactive coping strategies. Therefore, learning proactive coping strategies to stroke patients seems to be a complex process, in which the influence of a broad variety of factors should be considered.

\section{The 'Plan Ahead!' self-management intervention for partners}

The Dutch government is increasingly asking citizens to provide informal care to relatives. ${ }^{170}$ However, providing such care is a new and challenging experience, with $51 \%$ of partners reporting significant burden one year post stroke. ${ }^{110}$ The 'Plan Ahead!' self-management intervention differed from most other strokespecific self-management intervention in the status of full participant given to 
partners, instead of leaving them in their more usual role as informal caregiver. That is, partners were motivated to work out their own proactive action plans and share their post-stroke experiences. Our process evaluation study showed that, in addition to peer support, partners found working out their own goals worthwhile. Moreover, the therapists involved indicated that they found the position of partners as full participants valuable. This finding is in line with studies emphasizing the need for healthcare professionals to devote attention to the problems and emotions of partners as well..$^{140,171}$

Our stroke-specific self-management intervention, 'Plan Ahead!', was not more effective among partners than the education intervention. This finding was not in line with an earlier study, which found interventions aimed at increasing proactive coping strategies in healthy adults to be effective. ${ }^{34}$ A possible explanation for our findings might be a lack of intrinsic motivation among partners to change their behaviour. This argument of a lack of intrinsic motivation might apply even more to the partners than to the patients in our trial, as partners were selected for the intervention based on the patient's problems rather than their own. In this respect, our trial differed from the study among healthy adults, which might explain our results.

However, as mentioned above, the differences found in effectiveness of our intervention and an earlier intervention in healthy elderly could also be attributed to the differences in study design: the study among healthy elderly persons compared the intervention of interest with a waiting control list, instead of a comparable intervention lacking only the proactive coping component. As such, the effectiveness of the study in healthy elderly might be the result of generic, non-intervention specific components, such as peer support and information provision. Our study controlled for the influence of such generic components, which could explain the lack of superiority of the self-management condition over the control condition.

Nevertheless, the self-management intervention was more effective than the education intervention in terms of self-efficacy at three months after the intervention. Something other than enhancement of proactive action planning must have been responsible for this trend of increased self-efficacy, as proactive coping was not more enhanced in the self-management group compared to the education intervention group at three months after intervention. Korpershoek et 
al. (2011) described several mechanisms for the enhancement of self-efficacy, including the effects of goal attainment, as well as modelling (i.e., observing others attaining a goal). ${ }^{172} \mathrm{We}$ think that these two mechanisms might explain the increased levels of self-efficacy reported by partners in the self-management condition three months post treatment. That is, our self-management intervention puts a strong emphasis on goal setting by partners, which may have resulted in more effort spent on goal pursuit, and therefore in increased goal attainment by partners. As a result of this, self-efficacy may have been enhanced in partners. Furthermore, goal attainment by participants was evaluated in the group of participants during each session of the self-management intervention. It could be that hearing about other partners' goal attainments (i.e., modelling) resulted in increased self-efficacy as well.

\section{Methodological strengths and considerations}

\section{Strengths}

To the best of our knowledge, our research was the first to examine the concept of proactive coping strategies in stroke patients and partners of people with a chronic condition. In addition, we were the first to investigate the associations between proactive coping and self-efficacy, and several psychosocial outcomes.

A strength of our Restore4Stroke Self-Management study was that it followed the Medical Research Council guidelines, a framework to assist researchers in developing and evaluating complex interventions. ${ }^{133}$ According to this framework the development and evaluation of complex interventions goes through four interrelated phases: 1) development of the intervention based on a sound theoretical framework and sufficient evidence, 2) feasibility/ piloting, 3) evaluation of both clinical effectiveness and cost-effectiveness of the intervention, complemented by a process evaluation study, and 4) implementation of the intervention if effective. We first developed the intervention based on an evidence-based intervention for diabetes patients ${ }^{111,112}$, the proactive coping theory ${ }^{35}$, and the Health Action Process Approach model ${ }^{109}$. Further fine tuning of this intervention took place based on experiences with the intervention for acquired brain injury patients at the University Medical Centre Utrecht ${ }^{115}$ and an intervention developed by the Dutch Heart Foundation for stroke patients ${ }^{113,114}$, 
as well as on consultations with researchers and healthcare professionals. The intervention was tested in two pilot studies, after which adjustments were made to the intervention. Sample sizes for the trial were calculated and recruitment and retention were estimated. Subsequently, the intervention was evaluated in terms of effectiveness by means of a randomized controlled trial, while the underlying processes were examined in a process evaluation study. In the near future, a costeffectiveness study will be performed as well, although this study is not included in this thesis.

In addition, Gillespie et al (2014) recently indicated that rehabilitation research is often methodologically compromised in three respects. First, sample sizes are often underpowered and not representative of the overall stroke population. Second, the investigated intervention is often not described in sufficient detail, lacks a rationale, and is not compared with a control treatment. Third, outcome measurements are often restricted to measurements of impairments instead of mapping the impact of the intervention on daily life outcomes. ${ }^{173}$ A strength of our study was that none of these methodological issues did apply to our trial. That is, the number of patients recruited was based on sample size calculations and inclusion criteria for patients and partners were not restrictive, reducing the risk of a non-representative sample. Furthermore, we published a paper presenting the rationale and a description of the intervention, to allow duplication of our study. In addition, the self-management intervention was compared with a similar control intervention, lacking only the self-management component of proactive action planning. Finally, the outcome measures in our trial assessed in daily life functioning (e.g., participation, mood, life satisfaction, and quality of life).

\section{Considerations}

Although the studies in this thesis had several strengths, there were also some important limitations. First, our explorative studies on proactive coping had a cross-sectional design, so we were unable to make inferences about the causality of relations. Second, our study was a pragmatic trial, intended to investigate the effectiveness of our self-management intervention compared to an education intervention in a real life setting. However, it is possible that an explanatory trial (i.e., a trial conducted in optimal conditions) might have resulted in different conclusions about the effectiveness of the intervention compared to the education intervention. ${ }^{174}$ 
Third, the finding of ineffectiveness of our self-management intervention could also be the result of the measures we used. First of all, it is unknown if the primary outcome measure (the Utrecht Proactive Coping scale) was responsive to changes over time in stroke patients. Secondly, research to assess the psychometric properties of the Utrecht Scale for Evaluation of Rehabilitation-Participation was lacking for partners of stroke patients. Finally, the outcome measures used in this trial may have been too generic to detect the changes in participants' concrete behaviours. That is, it could be that stroke patients did achieve the goals they set during the self-management intervention, but that the impact of this goal achievement was too specific to be detected by our generic outcome measures. Forexample, if someone set the goal of 'going out this Saturday night' it could be that he or she reached this specific goal, but that this achievement was too specific to have an impact on a patient's overall satisfaction with participation.

\section{Implications for clinical practice}

The findings of the studies reported in this thesis might question the appropriateness of self-management interventions based on teaching proactive coping strategies to stroke patients and partners. In any case, the Restore4Stroke self-management intervention 'Plan Ahead!' should not be implemented in clinical practice in its current form. However, we think it is too early to abandon these interventions for stroke patients and partners completely. Like other researchers, we think, that more knowledge is needed about factors facilitating and impeding the provision of self-management interventions such as ours. ${ }^{154}$ For example, we need to answer questions about the influence of personal factors and strokespecific factors on the outcomes of such an intervention. Next, the appropriate timing or format (group/ individual) of the intervention could be questioned. ${ }^{47}$ Therefore, instead of abandoning self-management immediately, we think it is more appropriate to take a step back, by first examining the factors that influence the outcomes of self-management interventions such as ours.

Next, the studies in this thesis shows the complexity of implementing an intervention such as ours. Not only did healthcare professionals have to adjust their professional attitude, but patients had to get used to an active role in their care process as well. It is therefore important to realize that such changes need time. Implementation can be facilitated by recruiting patients with the intrinsic 
motivation to change, and by providing healthcare professionals with sufficient training to give them sufficient time to adjust their professional attitude.

Finally, the studies in this thesis and earlier research point at the need for healthcare professionals to address the caregivers' own problems and goals, and the value of peer support for caregivers. However, in current healthcare practice, specific attention to partners' needs is still limited. ${ }^{142}$

Hence, the need for active effort from healthcare professionals to see the person behind the caregiver, and the importance of peer support for partners are important clinical messages from the studies in this thesis.

\section{Directions for future research}

Self-management is an umbrella term, comprising a broad variety of interventions. More clarity is needed about the concept of self-management and the minimum prerequisites for a self-management intervention. In addition, the effectiveness of self-management interventions varies widely. ${ }^{154}$ So knowledge is needed about the appropriate attitudes on the part of therapists, about the context in which an intervention is implemented, and about favourable patient characteristics. ${ }^{153}$ Effect sizes have also be found to vary greatly between patients, suggesting that it might be better to apply different approaches to different patients. ${ }^{154}$ Hence, patient-tailored approaches should also be investigated in stroke patients and partners.

In any case, we think it is too early to abandon proactive coping interventions for stroke patients and their partners completely. Like other researchers we think that, first, more knowledge is needed about factors facilitating or impeding the provision of such self-management interventions to stroke patients and partners. 154 That is, knowledge is needed about the appropriate therapists' attitudes, the context in which the intervention is implemented, and favourable patient characteristics. Several questions need to be answered, for example regarding the appropriate timing, and format (group/ individual) of the intervention. ${ }^{47}$ In the absence of this knowledge we cannot be sure if finding of an intervention to be ineffective can be attributed to the intervention itself, or to other factors impeding the appropriate delivery of the intervention. Therefore, instead of abandoning the concept of proactive coping as target for self-management interventions immediately, we think it is appropriate to take a step back first by examining factors influencing the outcomes of self-management interventions. 
In addition, as described above, there have been no studies showing selfmanagement interventions that are effective as a result of actual self-management components, such as our proactive action planning tool, rather than through generic elements such as peer support and information provision. Therefore, research should investigate the value added to these interventions by actual selfmanagement components to these interventions. Also research is needed into the appropriateness of proactive coping as a target to facilitate self-management abilities in stroke patients. Finally, research is needed how proactive coping can be enhanced in stroke patients, in view of the positive associations between proactive coping and several psychosocial outcomes post stroke.

The studies in this thesis point at the beneficial associations between proactive coping strategies and psychosocial outcomes post stroke. Longitudinal studies are needed to investigate the long-term course of proactive coping in stroke patients, and to clarify its predictive value for long-term outcomes post stroke. Studies are also needed that investigate proactive coping in partners of stroke patients.

Next, research is needed to develop a better classification system of coping strategies, in order to include proactive coping. A further subdivision may be needed within the category of proactive coping, just as subcategories exist within the category of reactive coping strategies (e.g. active coping, palliative coping, and seeking social support).

\section{Conclusion}

To conclude, the studies in this thesis found positive associations between proactive coping and psychosocial outcomes among stroke patients, so proactive coping might be an appropriate target for stroke-specific self-management interventions. Despite our finding that our group-based, self-management intervention 'Plan Ahead!' was not more effective than a regular education intervention, teaching proactive coping strategies to stroke patients and partners is not necessarily an inappropriate approach. Rather, it points at our lack of knowledge about the influence of contextual and personal factors on the effectiveness of selfmanagement interventions such as ours. Filling this knowledge gap will be no simple task, but if it can unlock the potential of proactive coping for stroke patients and their partners, the effort will certainly by worthwhile. 



\section{References}


1. Vaartjes I, Van Dis I, VissserenFLJ, Bots ML. Hart-en vaatziekten in Nederland 2010. Den Haag: Nederlandse Hartstichting; 2010.

2. Eyck A, Peerenboom, P. Revalidatie in Nederland: De grenzen van AWBZ en ZVW. Leusden: ETC Tangram; 2006.

3. Mayo NE, Wood-Dauphinee S, Carlton R, Durcan L, Carlton J. Activity, participation, and quality of life 6 months poststroke. Arch. Phys. Med. Rehabil. 2002; 83: 1035-42.

4. Duncan PW, Samsa GP, Weinberger M, Goldstein L, Bonito A, Witter DM, et al. Health status of individuals with mild stroke. Stroke. 1997; 28: 740-5.

5. Godwin KM, Ostwald SK, Cron SG, Wasserman J. Long-term health-related quality of life of stroke survivors and their spousal caregivers. J. Neurosci. Nurs. 2013; 45: 147-54.

6. Darlington AS, Dippel DWJ, Ribbers GM, Van Balen R, Passchier J, Busschbach JJV. A prospective study on coping strategies and quality of life in patients after stroke, assessing prognostic relationships and estimates of cost-effectiveness. J. Rehabil. Med. 2009; 41: 237-41.

7. White CL, Poissant L, Coté-LeBlanc G, Wood-Dauphinee S. Long-term caregiving after stroke: the impact on caregivers' quality of life. J. Neurosci. Nurs. 2006; 38: 354-60.

8. Haley WE, Roth DL, Kissela B, Perkins M, Howard G. Quality of life after stroke: a prospective longitudinal study. Qual. Life Res. 2011; 20: 799-806.

9. Watkins CL, Leathley MJ, Gregson JM, Moore AP, Smith TL, Sharma AK. Prevalence of spasticity post stroke. Clin. Rehabil. 2002; 16: 515-22.

10. Sommerfeld DK, Eek EUB, Svensson AK, Holmqvist LW, Von Arbin MH. Spasticity after stroke: Its occurrence and association with motor impairments and activity limitations. Stroke. 2004; 35: 134-9.

11. Warlow C, Van Gijn J, Dennis M, Wardlaw J, Bamford J, Hankey G, et al. Stroke: Practical Management. 3rd ed. Malden: Blackwell Publishing, 2008.

12. Cumming TB, Marshall RS, Lazar RM. Stroke, cognitive deficits, and rehabilitation: Still an incomplete picture. Int. J. Stroke 2013; 8: 38-45.

13. Beusmans G, Van Noortwijk-Bonga $\mathrm{H}$, Risseeuw N, Tjon-A-Tsien M, Verstappen W, Burgers J, et al. NHG-Standaard Beroerte. Huisarts Wet. 2013; 56: 626-38. 
14. O'Brien AN, Wolf TJ. Determining work outcomes in mild to moderate stroke survivors. Work 2010; 36: 441-7.

15. Hommel M, Trabucco-Miguel S, Joray S, Naegele B, Gonnet N, Jaillard A. Social dysfunctioning after mild to moderate first-ever stroke at vocational age. J. Neurol. Neurosurg. Psychiatry 2009; 80: 371-5.

16. Carlsson GE, Forsberg-Wärleby G, Möller A, Blomstrand C. Comparison of life satisfaction within couples one year after a partner's stroke. J. Rehabil. Med. 2007; 39: 219-24.

17. Darlington AS, Dippel DWJ, Ribbers GM, Van Balen R, Passchier J, Busschbach JJV. Coping strategies as determinants of quality of life in stroke patients: a longitudinal study. Cerebrovasc. Dis. 2007; 23: 401-7.

18. Gosman-Hedström G, Claesson L, Blomstrand, C. Consequences of severity at stroke onset for health-related quality of life (HRQL) and informal care: A 1-year follow-up in elderly stroke survivors. Arch. Gerontol. Geriatr. 2008; 47: 79-91.

19. Struijs JN, Van Genugten MLL, Evers SMAA Ament AJHA, Baan CA, Van den Bos GAM. Modeling the future burden of stroke in the Netherlands: Impact of aging, smoking, and hypertension. Stroke. 2005; 36: 1648-55.

20. Rochette A, Desrosiers J, Bravo G, St-Cyr-Tribble D, Bourget A. Changes in participation after a mild stroke: quantitative and qualitative perspectives. Top. Stroke Rehabil. 2007; 14: 59-68.

21. Visser-Meily A, Post M, Gorter JW, Van Berlekom SB, Van den Bos T, Lindeman E. Rehabilitation of stroke patients needs a family-centred approach. Disabil. Rehabil. 2006; 28: 1557-61.

22. Kerr SM, Smith LN. Stroke: an exploration of the experience of informal caregiving. Clin. Rehabil. 2001; 15: 428-36.

23. Draper $P$, Brocklehurst $H$. The impact of stroke on the well-being of the patient's spouse: an exploratory study. J. Clin. Nurs. 2007; 16: 264-71.

24. Visser-Meily A, Post M, Van de Port I., Van Heugten C, Van den Bos, T. Psychosocial functioning of spouses in the chronic phase after stroke: improvement or deterioration between 1 and 3 years after stroke? Patient Educ. Couns. 2008; 73: 153-8. 
25. Barlow J, Wright C, Sheasby J, Turner A, Hainsworth J. Self-management approaches for people with chronic conditions: a review. Patient Educ. Couns. 2002; 48: 177-87.

26. Wood, J. P., Connelly, D. M. \& Maly, M. R. "Getting back to real living": A qualitative study of the process of community reintegration after stroke. Clin. Rehabil. 2010; 24: 1045-56.

27. Huijbregts M., Myers A, Streiner D, Teasell R. Implementation, process, and preliminary outcome evaluation of two community programs for persons with stroke and their care partners. Top. Stroke Rehabil. 2008; 15: 503-20.

28. Johnston M, Bonetti D, Joice S, Pollard B, Morrison V, Francis JJ, et al. Recovery from disability after stroke as a target for a behavioural intervention: results of a randomized controlled trial. Disabil. Rehabil. 2007; 29: 1117-27.

29. Jones F, Mandy A, Partridge C. Changing self-efficacy in individuals following a first time stroke: preliminary study of a novel self-management intervention. Clin Rehab 2009: 23; 522-33.

30. Kendall E, Catalano T, Kuipers P, Posner N, Buys N, Charker J. Recovery following stroke: the role of self-management education. Soc. Sci. Med. 2007; 64: 735-46.

31. Carlsson G, Möller A, Blomstrand C. A qualitative study of the consequences of "hidden dysfunctions" one year after a mild stroke in persons $<75$ years. Disabil. Rehabil. 2004; 26: 1373-80.

32. Lazarus RS, Folkman S. Stress, appraisal and coping. New York: Springer, 1984.

33. Thoolen BJ, De Ridder D, Bensing J, Gorter K, Rutten G. Beyond good intentions: The role of proactive coping in achieving sustained behavioural change in the context of diabetes management. Psychol. Health 2009; 24 : 237-54.

34. Bode C, De Ridder DTD, Kuijer RG, Bensing JM. Effects of an intervention promoting proactive coping competencies in middle and late adulthood. Gerontologist 2007; 47: 42-51.

35. Aspinwall LG, Taylor SE. A stitch in time: Self-regulation and proactive coping. Psychol. Bull. 1997; 121: 417-36. 
36. Van Mierlo ML, Van Heugten CM, Post MWM, Lindeman E, De Kort PLM, Visser-Meily JMA. A longitudinal cohort study on quality of life in stroke patients and their partners: Restore4Stroke Cohort. Int. J. Stroke 2014; 9 , 148-54.

37. Kootker JA, Fasotti L, Rasquin SM, Van Heugten CM, Geurts AC. The effectiveness of an augmented cognitive behavioural intervention for poststroke depression with or without anxiety (PSDA): the Restore4StrokePSDA trial. BMC Neurol. 2012; 12: 51.

38. Tielemans NS, Visser-Meily JMA, Schepers VPM, Post MWM, Wade DT, Van Heugten CM. Study protocol of the Restore4Stroke self-management study: a multicenter randomized controlled trial in stroke patients and their partners. Int. J. Stroke. 2014; 9: 818-23.

39. Van Eeden M, Van Heugten CM, Evers SMAA. The economic impact of stroke in The Netherlands: the €-Restore4Stroke study. BMC Public Health. 2012; 12: 122.

40. Sarti C, Stegmayr B, Tolonen H, Mähönen M, Tuomilehto J, Asplund K. Are changes in mortality from stroke caused by changes in stroke event rates or case fatality? Results from the WHO MONICA Project. Stroke. 2003; 34: 1833-40.

41. United Nations. World population ageing 2009. New York: United Nations, 2009.

42. Rochette A, Bravo G, Desrosiers J, St-Cyr Tribble D, Bourget A. Adaptation process, participation and depression over six months in first-stroke individuals and spouses. Clin. Rehabil. 2007; 21: 554-62.

43. Folkman S, Lazarus RS. An Analysis of Coping in a Middle-Aged Community Sample. 2014; 21: 219-39.

44. Wolters G, Stapert S, Brands I, Van Heugten C. Coping styles in relation to cognitive rehabilitation and quality of life after brain injury. Neuropsychol. Rehabil. 2010; 20: 587-600.

45. Schwarzer R. Tenacious goal pursuits and striving toward personal growth: Proactive coping. In: Frydenberg E, editor. Beyond coping: Meeting goals, visions and challenges. London: Oxford University Press, 2002. p. 19-35. 
46. Forster A, Brown L, Smith J, House A, Knapp P, Wright JJ. et al. Information provision for stroke patients and their caregivers. Cochrane Database Syst Rev. 2012; 11: CD001919.

47. Lennon S, McKenna S, Jones F. Self-management programmes for people post stroke: a systematic review. Clin. Rehabil. 2013; 27: 867-78.

48. Bode C, Thoolen B, De Ridder D. Het meten van proactieve copingvaardigheden: Psychometrische eigenschappen van de Utrechtse Proactieve Coping Competentie lijst (UPCC). Psychol. Gezondh. 2008; 36: 81-91.

49. Visser-Meily A, Meijer R. Beslishulp beroerte: Testset voor het bepalen van het zorgpad voor mensen met een beroerte in de ziekenhuisfase. Hilversum: Mewadruk, 2010.

50. Collin C, Wade DT, Davies S, Horne V. The Barthel ADL Index : a reliability study. Int Disabil Stud. 1988; 10: 61-3.

51. Schreurs PJG, Van de Willege G, Brosschot JF, Tellegen B, Graus GMH. De Utrechtse Coping Lijst: UCL Omgaan met problemen en gebeurtenissen. Utrecht: Swets en Zeitlinger, 1993.

52. Post MWM, Boosman H, Van Zandvoort MM, Passier PECA Rinkel GJE, Visser-Meily JMA. Development and validation of a short version of the Stroke Specific Quality of Life Scale. J. Neurol. Neurosurg. Psychiatry 2011; 82: 283-6.

53. Aben L, Busschbach JJV, Ponds RWHM, Ribbers GM. Memory selfefficacy and psychosocial factors in stroke. J. Rehabil. Med. 2008; 40: 681-3.

54. Bulmer MG. Principles of statistics. New York: Dover Publications, 1979.

55. Terwee CB, Bot SDM, De Boer MR, Van der Windt DA, Knol DL, Dekker $\mathrm{J}$, et al. Quality criteria were proposed for measurement properties of health status questionnaires. J. Clin. Epidemiol. 2007; 60: 34-42.

56. Visser-Meily, JMA, Post MWM, Riphagen II, Lindeman E. Measures used to assess burden among caregivers of stroke patients: a review. Clin. Rehabil. 2004; 18: 601-23.

57. Wade DT, Hewer RL. Functional abilities after stroke: measurement, natural history and prognosis. J. Neurol. Neurosurg. Psychiatry 1987; 50: 177-82. 
58. Donnellan C, Hevey D, Hickey A, O’Neill D. Defining and quantifying coping strategies after stroke: a review. J. Neurol. Neurosurg. Psychiatry 2006; 77: 1208-18.

59. Skinner EA, Edge K, Altman J, Sherwood H. Searching for the structure of coping: A review and critique of category systems for classifying ways of coping. Psychol. Bull. 2003; 129: 216-69.

60. Feigin VL, Forouzanfar MH, Krishnamurthi R, Mensah GA, Connor M, Bennett DA, et al. Global and regional burden of stroke during 1990-2010: findings from the Global Burden of Disease Study 2010. Lancet 2014; 383: 245-55.

61. Vaartjes I, O’Flaherty M, Capewell S, Kappelle J, Bots M. Remarkable decline in ischemic stroke mortality is not matched by changes in incidence. Stroke. 2013; 44: 591-7.

62. Vaartjes I, Reitsma JB, De Bruin A, Berger-Van Sijl M, Bos MJ, Breteler MMB, et al. Nationwide incidence of first stroke and TIA in the Netherlands. Eur. J. Neurol. 2008; 15: 1315-23.

63. Van Exel NJA, Koopmanschap MA, Scholte op Reimer W, Niessen LW, Huijsman R. Cost-effectiveness of integrated stroke services. QJM 2005; 98: 415-25.

64. Brands IMH, Wade DT, Stapert SZ, Van Heugten CM. The adaptation process following acute onset disability: an interactive two-dimensional approach applied to acquired brain injury. Clin. Rehabil. 2012; 26: 840-52.

65. Folkman S, Lazarus R, Gruen R, DeLongis A. Appraisal, coping, health status, and psychological symptoms. J. Pers. Soc. Psychol. 1986; 3: 571-9.

66. Tielemans NS, Visser-Meily JMA, Schepers VPM, Post MWM, Van Heugten CM. Proactive coping poststroke: psychometric properties of the Utrecht Proactive Coping Competence Scale. Arch. Phys. Med. Rehabil. 2014; 95, 670-5.

67. Bandura A. Self-efficacy: Toward a unifying theory of behavioral change. Psychol. Rev. 1977; 84: 191-215.

68. Luszczynska A, Schwarzer R, Lippke S, Mazurkiewicz M. Self-efficacy as a moderator of the planning-behaviour relationship in interventions designed to promote physical activity. Psychol. Health 2011; 26: 151-66. 
69. Middleton J, Craig A. Psychological challenges in treating persons with spinal cord injury. In: Craig A, Tran Y, editors. Psychological Aspects Associated with Spinal Cord Injury Rehabilitation: New Directions and Best Evidence. New York: Science Publishers, 2008.

70. Post MWM. Van der Zee CH, Hennink J, Schafrat CG, Visser-Meily JMA, Van Berlekom SB. Validity of the utrecht scale for evaluation of rehabilitationparticipation. Disabil. Rehabil. 2012; 34: 478-85.

71. Scholz U, Dona BG, Su S, Schwarzer R. Is General Self-Efficacy a universal construct? Eur. J. Psychol. Assess. 2002; 18: 242-51.

72. Van der Zee CH, Kap A, Rambaran Mishre R, Schouten EJ, Post MWM. Responsiveness of four participation measures to changes during and after outpatient rehabilitation. J. Rehabil. Med. 2011; 43: 1003-9.

73. Sagen U, Vik TG, Moum T, Mørland T, Finset A, Dammen T. Screening for anxiety and depression after stroke: comparison of the hospital anxiety and depression scale and the Montgomery and Asberg depression rating scale. J. Psychosom. Res. 2009; 67: 325-32.

74. Spinhoven PH, Ormel J, Sloekers PPA, Kempen GIJM, Speckens AEM, Van Hemert AM. A validation study of the Hospital Anxiety and Depression Scale (HADS) in different groups of Dutch subjects. Psychol. Med. 1997; 27: 363-70.

75. Post MW, Van Leeuwen CM, Van Koppenhagen CF, De Groot S. Validity of the Life satisfaction questions, the life satisfaction questionnaire, and the satisfaction with life scale in persons with spinal cord injury. Arch. Phys. Med. Rehabil. 2012; 93: 1832-7.

76. Nasreddine ZS, Phillips NA, Bédirian V, Charbonneau S, Whitehead V, Collin I. et al. The Montreal Cognitive Assessment, MoCA: A Brief Screening. J. Am. Geriatr. Soc.2005; 53: 695-9.

77. Baron RM, Kenny DA. The moderator-mediator variable distinction in social psychological research: Conceptual, strategic, and statistical considerations. J. Pers. Soc. Psychol. 1986; 51: 1173-82.

78. Van Leeuwen CMC, Post MWM, Van Asbeck FW, Bongers-Janssen HMH, Van der Woude LH, De Groot S, et al. Life satisfaction in people with spinal cord injury during the first five years after discharge from inpatient rehabilitation. Disabil. Rehabil. 2012; 34: 76-83. 
79. Weldam SWM, Lammers J-WJ, Decates RL, Schuurmans MJ. Daily activities and health-related quality of life in patients with chronic obstructive pulmonary disease: psychological determinants: a cross-sectional study. Health Qual. Life Outcomes 2013; 11: 190.

80. Peter C, Müller R, Post MWM, Van Leeuwen CMC, Werner CS, Geyh S. Psychological resources, appraisals, and coping and their relationship to participation in spinal cord injury: a path analysis. Arch. Phys. Med. Rehabil. 2014; 95: 1662-71.

81. Van Asbeck, F. Handboek dwarlaesierevaliatie. Houten: Bohn Stafleu van Loghum, 2007.

82. Broomfield NM, Scoular A, Welsh P, Walters M, Evans JJ. Poststroke anxiety is prevalent at the population level, especially among socially deprived and younger age community stroke survivors. Int. J. Stroke 2013 Nov 10. doi:10.1111/ijs.12109

83. Carlsson GE, Möller A, Blomstrand C. Consequences of mild stroke in persons < 75 years: A 1-year follow-up. Cerebrovasc. Dis. 2003; 16: 383-8.

84. Planton M, Peiffer S, Albucher JF, Barbeau EJ, Tardy J, Pastor J, et al. Neuropsychological outcome after a first symptomatic ischaemic stroke with "good recovery". Eur. J. Neurol. 2012; 19: 212-9.

85. Rush BK, McNeail RB, Gamble DM, Luke SH, Richie AN, Albers CS, et al. Behavioral symptoms in long-term survivors of ischemic stroke. J. Stroke Cerebrovasc. Dis. 2010; 19: 326-32.

86. Erikson A, Park M, Tham K. Belonging: a qualitative, longitudinal study of what matters for persons after stroke during the one year of rehabilitation. J. Rehabil. Med. 2010; 42: 831-8.

87. O'Halloran J, Miller GC, Britt H. Defining chronic conditions for primary care with ICPC-2. Fam. Pract. 2004; 21: 381-6.

88. Lorig KR, Holman HR. Self-management education: History, definition, outcomes and mechanisms.pdf. Ann Behav Med 2003; 26: 1-7.

89. Bourbeau J, Julien M, Maltais F, Rouleau M, Beaupré A, Bégin R, et al. Reduction of hospital utilization in patients with chronic obstructive pulmonary disease: A disease-specific self-management intervention. Arch Intern Med 2003; 163: 585-91. 
90. Thoolen B, De Ridder D, Bensing J, Gorter K, Rutten G. Beyond Good Intentions: the development and evaluation of a proactive self-management course for patients recently diagnosed with type 2 diabetes. Health Educ. Res. 2008; 23: 53-61.

91. Barlow JH, Turner AP, Wright CC. A randomized controlled study of the Arthritis Self-Management Programme in the UK. Health Educ Res 2000; 15: 665-80.

92. Cadilhac DA, Hoffmann S, Kilkenny M, Lindley R, Lalor E, Osborne RH, et al. A phase II multicentered, single-blind, randomized, controlled trial of the stroke self-management program. Stroke. 2011; 42: 1673-9.

93. Van der Zee CH, Priesterbach AR, Van der Dussen L, Kap A, Schepers VPM, Visser-Meily JMA, et al. Reproducibility of three self-report participation measures: The ICF Measure of Participation and Activities Screener, the Participation Scale, and the Utrecht Scale for Evaluation of Rehabilitation-Participation. J. Rehabil. Med. 2010; 42: 752-7.

94. Wilson BA, Alderman N, Burgess PW, Emslie H, Evans JJ. Behavioural Assessment of the Dysexecutive Syndrome (BADS). J Occup Psychol Employ Disabil 2003; 5: 33-7.

95. Van Heugten C, Rasquin S, Winkens I, Beusmans G, Verhey F. Checklist for cognitive and emotional consequences following stroke (CLCE-24): development, usability and quality of the self-report version. Clin. Neurol. Neurosurg. 2007; 109: 257-62.

96. Al-Janabi H, Frew E, Brouwer W, Rappange D, Van Exel J. The inclusion of positive aspects of caring in the Caregiver Strain Index: tests of feasibility and validity. Int. J. Nurs. Stud. 2010; 47: 984-93.

97. Krabbe PFM, Stouthard MEA, Essink-Bot M-L, Bonsel GJ. The Effect of adding a cognitive dimension to the EuroQol multiattribute healthstatus classification system. J. Clin. Epidemiol. 1999; 52: 293-301.

98. Van Koppenhagen CF, Post MW Van der Woude LH, De Groot S, De Witte LP, Van Asbeck FW, et al. Recovery of life satisfaction in persons with spinal cord injury during inpatient rehabilitation. Am. J. Phys. Med. Rehabil. 2009; 88: 887-95.

99. Jones SR, Carley S, Harrison M. An introduction to power and sample size estimation. Emerg Med J. 2003; 20: 453-8. 
100. White MA, Johnstone AS. Recovery from stroke: does rehabilitation counselling have a role to play? Disabil. Rehabil. 2000; 22: 140-3.

101. Slatin C, Galizzi M, Mawn B, Melillo K. D. Conducting Interdisciplinary Research to Promote Healthy Care and Safe Employment in Health Care: Promises and Pitfalls. Public Health Rep. 2004; 119: 60-72.

102. Newman S, Steed L Mulligan K. Self-management interventions for chronic illness. Lancet 2004; 364: 1523-37.

103. Wagner EH, Austin BT, Davis C, Hindmarsh M, Schaefer J, Bonomi A. improving chronic illness care: Translating evidence into action. Health Aff. 2001; 20: 64-78.

104. Jones F, Riazi A, Norris M. Self-management after stroke: time for some more questions? Disabil. Rehabil. 2013; 35: 257-64.

105. Hegel MT, Dietrich AJ, Seville JL, Jordan CB. Training residents in problemsolving treatment of depression: A pilot feasibility and impact study. Fam. Med. 2004; 36: 204-8.

106. Lundahl B, Moleni T, Burke BL, Butters R, Tollefson D, Butler, et al. Motivational interviewing in medical care settings: a systematic review and meta-analysis of randomized controlled trials. Patient Educ. Couns. 2013; 93: 157-68.

107. Robinson RG, Jorge RE, Moser DJ, Acion L Solodkin A, Small SL, et al. Escitalopram and problem-solving therapy for prevention of poststroke depression. JAMA 2008; 299: 2391- 400.

108. Watkins CL, Wathan JV, Leathley MJ, Auton MF, Deans CF, Dickinson HA, et al. The 12-month effects of early motivational interviewing after acute stroke: a randomized controlled trial. Stroke. 2011; 42: 1956-61.

109. Schwarzer R, Lippke S, Luszczynska A. Mechanisms of health behavior change in persons with chronic illness or disability: the Health Action Process Approach (HAPA). Rehabil. Psychol. 2011; 56: 161-70.

110. Visser-Meily A, Post M, Van de Port I, Maas C, Forstberg-Wärleby G, Lindeman E. Psychosocial functioning of spouses of patients with stroke from initial inpatient rehabilitation to 3 years poststroke: course and relations with coping strategies. Stroke. 2009; 40: 1399-404.

111. Thoolen B, De Ridder D, Bensing J, Rutten G. Geen woorden maar daden: Werkboek. Utrecht: Universiteit Utrecht, 2004. 
112. Thoolen B, De Ridder D, Bensing J, Rutten G. Geen woorden maar daden: Handleiding voor verpleegkundigen. Utrecht: Universiteit Utrecht, 2004.

113. Van Erp J, Schipper K. Aandacht voor draagkracht omgaan met CVA: Een nazorgcursus voor patiënten met CVA en partners. Den Haag: De Nederlandse Hartstichting, 2010.

114. Schipper K, Kessels T, Van Erp J. Aandacht voor draag- kracht: Omgaan met niet-aangeboren hersenletsel. Een nazorginterventie voor getroffenen en naasten. Psychol Gezondh. 2010: 38: 177-82.

115. Sibbel J, Visser-Meily A, Hoekstra J, Ruiter N. Groepsgewijze psychoeducatie voor mensen met licht hersenletsel: Beschrijving van deelnemers en evaluatie. Wet. Tijdscrift voor Ergotherapie 2008: 1; 2-6.

116. Langhorne P, Bernhardt J, Kwakkel G. Stroke rehabilitation. Lancet 2011; 377: 1693-702.

117. Green TL, King KM. Functional and psychosocial outcomes 1 year after mild stroke. J. Stroke Cerebrovasc. Dis. 2010; 19: 10-6.

118. Muren MA, Hütler M, Hooper J. Functional capacity and health-related quality of life in individuals post stroke. Top. Stroke Rehabil. 2008; 15: 51-8.

119. Berg IK, De Jong P. De kracht van oplossingen: Handwijzer voor oplossingsgerichte gesprekstherapie. Amsterdam: Pearson Assessment and Information, 2004.

120. Lucas SE, Fleming JM. Interventions for improving self-awareness following acquired brain injury. Aust. Occup. Ther. J. 2005; 52: 160-70.

121. Leach E, Cornwell P, Fleming J, Haines T. Patient centered goal-setting in a subacute rehabilitation setting. Disabil. Rehabil. 2010; 32: 159-72.

122. Sugavanam T, Mead G, Bulley C, Donaghy M, Van Wijck F. The effects and experiences of goal setting in stroke rehabilitation: A systematic review. Disabil. Rehabil. 2013; 35, 177-90.

123. Koestner R, Otis N, Powers TA, Pelletier L, Gagnon H. Autonomous motivation, controlled motivation, and goal progress. J. Pers. 2008; 76: 1201-30.

124. Lynch EB, Butt Z, Heinemann A, Victorson D, Nowinski CJ, Perez L, et al. A qualitative study of quality of life after stroke: the importance of social relationships. J. Rehabil. Med. 2008; 40: 518-23. 
125. Wade DT. Goal setting in rehabilitation: an overview of what, why and how. Clin. Rehabil. 2009; 23: 291-5.

126. Geusgens CAV, Winkens I, Van Heugten CM, Jolles J, Van den Heuvel WJA. Occurrence and measurement of transfer in cognitive rehabilitation: A critical review. J. Rehabil. Med. 2007; 39: 425-39.

127. Fleig L, Pomp S, Schwarzer R, Lippke S. Promoting exercise maintenance: how interventions with booster sessions improve long-term rehabilitation outcomes. Rehabil. Psychol. 2013; 58: 323-33.

128. White JH, Magin P, Attia J, Sturm J, Carter G, Pollack M. Trajectories of psychological distress after stroke. Ann Fam Med. 2012; 10: 435-42.

129. Boger EJ, Demain SH, Latter SM. Stroke self-management: A focus group study to identify the factors influencing self-management following stroke. Int. J. Nurs. Stud. 2015; 52: 175-87.

130. Tielemans NS, Schepers VPM, Visser-Meily JMA, Van Erp J, Eijkenaar M, Van Heugten CM. The Restore4Stroke self-management intervention "Plan ahead!": rationale and description of the treatment protocol based on proactive action planning. Clin. Rehabil. 2014; 28: 530-40.

131. Linnan L, Steckler A. Process evaluation for public health interventions and research: An overview. In Steckler A, Linnan L, editors. Process Evaluation for Public Health Interventions and Research. San Francisco CA: JosseyBass, 2002. p.1-23.

132. Hulscher MEJL. Process evaluation on quality improvement interventions. Qual. Saf. Heal. Care. 2003; 12: 40-6..

133. Craig P, Dieppe P, Macintyre S, Michie S, Nazareth I, Petticrew M. Developing and evaluating complex interventions: The new Medical Research Council guidance. Int. J. Nurs. Stud. 2013; 50: 587-92.

134. Leontjevas R, Gerritsen DL, Koopmans RTCM, Smalbrugge M, VernooijDassen MJFJ. Process evaluation to explore internal and external validity of the "Act in Case of Depression" care program in nursing homes. J. Am. Med. Dir. Assoc. 2012; 13: 488.e1-8.

135. Saunders RP, Evans MH, Joshi P. Developing a process-evaluation plan for assessing health promotion program implementation: a how-to guide. Health Promot. Pract. 2005; 6: 134-47. 
136. Boeije, H. Analyseren in kwalitatief onderzoek: denken en doen. Den Haag Boom/Lemma, 2005.

137. Kessler D, Dubouloz C-J, Urbanowski R, Egan M. Meaning perspective transformation following stroke: the process of change. Disabil. Rehabil. 2009; 31: 1056-65.

138. Morris R, Morris P. Participants' experiences of hospital-based peer support groups for stroke patients and carers. Disabil. Rehabil. 2012; 34: 347-54.

139. Bulley C, Shiels J, Wilkie K, Salisbury L. Carer experiences of life after stroke - a qualitative analysis. Disabil. Rehabil. 2010; 32: 1406-13.

140. Cameron JI., Naglie G, Silver FL, Gignac MAM. Stroke family caregivers' support needs change across the care continuum: a qualitative study using the timing it right framework. Disabil. Rehabil. 2013; 35: 315-24.

141. Krevers B, Oberg B. Support/services and family carers of persons with stroke impairment: perceived importance and services received. J. Rehabil. Med. 2011; 43: 204-9.

142. Tellier M, Rochette A, Lefebvre H. Impact of mild stroke on the quality of life of spouses. Int. J. Rehabil. Res. 2011; 34: 209-14.

143. Kunst AE, Amiri M, Janssen F. The decline in stroke mortality: exploration of future trends in 7 Western European countries. Stroke. 2011; 42: 212630.

144. Smith J, Forster A, Young J. Cochrane review: information provision for stroke patients and their caregivers. Clin. Rehabil. 2009; 23: 195-206.

145. McKenna S, Jones F, Glenfield P, Lennon S. Bridges self-management program for people with stroke in the community: A feasibility randomized controlled trial. Int. J. Stroke 2013 Nov 21. doi:10.1111/ijs. 12195

146. Robinson BC. Validation of a Caregiver Strain Index. J Gerontol 1983; 38 : 344-8.

147. Kruithof WJ, Post MWM, Visser-Meily JMA. Measuring negative and positive caregiving experiences: A psychometric analysis of the Caregiver Strain Index Expanded. Clin Rehabil 2015 Feb 4.

DOI: $10.1177 / 0269215515570378$

148. Twisk JWR. Applied longitudinal data analysis for epidemiology: A practical guide. Cambrdige: Cambridge University Press, 2013. 
149. Winkens I, Van Heugten CM, Visser-Meily JMA, Boosman H. Impaired self-awareness after acquired brain injury: clinicians' ratings on its assessment and importance for rehabilitation. J. Head Trauma Rehabil. 2014; 29: 153-6.

150. Gross Y, Schutz L. Intervention models in neuropschology. In: Uzzell B, Gross Y,editors. Clinical neuropsychology of intervention. Boston: Martinus-Nijhoff, 1986. p. 179-204.

151. Tielemans NS, Schepers VPM, Visser-Meily JMA, Van Haastregt J, Van Veen W, Van Stralen HE, et al. Process evaluation of the Restore4Stroke self-management intervention "Plan Ahead!" used in a randomised study. Submitted.

152. Norris M, Kilbride C. From dictatorship to a reluctant democracy: stroke therapists talking about self-management. Disabil. Rehabil. 2014; 36: 32-8.

153. Nici L, Bontly TD, Zuwallack R, Gross N. Self-management in chronic obstructive pulmonary disease. Time for a paradigm shift? Ann. Am. Thorac. Soc. 2014; 11: 101-7.

154. Trappenburg J, Jonkman N, Jaarsma T, Van Os-Medendorp H, Kort H, De Wit N, et al. Self-management: one size does not fit all. Patient Educ. Couns. 2013; 92: 134-7.

155. Rocha N, Marques AJ, Queirós C, Rocha S. Proactive coping in schizophrenia: Examining the impact of neurocognitive variables. J. Psychiatr. Ment. Health Nurs. 2014; 21: 471-6.

156. Vinkers CDW, Adriaanse MA, Kroese FM, De Ridder DTD. The role of pretreatment proactive coping skills in successful weight management. Eat. Behav. 2014; 15, 515-8.

157. Green TL, King KM. The trajectory of minor stroke recovery for men and their female spousal caregivers: literature review. J. Adv. Nurs. 2007; 58: 517-31.

158. Wrosch C, Amir E, Miller GE. Goal adjustment capacities, coping, and subjective well-being: the sample case of caregiving for a family member with mental illness. J. Pers. Soc. Psychol. 2011; 100: 934-46.

159. White, J. H. et al. Exploring the experience of post-stroke fatigue in community dwelling stroke survivors: a prospective qualitative study. Disabil. Rehabil. 2012; 34: 1376-84. 
160. Brands, I., Stapert, S., Köhler, S., Wade, D. \& van Heugten, C. Life goal attainment in the adaptation process after acquired brain injury: the influence of self-efficacy and of flexibility and tenacity in goal pursuit. Clin. Rehabil. 2014 Sep 16. doi:10.1177/0269215514549484

161. Van der Zee CH, Visser-Meily JMA, Lindeman E, Kappelle JL, Post MWM. Participation in the chronic phase of stroke. Top. Stroke Rehabil. 2013; 20: 52-61.

162. Lewin A, Jöbges M, Werheid K. The influence of self-efficacy, pre-stroke depression and perceived social support on self-reported depressive symptoms during stroke rehabilitation. Neuropsychol. Rehabil. 2013; 23 : $546-62$.

163. Ajzen I. The theory of planned behavior. Organ. Behav. Hum. Decis. Process. 1991; 50: 179-211.

164. Ralph A, Derbyshire C. Survivors of brain injury through the eyes of the public: A systematic review. Brain Inj. 2013; 27: 1475-91.

165. Levy R, Dubois B. Apathy and the functional anatomy of the prefrontal cortex-basal ganglia circuits. Cereb. Cortex. 2006; 16: 916-28.

166. Prochaska J, Velicer W. The transtheoretical model of health behavior change. Heal. Promot. 1997; 12: 38-48.

167. Wilson BA. Neuropsychological rehabilitation: Theory and practice. Lisse: Swets \& Zeitlinger, 2003.

168. Fischer S, Gauggel S, Trexler LE. Awareness of activity limitations, goal setting and rehabilitation outcome in patients with brain injuries. Brain Inj. 2004; 18: 547-62.

169. Spikman JM, Boelen DHE, Lamberts KF, Brouwer WH, Fasotti, L. Effects of a multifaceted treatment program for executive dysfunction after acquired brain injury on indications of executive functioning in daily life. J. Int. Neuropsychol. Soc. 2010; 16: 118-29.

170. Rutte, M. \& Samson, D. Bruggen Slaan: Regeerakkoord VVD-PvdA. Den Haag: 2012. Available from: http://www.invoeringwmo.nl/sites/default/ files/291012_regeerakkoord[1].pdf

171. Kim JW, Moon SS. Social Work in Health Care Needs of Family Caregivers Caring for Stroke Patients. Soc. Work Health Care. 2007; 45: 37-41. 
172. Korpershoek C, Van der Bijl J, Hafsteinsdóttir TB. Self-efficacy and its influence on recovery of patients with stroke: a systematic review. J. Adv. Nurs. 2011; 67: 1876-94.

173. Gillespie DC, Bowen A, Chung CS, Cockburn J, Knapp P, Pollock

A. Rehabilitation for post-stroke cognitive impairment: an overview of recommendations arising from systematic reviews of current evidence. Clin. Rehabil. 2015; 29: 120-8.

174. Roland M, Torgerson DJ. Understanding Controlled Trials: What Are Pragmatic Trials? BMJ Br. Med. J. 2014; 316: 23-4. 

Summary 
Each year, 45,000 people suffer a stroke in the Netherlands. Approximately $60 \%$ of those who survive a stroke return home after discharge from a hospital or rehabilitation centre. Despite good physical recovery, many of these patients report long-term consequences regarding emotional, behavioural and cognitive functioning. At home, stroke patients and their partners are largely self-responsible for managing the consequences of stroke in daily life themselves. The way they deal with these consequences affects their quality of life, so interventions aimed at enhancing their self-management abilities by teaching them beneficial strategies to deal with these consequences might be appropriate.

The main objective of the work reported on in this thesis was to evaluate the feasibility and effectiveness of a stroke-specific, group-based self-management intervention aimed at enhancing proactive coping strategies in stroke patients and their partners. In addition we investigated the psychometric properties of the Utrecht Proactive Coping Competence scale for stroke patients and the associations between proactive coping and self-efficacy, as well as psychosocial functioning post stroke.

Chapter 1 presents general background information about the consequences of stroke for stroke patients and their partners. The construct of self-management is introduced and findings of earlier stroke-specific self-management interventions are discussed. Subsequently, the concept of proactive coping is introduced and its potential benefit as a target in stroke-specific self-management interventions is explained. Next, the Dutch Restore4Stroke consortium is introduced, in which the current studies are embedded. At the end of the chapter, the aims and outline of the thesis are described. The following research questions were addressed:

1) Is the Utrecht Proactive Coping Competence scale a reliable and valid measure to assess proactive coping strategies in stroke patients?

2) What are the associations between proactive coping and self-efficacy, and psychosocial outcomes post stroke?

3) Is a group-based, stroke-specific self-management intervention aimed at teaching stroke patients and their partners proactive coping strategies feasible and more effective than a group-based, stroke-specific education intervention? 
Chapter 2 describes a study examining the psychometric properties of the Utrecht Proactive Coping Competence scale (UPCC). We investigated the reliability of this scale in terms of internal consistency and convergent validity by examining the correlations between the UPCC and the subscales of the Utrecht Coping List (UCL) for active problem solving, avoidance, expression of emotions, reassuring thoughts, palliative reactions, seeking social support, and passive reactions, using cross-sectional data of 55 stroke patients. We showed that the UPCC had excellent reliability (Cronbach's $\alpha=.95$ ). In addition, convergent validity of this scale for stroke patients was shown by moderate positive relations with the UCL active problem-solving subscale $(\mathrm{r}=.38)$ and moderate negative relations with the UCL subscales on passive reactions $(r=-.50)$, avoidance $(r=-.40)$, and expression of emotions $(r=-.42)$. Therefore, future studies should use this scale when investigating proactive coping by stroke patients. In addition, the findings pointed at the potential importance of enhancing proactive coping strategies in stroke patients, as we found positive associations with overall, psychosocial and physical health-related quality of life as measured with the short Stroke Specific Quality of Life scale $(\mathrm{r}=.48-.61)$. These associations were stronger than with the traditionally investigated coping strategies of active problem solving $(\mathrm{r}=.20-$ $.33)$, avoidance $(\mathrm{r}=-.29--.45)$, passive reactions $(\mathrm{r}=-.43--.51)$, and expression of emotions $(r=-.27--.45)$

Chapter 3 discusses the associations between proactive coping and self-efficacy, and several psychosocial outcomes post stroke. Data for this study was derived from the baseline assessment of 112 stroke patients taking part in the Restore4Stroke Self-Management study, a randomized controlled trial investigating the effectiveness of a 10-week stroke-specific self-management intervention aimed at teaching stroke patients and their partners proactive coping. Proactive coping was measured with the UPCC, and self-efficacy with the General Self Efficacy Scale (GSES). Psychosocial functioning was measured in terms of restrictions of participation using the restrictions subscale of the Utrecht Scale for Evaluation of Rehabilitation-Participation (USER-Participation). In addition, psychosocial functioning was measured in terms of health-related quality of life using the Short Stroke-Specific Quality of Life scale (SS-QOL-12), emotional problems using the Hospital Anxiety and Depression Scale (HADS total), life satisfaction 
using two questions (2LS) and satisfaction using the satisfaction subscale of the USER-Participation scale: these were considered domains reflecting emotional acceptance. We found that proactive coping was not associated with restriction of participation ( $p>.05$ ), while it was associated with psychosocial outcomes related to emotional acceptance of the situation post stroke. That is, higher UPCC scores were associated with lower HADS total scores $(\beta=-.55 ; p<.001)$, and with higher USER-Participation satisfaction scores $(\beta=.31 ; \mathrm{p}=.001)$, 2LS scores $(\beta=.34$; $\mathrm{p}<.001)$, and SS-QOL-12 scores $(\beta=.44 ; \mathrm{p}<.001)$. Furthermore, higher GSES scores were associated with lower HADS total scores $(\beta=-.51 ; \mathrm{p}<.001)$ and with higher 2 LS scores $(\beta=.34 ; p<.001)$, and SS-QOL-12 scores $(\beta=.47 ; p<.001)$. The association between self-efficacy and life satisfaction was fully transmitted through proactive coping. The association of self-efficacy with emotional problems as well as with health-related quality of life turned out to be both direct and transmitted through proactive coping. Self-efficacy did not moderate these associations between proactive coping and the psychosocial outcomes (all p $>.05$ ). This means that the level of self-efficacy did not influence the strength of the association between proactive coping and psychosocial outcomes post stroke. Thus, this study showed that the associations between proactive coping and self-efficacy differ depending on which psychosocial outcome is being studied. Further investigation is needed for a better understanding of the ways in which psychosocial outcomes can be influenced post stroke.

Chapter 4 presents the study protocol of the Restore4Stroke Self-Management study. This multicentre randomized controlled trial evaluated the effectiveness of a 10-week stroke-specific self-management intervention aimed at teaching proactive coping strategies to stroke patients and their partners, by comparing the outcomes of this intervention with the outcomes of a 10-week stroke-specific education intervention. Stroke patients were randomly assigned to either the self-management intervention or the education intervention; partners were allocated to the same group as the patients. The post intervention measurement was performed immediately after completion of the intervention, followed by two follow-up measurements at 3 and 9 months after the end of the intervention. Primary outcome measures were proactive coping, measured with the UPCC, and experienced restriction of participation, measured with the USER-Participation 
restriction among both patients and partners. Secondary outcome measures were caregiver burden measured with the Caregiver Strain Index, disease-specific and generic health-related quality of life and subjective well-being of patients, measured with the EuroQol5D and the SS-QoL-12, patients' and partners' self-efficacy measured with the GSES, the frequency of and satisfaction with participation measured with the USER-Participation satisfaction and frequency subscales, and emotional functioning, measured with the HADS.

Chapter 5 provides a detailed description of the theoretical background, rationale and content of the investigated stroke-specific self-management intervention, called 'Plan Ahead!'. The intervention was developed based on the proactive coping theory, the Health Action Process Approach model, an effective selfmanagement intervention in patients with diabetes type 2, two interventions specifically intended for acquired brain injury patients, and expert consultations. The concept of the treatment protocol was further fine-tuned based on two pilot studies, leading to the addition of solution-based therapeutic techniques. The intervention lasts ten weeks with six two-hour sessions in the first six weeks and a two-hour booster session in the tenth week. The main elements of the intervention are proactive action planning, peer support, and information provision about stroke-specific themes. This intervention is innovative in its focus on changing proactive coping strategies in stroke patients, and considering partners as full participants with their own goals and opportunities.

Chapter 6 describes the findings of the process evaluation study, which investigated if the interventions had been implemented as intended, as well as assessing the involvement and satisfaction of the participants. This evaluation was performed in parallel to the Restore4Stroke Self-Management trial, combining qualitative and quantitative data collected by means of session evaluation forms for therapists, questionnaires for therapists and participants, and focus groups with therapists. In total 53 patients, 26 partners and 19 therapists participated. This study showed that the targeted audience was reached in terms of recruitment and retention. In addition, both participants and therapists were satisfied with the intervention in terms of usefulness, content and structure. However, the implementation of the intervention had not been optimal, in terms of compliance 
to the treatment protocol and engagement of the participants. The sub-optimal implementation of the intervention may have influenced the effectiveness found in the trial.

Chapter 7 presents the outcomes of the randomized controlled trial assessing the effectiveness of the 'Plan Ahead!' self-management intervention, whose design was described in Chapter 4. The effectiveness of our self-management intervention was determined by comparing the outcomes of the intervention with those of an education intervention for stroke patients and their partners. In total, 113 stroke patients and 57 partners participated in this trial. The findings showed that the self-management intervention was not superior to the education intervention, as proactive coping strategies were not significantly enhanced and participation restrictions were not significantly reduced in stroke patients (both p-values $>.0042$ ) and their partners (both p-values $>.05$ ) of the selfmanagement intervention compared to the patients and partners of the education intervention. Nevertheless, some trends towards beneficial effects of the selfmanagement intervention were seen: a positive trend was found in patients' levels of participation restriction(estimated mean difference $6.5 ; \mathrm{p}=.016$ ), as well as significantly higher levels of self-efficacy in partners three months after the intervention was completed (estimated mean difference $2.5 ; \mathrm{p}=.028$ ). We concluded that the intervention should not be implemented in clinical practice in its current form, a conclusion which was further strengthened by the process evaluation (Chapter 6). More research is needed into ways to enhance proactive coping in stroke patients, and into contextual and personal factors influencing the outcomes of interventions such as ours.

Chapter 8 provides a general discussion of the work presented in this thesis. It discusses the main findings of the thesis and provides clinical messages and suggestions for further research. We suggest that the association between proactive coping and emotional acceptance could in fact be the result of the associations between goal adjustment and both of these processes. As such, the association between proactive coping and emotional acceptance might not really exist. However, it could also be that proactively coping with fatigue post stroke results in greater achievement of valued goals and thus greater emotional acceptance 
of the situation, while the restrictions imposed by fatigue on participation stay the same. The studies reported on in this thesis showed that our stroke-specific self-management intervention, 'Plan Ahead!', was not more effective than an education intervention for patients and their partners. This result may have been caused by the fact that we compared with an education intervention, rather than with care as usual or a waiting control condition, as other studies have done. Another possibility is that personal factors of participants, such as their intrinsic motivation to change their behaviour or their levels of self-efficacy, may have affected the effectiveness found in our study. In addition, stroke-specific factors such as cognitive impairments and reduced self-awareness could have reduced the effectiveness of the intervention in our trial. An important clinical message of this thesis is therefore that although our intervention appeared to offer no added value in terms of effectiveness, it is too early to abandon proactive coping as a target of stroke-specific self-management interventions. Instead more research is needed on the influence of personal, contextual and therapeutic-related factors influencing the outcomes of interventions such as ours, in order to allow a wellfounded decision to be made on this matter. 

Samenvatting 
Elk jaar krijgen in Nederland zo'n 45.000 mensen een beroerte, ook wel CVA (Cerebro Vasculair Accident) genoemd. Ongeveer 60\% van hen keert na opname in het ziekenhuis of revalidatiecentrum terug naar huis omdat zij fysiek relatief goed herstellen. Deze mensen rapporteren echter vaak blijvende gevolgen van de beroerte in het cognitief, emotioneel, gedragsmatig en/ of sociaal functioneren, waardoor een beroerte kan worden gezien als een chronische aandoening. Eenmaal thuis zijn patiënten en partners grotendeels zelf verantwoordelijk voor het omgaan met deze gevolgen in hun dagelijks leven. Het vermogen om te kunnen gaan met de gevolgen van een chronische conditie zoals een beroerte wordt zelfmanagement genoemd. Om het vermogen tot zelfmanagement van mensen met een beroerte te bevorderen zou het zinvol kunnen zijn om hen strategieën aan te leren die hen hierbij helpen.

Het belangrijkste doel van het in dit proefschrift beschreven onderzoek was om de haalbaarheid en effectiviteit van een groepsgewijze, zelfmanagement interventie te onderzoeken die speciaal was ontwikkeld voor mensen die een beroerte hadden gehad en hun partners. Doel van deze interventie is om het gebruik van proactieve coping strategieën te bevorderen bij deze doelgroep. Met proactieve coping wordt bedoeld: de inspanningen die iemand verricht om een toekomstige probleem situatie te voorkomen, of om de negatieve gevolgen van deze toekomstige probleem situatie reeds te verminderen. Het onderzoek in dit proefschrift maakte deel uit van het Restore4Stroke revalidatieonderzoeksprogramma.

Hoofdstuk 1 is een algemene inleiding waarin we de gevolgen van een beroerte voor zowel mensen die een beroerte hadden gehad als hun partners beschrijven. Ook introduceren we de concepten 'zelfmanagement' en 'proactieve coping', en de bevindingen van eerdere studies naar effectiviteit van beroertespecifieke zelfmanagement interventies. De volgende onderzoekvragen worden in het proefschrift besproken:

1) Is de Utrechtse Proactieve Coping Competentie lijst een betrouwbaar en valide meetinstrument om proactieve coping strategieën in mensen met een beroerte te meten?

2) Wat zijn de associaties tussen proactieve coping en persoonlijke effectiviteit, en psychosociaal functioneren in mensen met een beroerte? 
3) Is een groepsgewijze, beroerte-specifieke zelfmanagement interventie gericht op het leren van proactieve coping strategieën aan mensen met een beroerte en hun partners haalbaar en effectiever dan een groepsgewijze beroertespecifieke educatie interventie?

In Hoofdstuk 2 beschrijven we een studie naar de psychometrische eigenschappen van de Utrechtse Proactieve Coping Competentie lijst (UPCC) bij patiënten met een beroerte. In deze studie onderzochten we de betrouwbaarheid van deze schaal in termen van interne consistentie en convergente validiteit. We toonden aan dat de UPCC een uitstekende betrouwbaarheid heeft (Cronbach's $\alpha=.95$ ). Daarnaast werd de convergente validiteit van deze schaal aangetoond middels matige, positieve relaties met de Utrechtse Coping Lijst subschalen actief aanpakken $(r=.38)$ en matige, negatieve relaties met de subschalen passief reactiepatroon $(r=-.50)$, vermijden $(r=-.40)$ en expressie van emoties $(r=-.42)$. Op basis van deze resultaten raden wij toekomstige onderzoekers aan om deze schaal te gebruiken wanneer men proactieve coping wil meten bij mensen met een beroerte. Daarnaast wijzen onze resultaten op het mogelijke belang van het bevorderen van proactieve coping bij mensen met een beroerte, aangezien we positieve associaties vonden tussen proactieve coping en algemene, psychosociale en fysieke gezondheidsgerelateerde kwaliteit van leven gemeten met de Stroke Specific Quality of Life schaal ( $r=.48-.61)$.

In Hoofdstuk 3 bespreken we de associaties tussen proactieve coping, persoonlijke effectiviteit en verscheidene psychosociale uitkomsten na een beroerte. Data voor deze studie was afkomstig van de eerste meting van de 112 mensen met een beroerte die deelnamen aan de Restore4Stroke Zelfmanagement studie: een gerandomiseerde, gecontroleerde studie naar de effectiviteit van een 10-weekse, beroerte-specifieke zelfmanagement interventie gericht op het bevorderen van proactieve coping strategieën bij mensen met een beroerte en hun partners (zie hoofdstuk 7). In deze studie vonden we dat proactieve coping niet was geassocieerd met ervaren restricties in participatie $(\mathrm{p}>.05)$, terwijl het wel was geassocieerd met alle psychosociale uitkomsten die emotionele acceptatie van de situatie na de beroerte reflecteerden (i.e. participatie satisfactie, kwaliteit van leven, stemming en levenssatisfactie). Daarnaast waren hogere persoonlijke effectiviteitsscores 
geassocieerd met lagere stemming scores en met lagere satisfactie en kwaliteit van leven scores( $\mathrm{p}<.001)$. De associatie tussen persoonlijke effectiviteit en levenssatisfactie was indirect, aangezien deze associatie volledig verliep via proactieve coping. De associatie van persoonlijke effectiviteit met zowel stemming als kwaliteit van leven was zowel direct als indirect via proactieve coping. Het niveau van persoonlijke effectiviteit beïnvloedde niet de sterkte van de relatie tussen proactieve coping en psychosociale uitkomsten na een beroerte. Dus met deze studie toonden we aan dat de associaties tussen proactieve coping en persoonlijke effectiviteit niet hetzelfde zijn voor alle psychosociale uitkomsten van onze studie. En dus dat proactieve coping en persoonlijke effectiviteit mogelijk elk als andere aangrijpingspunten kunnen dienen voor behandeling. Om meer zicht te krijgen op de manieren waarop psychosociale uitkomsten kunnen worden beïnvloed na een beroerte is meer onderzoek nodig.

In Hoofdstuk 4 presenteren we het studie protocol van de Restore4Stroke Zelfmanagement studie. Met dit multicenter, gerandomiseerd gecontroleerde onderzoek evalueerden we de effectiviteit van een 10-weekse, beroerte-specifieke zelfmanagement interventie gericht op het bevorderen van proactieve coping strategieën van mensen met een beroerte en hun partners. We onderzochten dit door de effectiviteit van de zelfmanagement interventie te vergelijken met een 10 -weekse, beroerte-specifieke educatie interventie. Na het eerste meetmoment werden mensen met een beroerte willekeurig toegewezen aan ofwel de zelfmanagement interventie, ofwel de educatie interventie. Partners van deze mensen werden toegewezen aan dezelfde interventie als de persoon met de beroerte. Na de interventie werden metingen verricht direct, en na 3 en 9 maanden na het einde van de interventie.

Als primaire uitkomstmaten in deze studie kozen we voor (1) proactieve coping gemeten met de UPCC, en (2) de ervaren beperkingen in participatie gemeten met de USER-Participatie restrictie subschaal. Secundaire uitkomstmaten waren (1) de ervaren belasting door de partner gemeten met de Caregiver Strain Index, (2) generieke gezondheidsgerelateerde kwaliteit van leven gemeten met de SS-QOL-12, (3) levenssatisfactie gemeten met de 2LS, (4) ziekte-specifieke gezondheidsgerelateerde kwaliteit van leven van mensen met een beroerte en hun partners gemeten met de EuroQoL5D, (5) persoonlijke effectiviteit van mensen 
met een beroerte en hun partners gemeten met de GSES, (6) de frequentie van en satisfactie met participatie van mensen met de beroerte en hun partners gemeten met de satisfactie en restrictie subschalen van de USER-Participatie, en (7) stemming van mensen met een beroerte en hun partners gemeten met de HADS.

In Hoofdstuk 5 geven we een gedetailleerde beschrijving van de theoretische achtergrond, motivering en inhoud van de onderzochte, beroerte-specifieke zelfmanagement interventie, die we ‘Bruggen Slaan'noemden. Bij de ontwikkeling van de interventie baseerden we ons op de proactieve coping theorie, het Health Action Process Approach model, een effectieve zelfmanagement interventie voor mensen met diabetes type 2, twee interventies die speciaal waren ontwikkeld voor mensen met hersenletsel, en consultaties met experts. We verfijnden het conceptbehandelprotocol op grond van twee pilot studies. De belangrijkste verandering was dat we aan therapeuten vroegen om oplossingsgerichte gesprekstechnieken te gaan gebruiken tijdens de interventie. De uiteindelijke interventie duurt 10 weken, waarin 6 sessies van twee uur worden gegeven in de eerste zes weken van de interventie en een opfrissessie in de tiende week van de interventie. De belangrijkste onderdelen van de interventie zijn het opstellen van het proactieve actieplan, lotgenotencontact, en het bieden van informatie over beroertespecifieke thema's. Het vernieuwende aspect van de zelfmanagement interventie is de focus op het bevorderen van proactieve coping strategieën bij mensen met een beroerte en hun partners, en het beschouwen van partners als volwaardige cursisten met eigen doelen en mogelijkheden.

In Hoofdstuk 6 beschrijven we de uitkomsten van onze procesevaluatie studie. In deze studie onderzochten we of de interventie daadwerkelijk was geïmplementeerd zoals wij het hadden bedoeld, en onderzochten we de betrokkenheid en tevredenheid van deelnemers en therapeuten ten aanzien van de interventie. We voerden deze procesevaluatie parallel uit aan de Restore4Stroke Zelfmanagement studie. We verzamelden kwalitatieve en kwantitatieve data voor deze procesevaluatie met sessie evaluatieformulieren voor therapeuten, vragenlijsten voor therapeuten en patiënten en focus groepen met therapeuten. In totaal namen 53 patiënten, 26 partners en 19 therapeuten deel aan de procesevaluatie. We vonden dat tijdens de Restore4Stroke Zelfmanagement studie de beoogde deelnemers waren geworven 
voor de interventie, en dat zij bleven deelnemen aan de interventie. Daarnaast waren zowel deelnemers als therapeuten tevreden over de interventie in termen van het nut van de interventie, en de inhoud en structuur van de interventie. Echter, de implementatie van de interventie was niet optimaal wat betreft de mate waarin het behandelprotocol werd gevolgd en de mate van inzet door deelnemers. Vooral het opstellen van het proactieve actieplan, een belangrijk element van onze interventie, bleek niet altijd te zijn gedaan. Dit zou de uitkomsten van de Restore4Stroke Zelfmanagement studie mede kunnen bepalen.

In Hoofdstuk 7 presenteren we de uitkomsten van de Restore4Stroke Zelfmanagement studie, het gerandomiseerd gecontroleerde onderzoek naar de effectiviteit van de 'Bruggen Slaan' zelfmanagement interventie. De opzet van deze studie was beschreven in Hoofdstuk 4. De effectiviteit van de zelfmanagement interventie werd bepaald door het vergelijken met de uitkomsten van een educatie interventie voor mensen die en beroerte hebben gehad en hun partners. In totaal namen 113 mensen met een beroerte en 57 partners deel aan de studie. Uit de resultaten bleek dat de zelfmanagement interventie niet tot betere uitkomsten leidde dan de educatie interventie. Het was namelijk niet zo dat mensen met een beroerte en hun partners meer proactieve coping strategieën gingen toepassen of minder beperkingen in hun participatie ervoeren na het volgen van de zelfmanagement interventie dan na het volgen van de educatie interventie (alle p-waarden in patiënten $>.0042$ en in partners $>.05)$. Desalniettemin waren er enkele trends zichtbaar in het voordeel van de zelfmanagement interventie. Er was namelijk een positieve trend zichtbaar in het niveau van ervaren restricties in participatie van mensen met een beroerte (geschatte gemiddelde verschil $=6.5$; $\mathrm{p}=.016$ ). Verder was de persoonlijke effectiviteit van partners 3 maanden na de interventie hoger bij partners die de zelfmanagement interventie hadden gevolgd dan bij partners die de educatie interventie hadden gevolgd (geschatte gemiddelde verschil $=2.5 ; \mathrm{p}=.028$ ). Op grond van deze resultaten concludeerden we dat de interventie in zijn huidige vorm niet zou moeten worden geïmplementeerd in de klinische praktijk. Deze conclusie werd verder onderbouwd door de bevindingen van de procesevaluatie, zoals beschreven in Hoofdstuk 6. Meer onderzoek is daarom nodig naar manieren waarop proactieve coping kan worden bevorderd bij mensen met een beroerte, en naar contextuele en persoonlijke factoren die de uitkomsten van interventies zoals de onze beïnvloeden. 
In Hoofdstuk 8 presenteren we een algemene discussie over het onderzoek zoals gepresenteerd in dit proefschrift. Allereerst worden de hoofdbevindingen van het proefschrift besproken. Op grond van deze resultaten hebben we klinische boodschappen en suggesties voor verder onderzoek geformuleerd.

De door ons beschreven studies in dit proefschrift lieten zien dat de door ons ontwikkelde beroerte-specifieke zelfmanagement interventie 'Bruggen slaan' niet effectiever was dan een educatie interventie voor mensen die een beroerte hadden gehad en hun partners. Mogelijk kan dit resultaat worden verklaard door het feit dat we onze zelfmanagement interventie vergelijken met een educatie interventie in plaats van met de gebruikelijke zorg, zoals in andere studies wel is gedaan. Een andere mogelijkheid is dat persoonlijke factoren van deelnemers, zoals bijvoorbeeld intrinsieke motivatie om hun gedrag te veranderen of hun persoonlijke effectiviteit, de effectiviteit van onze zelfmanagement interventie hebben beïnvloed. Ook kan het zijn dat beroerte-specifieke factoren, zoals de cognitieve gevolgen van een beroerte en verminderd zelfinzicht, de effectiviteit van onze zelfmanagement interventie hebben verminderd.

Een belangrijke klinische boodschap van dit proefschrift is daarom dat proactieve coping niet moet worden losgelaten als aangrijpingspunt voor beroertespecifieke zelfmanagement interventies. In plaats daarvan zou er meer onderzoek moeten komen naar de invloed van persoonlijke, contextuele en therapeutische factoren die de uitkomsten van interventies zoals de onze beïnvloeden. Immers, alleen met deze informatie kan een goed gefundeerde keuze worden gemaakt. 



\section{Valorization}




\section{Relevance}

A stroke, also called a cerebrovascular accident, is a disruption of the blood flow in the brain. Approximately $80 \%$ of all strokes result from an obstruction in a blood vessel of the brain, which is called a cerebral infarct or ischemic stroke. The other $20 \%$ of strokes is the result of a rupturing blood vessel, of which $75 \%$ occurs in the brain itself and is called an intracerebral hemorrhage. ${ }^{1}$

Each year, 45,000 people suffer a first stroke in The Netherlands. ${ }^{2}$ As such stroke belongs to one of the three largest chronic health conditions in the Dutch population. ${ }^{3}$ Nowadays, around $60 \%$ of the people who survive a stroke return home after discharge from hospital or rehabilitation centre. ${ }^{4}$ This group is expected to grow, due to reduced mortality rates, a government policy aimed at noninstitutional care, and ageing of the Dutch population..$^{5-9}$

When patients return home after stroke, they often experience consequences of stroke in their daily life. That is, although these patients are often independent in activities of daily living (e.g., bathing, grooming, dressing, or toilet use), they still report lasting consequences. Such consequences can be physical, such as paralyses or spasticity. ${ }^{10-12}$ However, the consequences are also often less visible. For example, many patients report cognitive problems (i.e., problem in thinking), such as problems with planning and information processing speed. ${ }^{13,14}$ Also, emotional and behavioural changes have been reported post stroke, such as feelings of depression and emotional instability. ${ }^{12,14}$ These consequences affect both patients' and their partners' post-stroke psychosocial functioning, in terms of reduced participation levels, quality of life and life satisfaction, and increased caregiver burden. ${ }^{15-23}$ As they are living at home, patients and partners are largely self-responsible for the way they deal with the consequences of stroke. Therefore, formal healthcare services for these patients and partners should focus on enhancing these self-management abilities.

Next to the impact of stroke for individual patients and partners, stroke also has a considerable economic impact for society. In the coming years a growing group of stroke survivors is expected to appeal on formal healthcare services for support in their post stroke lives. As a consequence, an increase of $28 \%$ is expected in the healthcare costs of stroke in 2020 in the Netherlands..$^{24}$ In addition, current society faces a gap between the supply and demand of healthcare services. ${ }^{25}$ As such, we have to look for other ways to organize our healthcare services, to keep 
the healthcare affordable and of good quality. A promising option would be to enhance patients' own role in managing their disease, as these patients will need less support from formal healthcare services.

So, both from the patient and societal perspective it seems valuable to develop and evaluate interventions aimed at enhancing self-management abilities. Selfmanagement refers to someone's abilities to deal with the symptoms, medical treatment, lifestyle changes, and physical and psychosocial consequences of a condition, and their impact on daily life. ${ }^{26}$ For example, patients with type 2 diabetes have to control their glucose levels, to prevent complications such as high blood pressure (i.e., monitoring and controlling physical disruptions). In addition, lifestyle changes can be advised in terms of a proper diet, more exercising, and losing weight. It can therefore be imagined that being a good self-manager of a chronic condition is a challenging task.

Self-management interventions have been shown to enhance selfmanagement abilities of patients with asthma, chronic obstructive pulmonary disease (COPD), and diabetes mellitus type $2 .{ }^{27}$ Good self-management in these conditions is mainly marked by adequate monitoring of symptoms, medical treatment, and lifestyle changes. In this perspective, the situation of patients with stroke is different. That is, in stoke patients the larger part of self-management tasks results from the need for adjustment to lasting consequences, although some control or change of lifestyle and cardiovascular risk factors is needed. ${ }^{28}$ Therefore, a stroke-specific self-management approach seems to be most adequate for enhancing self-management abilities in stroke patients.

In recent years, several stroke-specific self-management interventions have been developed. In most of these interventions it was assumed that selfmanagement abilities could be enhanced by increasing patients' confidence in their own competencies to successfully accomplish a task, called self-efficacy. ${ }^{29}$ The rationale behind this assumption is that someone's behaviour is influenced by the expectations he has about the outcomes of his actions. However, there is still no compelling evidence that such interventions indeed improve self-efficacy or psychosocial outcomes post stroke. ${ }^{30-33}$ Thus, other strategies to enhance selfmanagement abilities of stroke patients should also be examined. Studies in healthy elderly and patients with type 2 diabetes have suggested proactive coping as an alternative strategy. ${ }^{34,35}$ 
Proactive coping is defined as the effort undertaken in advance of a potentially problematic situation, to prevent its occurrence or to modify its form before it actually arises.$^{36}$ For example, a fire drill is a proactive coping effort, as it helps to be prepared for a potential fire in the future. Should a fire break out one day, people know what to do without being overwhelmed by the situation. Proactive coping strategies might be helpful for patients with stroke as well. That is, stroke patients sometimes fail in their activities, as stroke-related barriers such as mental slowness and reduced flexibility often overwhelm stroke patients during an activity. ${ }^{37,38}$ When stroke patients adopt proactive coping strategies, it would mean that they think of potential stroke-related barriers of an activity, and ways of solving them, before undertaking the activity itself. For example, when a stroke patient thinks of visiting a party, a proactive coping effort could be that he realizes the exhausting impact a busy party could have on him. As he realizes this beforehand, he could think of ways to reduce the potential impact of this barrier, e.g., by listing quiet places to visit during the party.

Although the concept of proactive coping is intuitively appealing, it was not yet investigated in stroke patients at the start of our research. Therefore, we investigated proactive coping in stroke patients, and developed and examined the effectiveness of a stroke-specific self-management intervention aimed at proactive coping in stroke patients and partners.

\section{Target groups}

The findings of our research are of relevance for patients and their partners, healthcare professionals, employees of insurance companies and policy makers.

Patients will profit from our research as it emphasizes the importance of personal factors such as proactive coping and self-efficacy for psychosocial functioning of stroke patients, in addition to the current focus on demographical factors (e.g., age, educational level, sex) and stroke-related factors (e.g, severity of the stroke and its consequences, type of stroke). As a consequence, the healthcare process can be better tailored to the individual needs of stroke patients and especially to the patients at risk of maladjustment to the consequences of stroke.

Partners are expected to profit from our research as it highlighted their desire to get more attention for their own problems and needs from healthcare 
professionals. This might result to new treatment paradigm with more attention for partners' own problems and desires. Certainly, in the perspective of the growing demand on informal caregivers, better support to their needs seems to be adequate as it will enable them to perform their caregiving task in the long term.

Healthcare professionals working with stroke patients (e.g., psychologists, occupational therapists, social workers, rehabilitation physicians) will profit from our findings as well. That is, our study showed that if they take personal factors into account as indicators of psychosocial functioning they will be better able to support patients at risk of poor emotional acceptance. Next, by introducing proactive coping in rehabilitation care of stroke patients, it provides them a new target for interventions aimed at improving psychosocial functioning in stroke patients.

A very important message from our study is meant for policy makers and insurance companies. In the past few years, these parties have increasingly emphasized the need for patients to take a larger role in the management of their own chronic diseases. Our research points at the potential inability of some chronic patients to acquire such complex self-management abilities such as proactive coping. Interventions such as our might be less appropriate for this category of patients, so policy makers need to look for other ways to support this group of patients adequately in the future.

Next, our research points the importance for policy makers and insurance companies to become more aware of the role of personal factors in the healthcare of stroke patients, and the need for treatment options for patients with low proactive coping abilities.

Finally, a growing demand on informal caregivers seems inevitable in the perspective of the increasing number of people suffering a chronic condition. Providing such care is a demanding task. Policy makers and insurance companies need to become aware of the resources (e.g. financial) needed to enable healthcare professionals paying adequate attention to partners' own goals and desires.

\section{Activities and products}

Driven by our assumption that proactive coping strategies would be beneficial for stroke patients, we looked for an adequate measure to assess these strategies in stroke patients. We showed that the Utrecht Proactive Coping Competence scale 
(UPCC) was a suitable instrument to assess proactive coping in stroke patients. Hence, we provided researchers and clinicians with a concrete tool to assess these strategies in stroke patients.

Moreover, our results help to explain why patients with comparable brain injuries in terms of time since injury and severity may show large differences in experienced psychosocial functioning. Specifically, we showed that personal factors such as self-efficacy and proactive coping are of relevance for psychosocial functioning post stroke. As such, these personal factors should be measured explicitely and are promising targets for treatment of stroke patients. In addition, low levels of self-efficacy and proactive coping could indicate patients at risk of maladjustment post stroke. When healthcare professionals know such risk indicators, they are better able to provide individually tailored treatment programs to patients in need instead of providing a standardised treatment program to all patients. As such healthcare services can be provided more effectively to stroke patients.

Based on the promising benefits of proactive coping for stroke patients, we developed a stroke-specific self-management intervention aimed at teaching proactive coping to stroke patients and partners. However, the outcomes of our study resulted in some notes of criticism to the popularity of self-management interventions for stroke patients. Of course, the lack of effectiveness of our intervention questions the adequacy of self-management interventions aimed at teaching proactive coping to stroke patients and partners. However, we cannot be sure of this. First of all, we had no control over the influence of personal factors such as intrinsic motivation and self-efficacy on our results. In addition, we had no insight into therapeutic and contextual factors facilitating the intervention. For example we did not know what the preferred therapeutic approach for healthcare professionals would be. In addition, stroke-specific impairments such as reduced self-awareness and cognitive impairments might have limited patients' ability to profit from the self-management intervention. Hence, we think it is too early to abandon the idea of developing self-management interventions based on proactive coping for stroke patients and partners. Rather, our study gives rise to efforts to unravel the boundary conditions for effective provision of interventions such as ours, and to reveal criteria for an adequate selection of patients. Such knowledge may enable both researchers and clinicians to develop and provide stroke-specific 
self-management that can be proven to be effective. But also it will enable them to provide patient-tailored healthcare, as they are better able to select patients that possess the abilities to profit from interventions such as ours.

In spite of its lack of effectiveness, our self-management intervention did convince both participating therapists and stroke patients of the added value of proactive coping. So even though our intervention has not yet proved effective, our study may stimulate clinicians to think about alternatives to enhance these strategies in stroke patients. As such they might develop new interventions to enhance stroke patients' proactive coping strategies. However it is important for clinicians to keep in mind from our study that satisfaction with and confidence in an intervention is not a guarantee for the effectiveness of an intervention. So newly developed interventions will need thorough scientific evidence of their effectiveness to be sure that they actually help participants.

In addition to the value attributed to proactive coping, both partners and therapists appreciated the new role of caregivers as full participants in our intervention. As such, our study may give rise to the idea of a more central position of caregivers in the healthcare services post stroke. It is important to be sensitive to such caregivers' needs, also because there will be a growing appeal on informal caregivers due to the government policy. Sufficient attention to informal caregivers' needs is expected to enable them to continue their informal caregiving task in the long-term.

\section{Innovation}

With our research we introduced the concept of proactive coping to rehabilitation of stroke patients. We provided clinicians and researchers with an adequate measure to assess proactive coping in stroke patients, and showed that assessing levels of proactive coping might be valuable as an indicator of psychosocial functioning post stroke.

Another innovative aspect of our research was that we focused on the role of personal factors in psychosocial functioning post stroke. As mentioned earlier, most research has focused on the influence of demographical factors (e.g., age, educational level, sex) or stroke-related factors (e.g, severity of the stroke and its consequences, type of stroke). By examining personal factors such as proactive coping and self-efficacy, we have opened up possibilities for new treatment. 
These treatment options may also be potentially more successful, as personal factors may be sensitive to treatment, while demographical and stroke-related factors are unchangeable.

Our stroke-specific self-management intervention was innovative in considering partners as full participants with own goals and opportunities, instead of being in their usual role of caregiver. Partners appreciated the attention healthcare professionals had for caregivers' own goals, experiences, and problems. Sensitivity to informal caregivers' needs in addition to those of the stroke patient may enable these people to care for their patients longer, which is increasingly expected by society.

Finally, our study was relatively novel in following the Medical Research Council guidance. According to this framework the development and evaluation of complex interventions has to pass through the interrelated stages of 1) development of the intervention based on a sound theoretical framework and sufficient evidence, 2) feasibility/ piloting, 3) evaluation of both clinical and costeffectiveness of the intervention, complemented by a process evaluation study, and 4) implementation of intervention if effective. ${ }^{39}$ Though this might sound as a preach to the choir, the actual number of studies adopting this approach completely is limited. Our comprehensive study resulted not only in a clinical and cost effectiveness evaluation of the self-management intervention, but also in a disclosure of the processes underlying the outcomes of the study. Qualitative and quantitative data were combined in this process evaluation. The study and treatment protocol were made available for other researchers to learn from. At the 8th World Congress for Neurorehabilitation (2014) this four-step approach was advocated to increase the quality of Randomized Controlled Trials in rehabilitation. As such, our research can function as a model for new research projects wanting to follow this guideline.

\section{Schedule and implementation}

First of all, due to its ineffectiveness our stroke-specific self-management intervention should not be implemented in its current form in clinical practice. However, it is important to share our findings with both researchers and people in clinical practice, to provide a critical note to the popularity of stroke-specific self-management interventions. In addition, several other insights and products 
resulted from our study are meaningful for clinical practice, and this knowledge should therefore be shared with both important stakeholders.

Distribution of knowledge collected with our study was performed in different ways. First, several international publications have been published, to share knowledge with other researchers. In addition, the researchers wrote a chapter about self-management in rehabilitation in a Dutch handbook for rehabilitation psychologists. ${ }^{40}$ With this chapter they aim to inform rehabilitation psychologists about the current state of the art of self-management interventions in the context of rehabilitation. Furthermore, on a regular basis they published newsletters about their study to inform healthcare professionals, participants, and other interested parties about the progress in and outcome of their research. These newsletters could also be downloaded at the website www.restore4stroke.nl.

Next, the researchers presented the design and outcomes of our studies at several national conferences. Examples of such conferences were conferences of the Dutch CVA Kennisnetwerk, the symposium 'Het Venijn zit in de start IV' (invited speaker), WTH teamdag Eindhoven 2014 (invited speaker), and Hersenletselcongres 2014 (invited speaker). At these conferences not only researchers were present, but also healthcare professionals and patients. Furthermore, the researchers presented their study at several international conferences, for example WCNR Istanbul 2014, Neuropsyhologial Rehabilitation Special Interest Group WFNR 2013 and 2014 (best datablitz price assigned). In May 2015 the results were presented at the Neurorehabilitation and Neural Repair congress in Maastricht.

Together with the outcomes of the other studies of the Restore4Stroke research program a training course will be developed to share the findings of this research program with healthcare professionals (i.e., rehabilitation physician, psychologists, nurses, and paramedics), managers, and employees of health insurance companies. With this course the researchers aim to inform participants about the importance of personal factors such as proactive coping for psychosocial functioning post stroke. After the first provision of this course and evaluation it will be given to education institutes. Moreover, it will be explored if the content of this course can be used for education of new healthcare professionals in the Netherlands. Also information will become available to inform patients and partners about the role of personal factors such as proactive coping and selfefficacy. 
Next, the researchers think that the importance of personal factors such as proactive coping and self-efficacy for psychosocial functioning post stroke should be clear for all healthcare professionals. Therefore, the researchers recommend to include information about the influential role of these factors into clinical guidelines for healthcare professionals. In addition, more research is needed to investigate how these personal factors can be enhanced in stroke patients. However, before new interventions are developed to enhance these factors in stroke patients and partners, first research is needed about the influence of factors such as therapists' attitudes, context, and patient characteristics. With such information, interventions can be more efficiently provided to patients who need them, but who are also able to profit from such an intervention. Finally, clinical guidelines should emphasize the importance of considering partners as full client with own problems and experiences, instead of being in the more usual role of caregiver. 


\section{References}

1. Langhorne P, Bernhardt J, Kwakkel G. Stroke rehabilitation. Lancet. 2011;377:1693-702.

2. Vaartjes I, Dis I Van, Vissseren FLJ, Bots ML. Hart- en vaatziekten in Nederland 2010. Centrum. Den Haag; 2010 p. 132.

3. Hoeymans N, Van Loon AJM, Van den Berg M, Harbers MM, Hilderink HBM, Van Oers JAM, et al. Een gezonder Nederland: Kernboodschappen van de Volksgezondheid Toekomst Verkenning 2014. Bilthoven; 2014.

4. Eyck A, Peerenboom P. Revalidatie in Nederland: De grenzen van AWBZ en ZVW. Leusden; 2006.

5. Rutte M, Samson D. Bruggen Slaan: Regeerakkoord VVD-PvdA. Den Haag; 2012. Available from: http://www.invoeringwmo.n1/sites/ default/ files/291012_regeerakkoord[1].pdf

6. Sarti C, Stegmayr B, Tolonen H, Mähönen M, Tuomilehto J, Asplund $\mathrm{K}$. Are changes in mortality from stroke caused by changes in stroke event rates or case fatality? Results from the WHO MONICA Project. Stroke 2003;34:1833-40.

7. Struijs JN, Van Genugten MLL, Evers SMAA, Ament AJHA, Baan CA, Van Den Bos GAM. Modeling the future burden of stroke in the Netherlands: Impact of aging, smoking, and hypertension. Stroke. 2005;36:1648-55.

8. Kunst AE, Amiri M, Janssen F. The decline in stroke mortality: exploration of future trends in 7 Western European countries. Stroke. 2011;42:212630 .

9. Vaartjes I, Reitsma JB, de Bruin A, Berger-van Sijl M, Bos MJ, Breteler $\mathrm{MMB}$, et al. Nationwide incidence of first stroke and TIA in the Netherlands. Eur J Neurol. 2008;15:1315-23.

10. Sommerfeld DK, Eek EUB, Svensson AK, Holmqvist LW, Von Arbin MH. Spasticity after Stroke: Its occurrence and association with motor impairments and activity limitations. Stroke. 2004;35:134-9.

11. Watkins CL, Leathley MJ, Gregson JM, Moore AP, Smith TL, Sharma AK. Prevalence of spasticity post stroke. Clin Rehabil. 2002;16:515-22. 
12. Warlow C, Van Gijn J, Dennis M, Wardlaw J, Bamford J, Hankey G, et al. Stroke: Practical Management. 3rd ed. Malden, MA: Blackwell Publishing; 2008.

13. Cumming TB, Marshall RS, Lazar RM. Stroke, cognitive deficits, and rehabilitation: Still an incomplete picture. Int J Stroke. 2013;8:38-45.

14. Beusmans G, Van Noortwijk-Bonga H, Risseeuw N, Tjon-A-Tsien M, Verstappen W, Burgers J, et al. NHG-Standaard Beroerte. Huisarts Wet. 2013;56:626-38.

15. White CL, Poissant L, Coté-LeBlanc G, Wood-Dauphinee S. Long-term caregiving after stroke: the impact on caregivers' quality of life. J Neurosci Nurs. 2006;38:354-60.

16. Gosman-Hedström G, Claesson L, Blomstrand C. Consequences of severity at stroke onset for health-related quality of life (HRQL) and informal care: A 1-year follow-up in elderly stroke survivors. Arch Gerontol Geriatr. 2008;47:79-91.

17. Rochette A, Desrosiers J, Bravo G, St-Cyr-Tribble D, Bourget A. Changes in participation after a mild stroke: quantitative and qualitative perspectives. Top Stroke Rehabil. 2007;14:59-68.

18. Visser-Meily A, Post M, van de Port I, van Heugten C, van den Bos T. Psychosocial functioning of spouses in the chronic phase after stroke: improvement or deterioration between 1 and 3 years after stroke? Patient Educ Couns. 2008;73:153-8.

19. Godwin KM, Ostwald SK, Cron SG, Wasserman J. Long-term healthrelated quality of life of stroke survivors and their spousal caregivers. J Neurosci Nurs. 2013;45:147-54.

20. Carlsson GE, Forsberg-Wärleby G, Möller A, Blomstrand C. Comparison of life satisfaction within couples one year after a partner's stroke. J Rehabil Med. 2007;39:219-24.

21. Kerr SM, Smith LN. Stroke: an exploration of the experience of informal caregiving. Clin Rehabil. 2001;15:428-36.

22. Draper P, Brocklehurst $H$. The impact of stroke on the well-being of the patient's spouse: an exploratory study. J Clin Nurs. 2007;16:264-71. 
23. Visser-Meily A, Post M, Gorter JW, Berlekom SB V, Van Den Bos T, Lindeman E. Rehabilitation of stroke patients needs a family-centred approach. Disabil Rehabil. 2006;28:1557-61.

24. Struijs JN, van Genugten MLL, Evers SM a a, Ament AJH, Baan C a, van den Bos G a M. Future costs of stroke in the Netherlands: the impact of stroke services. Int J Technol Assess Health Care. 2006;22:518-24.

25. Klein JJAH, Theeuwes JJM, Bos JC, Boereboom MJ. Zorg voor mensen, mensen voor de zorg: Arbeidsmarktbeleid voor de zorgsector richting 2025. Den Haag; 2009.

26. Barlow J, Wright C, Sheasby J, Turner A, Hainsworth J. Self-management approaches for people with chronic conditions: a review. Patient Educ Couns. 2002;48:177-87.

27. Trappenburg J, Jonkman N, Jaarsma T, van Os-Medendorp H, Kort H, de Wit N, et al. Self-management: one size does not fit all. Patient Educ Couns. 2013;92:134-7.

28. Jones F, Riazi A, Norris M. Self-management after stroke: time for some more questions? Disabil Rehabil. 2013;35:257-64.

29. Bandura A. Self-efficacy: Toward a unifying theory of behavioral change. Psychol Rev. 1977;84:191-215.

30. Huijbregts M, Myers A, Streiner D, Teasell R. Implementation, process, and preliminary outcome evaluation of two community programs for persons with stroke and their care partners. Top Stroke Rehabil. 2008;15:503-20.

31. Johnston M, Bonetti D, Joice S, Pollard B, Morrison V, Francis JJ, et al. Recovery from disability after stroke as a target for a behavioural intervention: results of a randomized controlled trial. Disabil Rehabil. 2007;29:1117-27.

32. Jones F, Mandy A, Partridge C. Changing self-efficacy in individuals following a first time stroke : preliminary study of a novel selfmanagement intervention. Clin Rehab. 2009;23:522-33.

33. Kendall E, Catalano T, Kuipers P, Posner N, Buys N, Charker J. Recovery following stroke: the role of self-management education. Soc Sci Med. 2007;64:735-46. 
34. Thoolen BJ, de Ridder D, Bensing J, Gorter K, Rutten G. Beyond good intentions: The role of proactive coping in achieving sustained behavioural change in the context of diabetes management. Psychol Health. 2009;24:237-54.

35. Bode C, de Ridder DTD, Kuijer RG, Bensing JM. Effects of an Intervention Promoting Proactive Coping Competencies in Middle and Late Adulthood. Gerontologist. 2007;47:42-51.

36. Aspinwall LG, Taylor SE. A stitch in time: Self-regulation and proactive coping. Psychol Bull. 1997;121:417-36.

37. Carlsson G, Möller A, Blomstrand C. A qualitative study of the consequences of "hidden dysfunctions" one year after a mild stroke in persons < 75 years. Disabil Rehabil. 2004;26:1373-80.

38. Planton M, Peiffer S, Albucher JF, Barbeau EJ, Tardy J, Pastor J, et al. Neuropsychological outcome after a first symptomatic ischaemic stroke with "good recovery". Eur J Neurol. 2012;19:212-9.

39. Craig P, Dieppe P, Macintyre S, Michie S, Nazareth I, Petticrew M. Developing and evaluating complex interventions: The new Medical Research Council guidance. Int. J. Nurs. Stud. 2013; 50: 587-92.

40. Van Heugten CM, Tielemans NS, Schepers VPM, Visser-Meily JMA. Zelfmanagement. In: Van Heugten C, Post M, Rasquin S, Smits P, editors. Handboek Revalidatiepsychologie. Amsterdam: Uitgeverij Boom; 2014. p. 343-66. 


Dankwoord 
"Vroeger was ik een twijfelaar, ik ben daar nu niet meer zo zeker van." - Herman Finkers -

Wat een bijzondere jaren waren dit! En wat was het fijn om samen met zoveel anderen de zorg proberen te verbeteren voor mensen die een CVA hebben gehad en hun omgeving. Niet alleen heb ik veel geleerd als onderzoeker, maar ook als clinicus. Het heeft mij doen beseffen hoe belangrijk het is om aan te sluiten bij het perspectief van de cliënt. Maar ook om oog te hebben voor de mogelijkheden, ervaringen en wensen van naasten. Ik weet het nu zeker, mijn plek is daar waar wetenschap en praktijk samenkomen, waar nieuwe inzichten worden geïmplementeerd en waar wordt gestreefd naar verbetering en vernieuwing van de zorg.

Onderzoek doen is samenwerken en voor mijn gevoel is dat ons gelukt! Ons inderdaad, want zonder de bijdrage van alle deelnemers, zorgprofessionals, onderzoekers en experts was dit proefschrift er niet geweest.

Allereerst wil ik alle deelnemers bedanken die dit onderzoek mogelijk hebben gemaakt. Ondanks alles wat op jullie afkwam wisten jullie de tijd en energie te vinden om deel te nemen aan mijn onderzoek. Dikwijls kreeg ik van jullie letterlijk een kijkje achter de voordeur. Met een lach en een traan vertelden jullie over het CVA, het leven voor en na het CVA, en over veranderingen die volgens jullie nodig waren in de zorg. Jullie persoonlijke verhalen gaven mij niet alleen inzichten voor mijn onderzoek, maar hebben van mij ook een betere clinicus gemaakt.

Daarnaast wil ik graag mijn promotieteam danken voor hun begeleiding de afgelopen jaren. Caroline, dank voor alle keren dat jij vroeg de trein nam in Maastricht om met ons te kunnen vergaderen om kwart voor negen in Utrecht. Ik heb veel geleerd van jouw oog voor structuur in teksten. Anne, jouw oog voor de klinische praktijk heb ik als zeer prettig ervaren. Hierdoor leerde je mij hoe belangrijk het is om met een duidelijke klinische boodschap je artikelen te schijven. En natuurlijk dank voor de talloze handtekeningen die jij hebt gezet op documenten voor de monitoring van de studie. Vera, vanaf het tweede jaar was jij als copromotor betrokken bij mijn project. Ik heb veel geleerd van de manier 
waarop jij stagiaires en promovendi begeleidt. Jouw oog voor de persoon achter de promovendus/stagiaire heb ik als zeer prettig ervaren. Marcel, ook jou wil ik graag danken voor jouw bijdrage aan dit proefschrift. Zelfs toen je andere werkzaamheden het niet meer toelieten om lid te zijn van het promotieteam, bleef je betrokken. Regelmatig dacht je mee over statistische analyses of over nieuw op te zetten onderzoek.

Ook wil ik graag de leden van de beoordelingscommissie, prof. dr. Verbunt, prof. dr. Metsemakers, prof. dr. De Ridder, prof. dr. Schuurmans en dr. De Vugt, danken voor het lezen en beoordelen van mijn proefschrift.

Het onderzoek in dit proefschrift kwam tot stand met subsidies van het VSBfonds en de Nederlandse Hartstichting. Beste Jos, vanuit de Hartstichting was je gekoppeld aan de zelfmanagement studie. Ik heb veel geleerd van jouw ervaring en expertise. Niet alleen dacht jij mee over de door ons te ontwikkelen interventie, maar ook leerde jij mij veel over werkvormen voor groepsinterventies en trainingen. Ook jouw relativerende houding heb ik als erg prettig ervaren.

Het onderzoek maakte onderdeel uit van het Restore4Stroke onderzoeksprogramma. Beste Restore4Stroke consortium leden, wat was het een luxe om als promovendus op zo'n deskundige, rijdende trein te mogen springen als het Restore4Stroke Consortium. Regelmatig werden mijn ideeën verder aangescherpt doordat jullie kritisch bleven meedenken in het op te zetten onderzoek of de te interpreteren resultaten. Mitchel en Joyce, samen begonnen we als promovendi aan het Restore avontuur. Nu komt voor ons allen het einde in zicht en denk ik dat we trots mogen zijn op wat we met elkaar hebben neergezet. Willeke dank voor de ontzettend gezellige tijd in Istanbul.

Verder wil ik alle ziekenhuizen en revalidatiecentra danken die hebben meegewerkt aan mijn onderzoek: St Antonius Ziekenhuis, Nieuwegein; De Hoogstraat Revalidatie; Via Reva, Deventer; Universitair Medisch Centrum Utrecht; Merem Behandelcentra, revalidatiecentra Almere en Huizen; Heliomare, Centrum voor niet aangeboren hersenletsel, Amsterdam; Orbis Medisch Centrum, Sittard; Revant Revalidatiecentrum Breda; Reade, locatie Overtoom, Amsterdam; en Het Roessingh, Enschede. Vele planners, revalidatieartsen en behandelaren waren betrokken bij deze studie en hebben zeker hun steentje bijgedragen. Jullie trots, enthousiasme en leergierigheid werkten zeer motiverend. Maar ook de prikkelende vragen die jullie over het onderzoek stelden hebben me regelmatig aan het denken gezet. Zo herinner ik mij in Almere nog de vraag over de mogelijke 
invloed van interculturele verschillen en werden er in Sittard kritische vragen gesteld over de mogelijke invloed van andere behandelingen op onze uitkomsten. Maar ondanks alle drukte in de zorg kreeg ik ook regelmatig rondleidingen van jullie in de centra of was er tijd om samen te lunchen.

In het bijzonder wil ik Haike, Joke, Jacqueline en Rinske bedanken omdat jullie zo hebben meegedacht in de ontwikkeling van de interventie. Jullie ervaringen met de licht hersenletsel groep van het UMCU kwamen goed van pas. Ook heb ik veel geleerd van de keren dat ik met jullie mee mocht kijken. Prof. dr. De Ridder en dr. Thoolen wil ik graag danken, omdat ik mijn interventie op de door hen ontwikkelde interventie 'Geen woorden, maar daden' mocht baseren.

Ook wil ik alle coauteurs bedanken. Patricia, Pieter, Ingrid, en Judith, jullie waren in dit onderzoek de kampioenen in het werven van deelnemers. Mariëtte, jouw klinische voorbeelden in ons behandelprotocol bracht onze interventie tot leven voor lezers. Jolanda, van jou heb ik geleerd om van bergen kwalitatieve data een helder artikel te schrijven. Prof. dr. Wade, thank you for your feedback on my manuscript and the opportunity of reviewing manuscripts of others.

Jetty en Anne-Marije, toen het onderzoek in alle centra liep was het heel fijn om op jullie te kunnen bouwen. Met jullie hulp konden we alle metingen op het juiste moment inplannen en de data op tijd invoeren. Judith, Helene, Wendy en Anneriek, dank voor jullie bijdrages als stagiaires binnen het Restore4Stroke Zelfmanagement onderzoek. Door met jullie mee te mogen denken kreeg ik zelf ook steeds meer grip op complexe constructen zoals proactieve coping en persoonlijke effectiviteit.

Irene, vlak voor de start van de studie raakte jij als monitor betrokken bij mijn studie. Samen zochten we uit hoe een grote multicenter RCT kon worden uitgevoerd binnen de monitoring richtlijnen van het UMCU. Mede dankzij jouw visites ben ik een onderzoeker geworden die zich niet alleen aan de richtlijnen houdt omdat het moet, maar ook vanwege het ethisch belang van deze richtlijnen.

Collega's van het Kenniscentrum, dank voor de afgelopen jaren. (Oud) junioren, dank voor de het meelezen in artikelen, de lunches om successen te vieren en de juniorenuitjes. Hileen, Matagne, Anne en Imke, een speciaal woord van dank voor jullie vanwege de fijne, persoonlijke gesprekken die wij met elkaar konden voeren. Andrie, en Carlijn, dank voor alle praktische hand- en spandiensten die jullie voor mij hebben verricht. Alle andere onderzoekers en 
medewerkers bij het Kenniscentrum, ook jullie dank ik voor het meedenken met mijn onderzoek en voor jullie stimulerende feedback.

Ook mijn collega's in Maastricht wil ik graag bedanken. In het bijzonder wil ik Elsa en Els bedanken die op grote afstand mij hielpen bij praktische vragen.

Graag wil ik ook de leden van de onderzoeksgroep Verplegingswetenschappen van het UMCU bedanken, en in het bijzonder kartrekkers Jaap en prof. dr. Schuurmans. Wat was het fijn om na enkele jaren, een onderzoeksgroep tegen te komen die ook aan het stoeien waren met het concept zelfmanagement. En wat een luxe om daarna vrijwel wekelijks aan te mogen sluiten bij de leuke en inspirerende overleggen van jullie onderzoeksgroep. Dikwijls fietste ik terug van het UMCU naar De Hoogstraat met een hoofd vol ideeën: wat voelde de afstand UMCU - De Hoogstraat dan ver.

Het hele idee van promoveren ontstond tijdens mijn stage in het Epilepsiecentrum Kempenhaeghe. Beste Marc, ik weet nog dat ik enigszins verbaasd reageerde toen $\mathrm{jij}$ mij vroeg of ik niet wilde promoveren. Na er even over nagedacht te hebben besloot ik je advies op te volgen. Dankzij jou, Martijn en Roy kreeg ik de kans om mijn eerste wetenschappelijke artikel te publiceren. Dank!

Beste Carla, ook jou wil ik danken voor alles wat ik van je heb mogen leren bij Aveleijn. Bij het ontwikkelen van de cursussen, maar ook bij het interpreteren van de resultaten heb ik hier veel aan gehad. Christel, jou wil ik bedanken voor de motiverende manier waarop jij met mij meedacht over mijn terugkeer naar de klinische praktijk. En tot slot wil ik mijn collega's bij Siza bedanken voor de kansen die ik daar krijg om mijn klinische ambities te verwezenlijken.

Lieve vrienden, jullie wil ik danken voor jullie interesse en gezelligheid de afgelopen jaren. Maarten, jou wil ik in het bijzonder danken voor alle keren dat ik bij jou heb mogen logeren in Maastricht. Het was iedere keer weer een feest! Vandaag kun je er helaas niet bij zijn, omdat jij in Stockholm op precies hetzelfde tijdstip je MSc ontvangt. Congrats!

Lieve Marloes, mede junior onderzoeker, Restore4Stroke AIO, congres maatje, paranimf... tja eigenlijk kun ik je naam op heel veel plaatsen neerzetten, maar bovenal ben je een ontzettend fijne vriendin. Wat herinner ik mij onze ontmoeting bij de eerste Restore4Stroke vergadering nog goed. 'Hey, jou ken ik!' riepen we uit. We bleken al vier jaar samen in Nijmegen te hebben gestudeerd, 
maar kenden elkaar alleen van gezicht. Ontzettend zonde, want wat is onze vriendschap waardevol! Niet alleen zijn we de afgelopen jaren nauw betrokken geweest bij elkaars promoties, maar ook toen het thuis pittig werd stond je altijd voor me klaar. Het is even wennen om niet meer directe collega's te zijn, maar $i k$ weet zeker dat er nog vele etentjes, en avondjes met de mannen zullen volgen.

En tot slot, last but not least, mijn lieve familie. Wat zijn jullie ontzettend waardevol voor mij.

Lieve mama, geheel onverwachts kwamen we drieënhalf jaar geleden zelf in de positie van patiënt en naaste terecht. Maar in plaats van bij de pakken neer te gaan zitten hebben we van de afgelopen jaren maximaal genoten. Diepe bewondering heb ik voor hoe jij je door alles hebt heen geslagen: stoer, veerkrachtig en altijd uitgaand van het positieve. Je belde altijd even als ik een belangrijke dag had om mijn verhalen te horen. Tot het laatst toe was het jouw doel om deze belangrijke dag mee te maken, en hoe ziek je ook was, je vroeg altijd hoe het met mijn promotie stond. Helaas komt mijn verdediging voor jou te laat. Maar ik weet dat je ontzettend trots op me bent. Lieve mama, ik mis je.

Lieve papa, samen met mama heb jij mij altijd gestimuleerd het beste uit mezelf te halen. Jouw vertrouwen in mij heb ik altijd heel fijn gevonden. Een grote bewondering heb ik voor hoe jij de afgelopen jaren alle balletjes in de lucht hebt weten te houden. Maar naast alle zorgen had je ook altijd ruimte om te praten over mijn promotietraject. Regelmatig dook je na zo'n verhaal in de boeken, om die ene theorie te vinden die aansloot op mijn dilemma. Jouw passie voor jouw vakgebied hebben altijd een inspirerend effect op mij gehad.

San, zorgzame, grote zus. Tien jaar geleden hadden we beiden niet verwacht dat ik vandaag mijn proefschrift zou verdedigen. Zo blijkt maar weer het belang van intrinsieke motivatie. Je bent een zus op wie ik kan bouwen en bij wie ik altijd terecht kan. Niet voor niets ben jij vandaag mijn paranimf. Peet, wat is het fijn om zo'n bijzondere band te hebben met zo'n lieve, trotse oom. Het is fijn om zo dicht bij elkaar te wonen, alhoewel Bob en ik nog steeds een keer echt met de racefiets langs moeten komen.

Marijke en Jaap, na elf jaar voelt het bij jullie ook echt als thuiskomen. Wat vond ik jullie steun de afgelopen jaren ontzettend fijn en wat ben ik door jullie verwend. Ik heb gewoon ontzettend met jullie geboft! Bram en Mara, dank voor de welkome gezelligheid, het is weer hoog tijd voor een spelletjesavond. 
Lieve lieve Bob, wat vind ik het bijzonder wat wij samen hebben. Ondanks alle drukte de afgelopen jaren, kon ik met jou altijd sparren over mijn onderzoek en artikelen. Ik vrees dat jij nu zelf ook een zelfmanagement expert bent geworden. Je hebt een eindeloos vertrouwen in mijn kunnen, en staat altijd voor mij klaar. Of we nou mooie reizen maken, fietsen of dansen, met jou is elke dag bijzonder. 



\section{Curriculum Vitae}



Nienke Tielemans werd op 29 mei 1987 geboren te Leusden. In 2005 behaalde ze haar Gymnasium diploma aan Het Stedelijk Lyceum Zuid te Enschede. Hierna ging ze psychologie studeren aan de Radboud Universiteit Nijmegen. Aan het einde van het tweede studiejaar koos zij voor de afstudeerrichting neuro- en revalidatiepsychologie. Haar klinische en onderzoeksstage vond plaats in het neurochirurgie programma van het Epilepsiecentrum Kempenhaeghe te Heeze. Vanaf april 2009 combineerde ze haar studie met haar werk als gedragskundige bij Aveleijn, een instelling voor mensen met een licht verstandelijke beperking. In augustus 2009 studeerde Nienke cum laude af in de richting neuro- en revalidatiepsychologie aan de Radboud Universiteit Nijmegen. Ook na haar afstuderen bleef zij werkzaam bij Aveleijn als gedragskundige. In augustus 2010 begon ze als promovendus aan de Universiteit Maastricht van waaruit ze werd gedetacheerd in De Hoogstraat Revalidatie te Utrecht. Sinds januari 2013 is zij geregistreerd PSYCHOLOOG NIP. Vanaf september 2013 combineerde ze haar promotieonderzoek met haar gespreksleiderschap bij Longpunt Utrecht van het Longfonds. Dit jaar zijn ze binnen dit Longpunt gestart met een jaarprogramma gericht op het bevorderen van zelfmanagement bij longpatiënten. Sinds maart 2015 is Nienke werkzaam als gedragskundige Niet Aangeboren Hersenletsel binnen de afdeling Behandeling, Kwaliteit en Ontwikkeling van Siza. 



\section{List of Publications}




\section{International publications}

- Tielemans NS, Schepers VPM, Visser-Meily JMA, Van Erp J, Eijkenaar M, Van Heugten CM. The Restore4Stroke self-management intervention "Plan ahead!": Rationale and description of the treatment protocol based on proactive action planning. Clin Rehab 2014; 28: 530-40.

- Tielemans NS, Visser-Meily JMA, Schepers VPM, Post MWM, Van Heugten CM. Proactive coping post-stroke: Psychometric properties of the Utrecht Proactive Coping Competence scale. Arch Phys Med Rehab 2014; 95: 670675.

- Tielemans NS, Visser-Meily JMA, Schepers VPM, Post MWM, Wade DT, Van Heugten CM. Study protocol of the Restore4Stroke self-management study: A multicentre randomized clinical trial in stroke survivors and their partners. Int J Stroke 2014; 9: 818-23.

- Tielemans NS, Hendriks MPH, Talamini L, Wester AJ, Meeter M, Kessels RPC. Facilitation of memory by contextual cues in patients with diencephalic or medial temporal lobe dysfunction. Neuropsychologia 2012; 50: 1603-8.

- Tielemans NS, Schepers VPM, Visser-Meily JMA, Post MWM, Van Heugeten CM. Associations of proactive coping and self-efficacy with psychosocial outcomes in individuals after stroke. Arch Phys Med Rehab, accepted for publication.

\section{National publications}

- Van Heugten C, Tielemans N, Schepers V, Visser-Meily J. Zelfmanagement. In: Van Heugten C, Post M, Rasquin S, Smits P. (red). Handboek Revalidatiepsychologie. Amsterdam: Uitgeverij Boom; 2014: 343-366.

- Kootker J, Tielemans N, \& Rasquin S. Restore4Stroke: een groot onderzoeksproject gericht op de kwaliteit van leven na CVA. CVA Magazine 2012; aug: 15 .

\section{Submitted articles}

- Tielemans NS, Visser-Meily JMA, Schepers VPM, Passier PE, Van de Port IGL, Vloothuis JDM, Struyf PAA, Van Heugten CM. Effectiveness of the Restore4Stroke self-management intervention 'Plan Ahead!': A randomized controlled trial in stroke patients and partners. Submitted. 
- Tielemans NS, Schepers VPM, Visser-Meily JMA, Van Haastregt JCM, Van Veen WJM, Van Stralen HE, Van Heugten CM. Process evaluation of the Restore4Stroke self-management intervention 'Plan Ahead!'. Submitted.

- Van Eeden M, Van Heugten CM, Van Mastrigt GAPG, Tielemans NS, Schepers VPM, Evers SMAA. An economic evaluation of the Restore4Stroke SelfManagement intervention for stroke patients and their partners. Submitted.

\section{Conferences and presentations}

- Tielemans NS. Zelfmanagement bij thuiswonende CVA patiënten en hun prarntesr. Oral presentation Hersenletsel Congres, Ede, The Netherlands, November 3, 2014.

- Tielemans NS, Visser-Meily JMA, Schepers VPM, Van Heugten CM. Study protocol of the Restore4Stroke self-management study: A multicentre randomized controlled trial in stroke patients and their partners. Datablitz 11th NR-SIG-WFNR Conference, Limassol, Cyprus, July 14-15, 2014.

- Tielemans NS. The Restore4Stroke zelfmanagement studie: Effectiviteit van zelfmanagement behandeling in CVA-patiënten en hun partners. Oral presentation Landelijke WTH teamdag. Eindhoven, The Netherlands, May 16, 2014.

- Tielemans NS, Visser-Meily JMA, Schepers VPM, Van Heugten CM. Effectiveness of the Restore4Stroke self-management intervention 'Plan Ahead!': a randomized controlled trial in stroke patients and partners. Poster Presentation 8th World Congress for NeuroRehabilitation, Istanbul, Turkey, April 8-12, 2014.

- Tielemans NS, Schepers VPM, Visser-Meily JMA, Van Veen W, Van Heugten CM. De Restore4Stroke Zelfmanagement interventie: De evaluatie met cursusleiders en cursisten. Poster presentation Symposium De Hoogstraat Revalidatie 'Kijk verder', Utrecht, The Netherlands, November 30, 2013.

- Tielemans NS, Schepers VPM, Visser-Meily JMA, Van Veen W, Van Heugten CM. De Restore4Stroke Zelfmanagement interventie: De evaluatie met cursusleiders en cursisten. Poster presentation Symposium Kennisnetwerk CVANL 'De keten door, van opname tot en met thuis', Zeist, The Netherlands, November 22, 2013.

- Tielemans NS, Visser-Meily JMA, Schepers VPM, Post MWM, Van Heugten 
CM. Proactive coping strategies in stroke survivors: Validity of the Utrecht Proactive Coping Competence list. Poster presentation 10th NR-SIG-WFNR Conference, Maastricht, The Netherlands, July 8-9, 2013

- Tielemans NS, Schepers VPM, Visser-Meily JMA, Van Erp J, Eijkenaar M, Van Heugten CM. "Plan ahead!": Treatment protocol of the Restore4Stroke self-management intervention based on proactive action planning. Poster presentation 10th NR-SIG-WFNR Conference, Maastricht, The Netherlands, July 8-9, 2013.

- Tielemans NS, Visser-Meily JMA Schepers VPM, Van Heugten CM. De Restore4Stroke zelfmanagement studie: Effectiviteit van een zelfmanagement behandeling voor CVA patiënten en hun partners. Oral presentation symposium 'Het venijn zit in de staart IV', Ede, The Netherlands, April 11, 2013.

- Tielemans NS, Visser-Meily JMA, Schepers VPM, Van Heugten CM. The Restore4Stroke self-management study: A multicentre RCT in stroke patients and their partners. Oral presentation Research Symposium RMC Groot Klimmendaal, Arnhem, The Netherlands, March 8, 2013.

- Tielemans NS, Visser-Meily JMA, Schepers VPM, Van Heugten CM. Study protocol of the Restore4Stroke self-management study: A multicentre randomized controlled trial in stroke patients and their partners. Poster presentation European Stroke Conference, Lisboa, Portugal, May 23, 2012.

- Tielemans NS, Visser-Meily JMA, Schepers VPM, Post MWM, Van Heugten CM. Proactive coping strategies in stroke survivors: Feasibility and psychometric properties of the Proactive Competence Inventory. Poster presentatie Symposium Kennisnetwerk CVA NL 'Vorderingen in de CVAzorg', Nijmegen, The Netherlands, November 11, 2011.

- Tielemans NS, Meeter M, Hendriks MPH. Facilitation of Memory by Contextual Cues after Temporal Lobectomy. Poster presentation Epilepsy and Sleep Symposium, Heeze, The Netherlands, March 26, 2010.

- Tielemans NS, Meeter M, Hendriks MPH. Facilitation of memory by contextual cues after temporal lobectomy. Poster presentation Winter Conference on Cognition, Brain \& Behavior of the Dutch Psychonomic Society, Egmond aan Zee, The Netherlands, December 18-19, 2009. 

